LONDOÑO, Fernando. "Aproximación histórico-comparada al Título VIII de la Ley de Mercado de Valores: bases para el reconocimiento de un contenido anti-manipulativo". Polít. crim. Vol. 10, N 20 (Diciembre 2015), Art. 1, pp. 390-467. [http://www.politicacriminal.cl/Vol_10/n_20/Vol10N20A1.pdf]

\title{
Aproximación histórico-comparada al Título VIII de la Ley de Mercado de Valores: bases para el reconocimiento de un contenido anti-manipulativo
}

\section{Historical-comparative law approach to Title VIII of the Securities Market Act: basis for the acknowledgement of an anti-manipulation content}

\author{
Dr. Fernando Londoño Martínez \\ Profesor asistente de la Facultad de Derecho de la Universidad Diego Portales. \\ fernando.londono@udp.cl
}

\section{Resumen}

A partir de una aproximación histórico-comparada se busca clarificar el contenido de injusto de los arts. 52 y 53 de la Ley $\mathrm{N}^{\circ} 18.045$ de Mercado de Valores (Título VIII de dicha ley), cuya infracción gatilla una severa responsabilidad penal (art. 59[e] de la mencionada ley), amén de dar lugar a sanciones administrativas y a responsabilidad civilindemnizatoria (arts. 58 y 55 de la anotada ley). Tras una rápida revisión de las figuras históricas de agio o alteración de precios, el estudio se detiene en una detallada comparación con el derecho extranjero más influyente en el sector: las secciones 9 (a) y 10(b) de la Securities Exchange Act de los Estados Unidos (incluyendo la Regla 10b-5) y la regulación de Abusos de Mercado de la Unión Europea (Directiva 2003/6 y Reglamento 2014/596, principalmente). Desde allí el autor procura develar el contenido antimanipulativo del Título VIII de la LMV (y especialmente de su artículo 53), anticipando claves para su correcta interpretación. Una vez puesta la normativa nacional en su contexto histórico-comparado, el camino hacia una reconstrucción dogmática del Título VIII y del respectivo tipo penal del art. 59 e) queda facilitado. El presente trabajo constituye así la base esencial para una propuesta hermenéutica integral del Título, la que -en sus detallesserá abordada en un artículo posterior del mismo autor.

Palabras clave: Artículos 52 y 53 de la Ley de Mercado de Valores (Ley $\mathrm{N}^{\circ}$ 18.045), Secciones 9(a) y 10(b) de la Ley Federal de Intercambio de Valores de los EE.UU., Regla 10b-5, Manipulación del mercado de valores, Abuso de mercado y Directiva 6/2003/CE, agio, alteración de precios, inducción a la compra o venta de valores.

\begin{abstract}
Based on a historical and comparative-law approach, the paper aims to clarify the content of sections 52 and 53 of the Chilean Securities Market Act (Title VIII of the Act), whose infraction triggers severe criminal liability (section 59 [e] of the Act), in addition to administrative sanctions and civil-damages liability (sections 58 and 55 of the Act). After considering the historical figures of agio and price tampering, the paper focuses on a comparison with the most influential foreign law in the field: sections 9 (a) and 10 (b) of the U.S. Securities Exchange Act (including Rule 10b-5) and the European Union Market
\end{abstract}


LONDOÑO, Fernando. “Aproximación histórico-comparada al Título VIII de la Ley de Mercado de Valores: bases para el reconocimiento de un contenido anti-manipulativo".

Abuse Regulation (Directive 2003/6 and Regulation 2014/596, mainly). In this way, the author seeks to unveil the precise anti-manipulative content of Title VIII of the Chilean Securities Market Act, and especially of its section 53, offering keys for a right understanding of Title VIII and the respective criminal offence of section 59 e). Once the Chilean law is placed in a historical and comparative-law context, the path towards an exhaustive dogmatic reconstruction of Title VIII - and its related rules - is highly favored. Thus, the paper aims to represent a substantive basis for a comprehensive and detailed hermeneutic proposal on the matters of Title VIII. Such proposal will be addressed in a subsequent work.

Key words: Sections 52 and 53 of the Chilean Securities Market Act (Act $\mathrm{N}^{\circ}$ 18.045), Sections 9(a) and 10(b) of the U.S. Securities Exchange Act, Rule 10b-5, Securities market manipulation, Market Abuse and the 2003/6/CE Directive, agio, price tampering, inducement of purchase or sale of securities.

\section{Introducción.}

La escasa atención que nuestra literatura ha dedicado a las prohibiciones del Título VIII de la Ley de Mercado de Valores ${ }^{1}$ (entiéndase, artículos 52 y 53 de dicha ley, en adelante

\footnotetext{
* El autor agradece las detalladas observaciones de los evaluadores anónimos de este artículo, gentileza que se procuró recambiar acogiéndolas en general, allí donde fue posible. El presente trabajo encontró su ocasión conclusiva en una solicitud de informe para un caso atingente al Título VIII de la Ley de Mercado de Valores, de interés en sede administrativa y civil. La tesis defendida se ubica en todo caso en línea con el iter ya sugerido en un artículo de mi autoría, publicado en 2013 en esta misma Revista (cfr. Londoño, Fernando, "Ilícito de manipulación" cit. nota ${ }^{\circ} 1$, especialmente pp. 105 ss. y, entre otras, notas a pie $n^{\circ}$ s $1,114,116$, 118 y 123, en las que se anticipa una toma de posición sobre el sentido general de los artículos 52 y 53 de la aludida ley). En fin, una versión muy preliminar de la misma tesis tuvo ocasión de ser "testeada" en septiembre de 2013, en un seminario abierto organizado por el Prof. Héctor Hernández B. en la Facultad de Derecho de la Universidad Diego Portales (Coloquio de Derecho Penal Económico, 4 de septiembre de 2013).

${ }^{1}$ Una toma de posición sobre su contenido puede apreciarse en ETCHEBERRY, Alfredo, Derecho Penal. Parte Especial, Tomo IV, $3^{\text {a }}$ ed., Santiago: Editorial Jurídica de Chile, 1998, pp. 280-81, aunque sólo tangencial y a propósito del tratamiento manualístico de la figura de agio del art. $285 \mathrm{CP}$ (viendo en dichas disposiciones formas especiales de alteración de precios). Por su parte, en ROSENBLUT, Verónica, "El denominado caso 'Schwager': análisis de histórica condena por uso de información privilegiada y manipulación bursátil”, Revista Jurídica del Ministerio Público, N. 46 (marzo 2011), pp. 185-209, esp. pp. 186-189, puede apreciarse un esfuerzo importante de esclarecimiento del alcance del art. 53 LMV (viendo en él una prohibición anti-manipulativa de los precios en el mercado de valores), si bien sólo a propósito de un comentario de sentencia relativo al caso Schwager. Por último, en LONDOÑO, Fernando, "Ilícito de manipulación bursátil: fenómeno y lesividad. Aspectos de política sancionatoria", Política criminal, Vol. 8, No 15 (2013), Art. 3, pp. 64 - 127 (en http://www.politicacriminal.cl/Vol 08/n 15/Vol8N15A3.pdf), se hallan también tomas de posición sobre el contenido del Título VIII y algunas de las disposiciones conexas de la LMV, si bien en un plano marginal, en el marco de un trabajo cuyo propósito inmediato no era el tratamiento del derecho positivo chileno; una toma de posición general sobre el sentido global de las disposiciones del Título VIII se aprecia ya en la apertura del citado trabajo, comprendiendo los arts. 52, 53 y 61 bajo la órbita de la categoría de la manipulación bursátil (p. 66, nota 1); luego, profundizando en ese planteamiento general, en el mismo trabajo se tomó posición sobre el alcance de las figuras del Título en comento, asociándolas en cada caso a las tipologías fácticas o de derecho comparado abordadas allí; entre otras, de especial interés resultan las notas 114, 116, 118 y 123 del citado trabajo.
} 


\section{Polít. crim. Vol. 10, № 20 (Diciembre 2015), Art. 1, pp. 390-467. [http://www.politicacriminal.cl/Vol_10/n_20/Vol10N20A1.pdf]}

LMV $)^{2}$ contrasta con su creciente relevancia práctica, al menos en los últimos diez años ${ }^{3}$. Si se considera el amplio rango de consecuencias a que da lugar la infracción de dichas prohibiciones -responsabilidad civil, administrativo-sancionatoria y penal ${ }^{4}$ (con penas de crimen de hasta diez años de presidio)- la desatención doctrinaria resulta aún más llamativa.

Si a lo anterior se añade el relativamente ambiguo tenor de las disposiciones principalmente del artículo 53 LMV- entonces se comprende que un esfuerzo hermenéutico resulte imperioso en este sector. A la espera de un adecuado esclarecimiento jurisprudencial y doctrinario, estando a una lectura superficial (que aquí se ha llamado "textualista") de las voces en juego, bajo estas disposiciones podría postularse -con mayor o menor plausibilidad- la subsunción de conductas tan dispares como (1) una manipulación de los precios de valores cotizados en Bolsa ${ }^{5}$ (2) una forma de defraudación con valores emparentada con la denominada estafa de inversión ${ }^{6}$, (3) una forma de apropiación indebida o de defraudación emparentada con la administración desleal-eventualmente en perjuicio de una minoría societaria- ejecutada mediante una o más transacciones con valores $^{7},(4)$ un contrato simulado cuyo objeto recaiga en valores, ejecutado con la finalidad de perjudicar a un acreedor ${ }^{8}$ y aún (5) una transacción cualquiera con valores, ejecutada en infracción a alguna normativa técnica o reglamentaria dictada para la tutela de intereses

\footnotetext{
${ }^{2}$ Las mencionadas prohibiciones rezan: Art. 52 inc. $1^{\circ}$ : "Es contrario a la presente ley efectuar transacciones en valores con el objeto de estabilizar, fijar o hacer variar artificialmente los precios". Art. 53 inc. $1^{\circ}$ : "Es contrario a la presente ley efectuar cotizaciones o transacciones ficticias respecto de cualquier valor, ya sea que las transacciones se lleven a cabo en el mercado de valores o a través de negociaciones privadas". Art. 53 inc. $2^{\circ}$ : "Ninguna persona podrá efectuar transacciones o inducir o intentar inducir a la compra o venta de valores, regidos o no por esta ley, por medio de cualquier acto, práctica, mecanismo o artificio engañoso o fraudulento".

${ }^{3}$ Primero a partir de los casos Schwager (Superintendencia de Valores y Seguros, Resolución exenta Núm. 247 de 9 de junio de 2006; con condena penal por el $4^{\circ}$ Tribunal Oral en lo Penal de Stgo., RIT 67-2010 de 19 de octubre de 2010) y MBI (Superintendencia de Valores y Seguros, Resolución exenta Núm. 402 de 8 de septiembre de 2006) a mediados de la década pasada, luego con motivo de una arista penal y civil vinculada al caso Inverlink (Corte de Apelaciones de Stgo., Rol Corte № 2227-2013, de 2 de diciembre de 2014; primera instancia Ministro en Visita Patricio Villarroel, Rol 176.739-MV-2003, 7 de octubre de 2013), parece ser Cascadas (Superintendencia de Valores y Seguros, Resolución Exenta $\mathrm{N}^{\circ} 223$ de 2 de septiembre de 2014) el más reciente de los casos que han concentrado la atención de la praxis sobre este Título de la LMV.

${ }^{4}$ En virtud de los artículos 55, 58 y 59 letra e) de la LMV, respectivamente.

${ }^{5} \mathrm{Al}$ respecto, sobre el tipo de conducta, cfr. LONDOÑO, "Ilícito de manipulación”, cit. nota n 1 , esp. pp. 83 y ss., con ulteriores referencias bibliográficas.

${ }^{6}$ Una lectura semejante colocaría erradamente al caso conocido como "La Polar" bajo el radio de alcance del art. 53, en circunstancias que tiene un locus más seguro y natural en disposiciones como el art. 59 a) y 59 f), en relación con la norma primaria del art. 10.

7 Erradamente, una lectura semejante podría pretender la colocación de un caso como "Serrano" (RIT 2672014, $4^{\text {o }}$ T.O.P. de Santiago, 15 de diciembre de 2014) bajo el radio de alcance del art. 53, en circunstancias que tiene un locus seguro y natural en una disposición como el art. 60 i) [apropiación indebida de valores en custodia] y, por lo que toca a entregas de información falsa, en el art. 59 a).

${ }^{8}$ Nótese que lo que en principio podría resultar subsumible bajo un tipo como el de contrato simulado del Código Penal - art. 471 N. 2, sancionado con pena de multa o presidio de hasta 540 días - podría resultar subsumido en la prohibición del inc. $1^{\circ} \mathrm{del}$ art. 53, lo que supone la aplicación de penas que comienzan en los 541 días de presidio y llegan hasta los diez años: una diferencia punitiva de tal entidad que parece entonces reclamar una diferenciación tipológica.
} 
LONDOÑO, Fernando. “Aproximación histórico-comparada al Título VIII de la Ley de Mercado de Valores: bases para el reconocimiento de un contenido anti-manipulativo".

patrimoniales $\mathrm{u}$ otras finalidades acotadas, no directamente reconducibles a la correcta formación de los precios en un mercado de valores ${ }^{9}$.

Un primer paso para el esclarecimiento del alcance del Título VIII se emprende en el presente trabajo, postulándose -según se verá- que sólo la primera alternativa hermenéutica recién formulada sería adecuada. Con todo, aquí no se propone todavía una reconstrucción dogmática detallada del preciso alcance de las normas en cuestión. Ello constituirá el objeto de un trabajo posterior, en proceso de publicación ${ }^{10}$. Lo que en cambio se intenta aquí es introducir las condiciones para una reconstrucción semejante, sobre bases históricocomparadas. Un objetivo entonces más modesto en sus pretensiones prácticas y reconstructivas, pero no por ello menos arduo y menos necesario desde un punto de vista dogmático.

A partir de un estudio de derecho comparado y tomando en consideración ciertas claves históricas del campo de referencia, el contenido de injusto de los arts. 52 y 53 de la LMV se irá clarificando progresivamente (casi "naturalmente", esperaríamos, de ser bien acogida la propuesta). Una vez puestas en evidencia las coincidencias teleológicas y técnicas con el principal derecho comparado de referencia en el sector bursátil, el camino hacia una reconstrucción dogmática del Título VIII LMV debería quedar facilitado hasta el punto de representar un ejercicio "cuesta abajo" (en comparación al más espinudo esfuerzo de colocación de las disposiciones en su adecuado contexto).

El trabajo se estructura del siguiente modo. En una primera sección (1) se ofrece un cuadro histórico y comparado que permite apreciar el contexto en el que se coloca el Título VIII de la LMV. El derecho de referencia corresponde a las secciones 9(a) y 10(b) de la Securities Exchange Act del derecho federal estadounidense, así como las Directivas y Reglamentos comunitarios y de la Unión Europea en materia de Abusos de Mercado (Dir. 2003/6/CE y Reglamento 2014/546/UE principalmente). A la vez, en la misma sección -normalmente hacia el final de las respectivas subsecciones- se ofrecen claves de comparación con los arts. 52 y 53 LMV, anticipando propuestas interpretativas en sintonía con las conclusiones del artículo. En la sección siguiente (2) se enlazan las estrategias de tipificación de derecho comparado (y nacional) con las mecánicas y tipologías de manipulación bursátil más conocidas por la literatura, abonando el terreno para las conclusiones. En ellas se ofrece un esquema de lectura global del Título VIII, el que debe ser complementado con una reconstrucción dogmática detallada del mismo, incluyendo por cierto factores hermenéuticos del derecho nacional. A esa reconstrucción lineal se dedica un estudio sucesivo (véase nota al pie $n^{\circ} 10$ ), respecto del cual el presente trabajo ha de considerarse como su fundamentación más amplia.

\footnotetext{
${ }^{9}$ El reciente fallo condenatorio en la arista BBVA del caso Inverlink (Corte de Apelaciones de Stgo., Rol Corte $N^{o}$ 2227-2013, de 2 de diciembre de 2014) se deja leer - críticamente - bajo este prisma.

${ }^{10}$ Artículo de autoría del suscrito dedicado a la reconstrucción dogmática del Título VIII de la Ley de Mercado de Valores, en proceso de evaluación en revista indexada.
} 
Polít. crim. Vol. 10, No 20 (Diciembre 2015), Art. 1, pp. 390-467.

[http://www.politicacriminal.cl/Vol_10/n_20/Vol10N20A1.pdf]

\section{Aproximación histórico-comparada al ilícito de manipulación de mercado de valores.}

En el apartado introductorio se ha sugerido que tanto el artículo 52 como el art 53 de la LMV constituirían fórmulas anti-manipulativas de los precios de los títulos transados en un mercado de valores. Se trataría pues de figuras que prohibirían la manipulación de los precios en un mercado de valore ${ }^{11}$. De este modo, dichas fórmulas tutelarían, antes que intereses individuales-patrimoniales, intereses supra-individuales o institucionales, correspondientes al buen funcionamiento de un sistema de mercado de valores y, más específicamente, a la correcta formación de los precios en el mismo. Por de pronto, consideremos esta toma de posición como una hipótesis de trabajo, a verificar en el curso de este apartado y el siguiente. En lo que inmediatamente sigue, se tratará de ofrecer un marco histórico-comparado suficiente, de modo que la validez de aquella toma de posición pueda ser debidamente apreciada.

\subsection{La manipulación bursátil como una forma de abuso de mercado. Introducción al contexto histórico-comparado.}

Emparentada con las figuras decimonónicas de alteración de precios o agio $^{12}$, con el término manipulación del mercado de valores la literatura especializada tiende a describir ${ }^{13}$ toda conducta ejecutada con la intención de hacer variar, artificialmente, el precio-demercado de instrumentos financieros transados en un mercado de valores ${ }^{14}$. Como sostiene un destacado especialista del sector:

${ }^{11}$ En lo sucesivo se usarán indistintamente expresiones como manipulación de mercado de valores, manipulación bursátil o manipulación a secas. Salvo que se indique lo contrario, ellas se usan de modo equivalente, por más que en rigor quepa advertir en la expresión manipulación bursátil un alcance más restrictivo, en cuanto se referiría exclusivamente a manipulaciones ejecutadas en el mercado secundario formal (en Bolsa, precisamente).

${ }^{12}$ Como lo es el art. 285 de nuestro Código Penal. Al respecto, cfr. LONDOÑO, "Ilícito de manipulación", cit. nota $\mathrm{n}^{\circ} 1$, p. 68 , nota 6 .

${ }_{13}$ Sobre las dificultades para una definición unívoca, cfr. AVGOULEAS, Emilios, The Mechanics and Regulation of Market Abuse. A legal and Economic Analysis, Oxford: Oxford University Press, 2005, pp. 104 y ss.

${ }_{14}$ De especial interés resulta la articulada y comprensiva definición ofrecida por AVGOULEAS, The Mechanics, cit. nota $\mathrm{n}^{\circ} 13$, p. 116. En lo demás, para diversos conceptos jurídicos de manipulación, en planos históricos y comparados diferenciados, cfr. BERLE, Adolf. A., "Stock Market Manipulation", Colum. L. Rev., n. 38 (1938), pp. 393 y ss.; PERDUE, Wendy C., "Manipulation of futures markets: redefining the offense", Fordham L. Rev., n. 56 (1987), pp. 345 y ss.; THEL, Steve, "\$ 850,000 in Six Minutes -- The Mechanics of Securities Manipulation", Cornell L. Rev., n.79 (1994), pp. 219 y ss.; PEDRAZZI, Cesare, "Turbativa dei mercati" (voce), Dig.Disc. Pen., 1999, pp. 421-432, SEMINARA, Sergio, "I reati di aggiotaggio", en: PEDRAZZI, Cesare et Al., Manuale di diritto penale dell'impresa, Bologna: Monduzzi, 2000, pp. 635-663; VOGEL, Joachim, $\$ \S 20 a$, 38-40b (kommentar), en: ASSMANN, H.D.; SCHNEIDER, U.H., Wertpapierhandelsgesetz Kommentar, Köln: Otto Schmidt, 2006, pp. 727 y ss. y 1669 y ss.; TIEDEMANN, Klaus, Wirtschaftsstrafrecht: Besonderer Teil, Köln: Heymanns, 2006, pp. 158-162 (en catellano, trad. de la 2da edición alemana, TIEDEMANN, Klaus, Manual de Derecho Penal Económico. Parte General y Especial, Valencia: Tirant Lo Blanch, 2010, pp. 380-383); ESTRADA, Albert, "Presente y futuro del delito de alteración de precios (art. 284 Cp)", InDret, 1/2014, esp. 15 y ss. Véase en fin STEINBERG, Marc I., Understanding Securities Law, $5^{\text {th }}$ ed., New Providence: Lexis Nexis, 2009, p. 259, con referencia a las definiciones de la Corte Suprema de los EE.UU: "'Manipulation' is 'virtually a term of art when used in connection with securities markets.' Ernst \& Ernst, 425 U.S., at 199, 96 S.Ct., at 1384. The term 
LONDOÑO, Fernando. “Aproximación histórico-comparada al Título VIII de la Ley de Mercado de Valores: bases para el reconocimiento de un contenido anti-manipulativo".

\begin{abstract}
“(...) manipulación de valores [securities manipulation] (...) significa una conducta dirigida a inducir a personas a negociar un valor [induce people to trade a security] o bien a forzar su precio a un nivel artificial [force its price to an artificial level]"15
\end{abstract}

La manipulación de los precios-de-mercado es un fenómeno conocido y desde siempre combatido en los mercados de capitales ${ }^{16}$. Es anterior a los mercados de valores -como las figuras tradicionales de agio o alteración de precios lo demuestra- pero su difusión y dañosidad se acentúa en los contextos bursátiles. Podría decirse que es tan antiguo como los mercados de valores mismos ${ }^{17}$. Hay reporte de manipulaciones bursátiles ya en el s. XVII, en la primera obra que se conozca dedicada a describir la fisiología (y patología) de un sistema de bolsa ${ }^{18}$.

En 1814 tuvo lugar el primer caso moderno y la primera sentencia relevante de manipulación bursátil en Europa: Rex v. De Berenger ${ }^{19}$, un caso muy comentado, incluso entre nosotros ${ }^{20}$. Los hechores (entre los que se contaba "nuestro" mismísimo Lord Thomas Cochrane) difundieron en la Bolsa de Londres el falso rumor de que Napoleón Bonaparte había sido asesinado. Como se sabe, Napoleón y Francia estaban entonces en brutal guerra contra el Reino Unido y otras naciones europeas aliadas. Pues bien, con esas falsas noticias los autores buscaban inducir al público a comprar instrumentos de deuda emitidos por el Gobierno Británico $^{21}$, los que producto de la incierta guerra cotizaban más bien a la baja. Los autores pretendían así elevar el precio de dichos instrumentos financieros, lo que en efecto lograron. Como puede imaginarse, esos mismos títulos habían sido adquiridos previamente por los autores, para luego venderlos a mayor precio, una vez extendido el rumor, pero antes de que el mercado viniese a conocer su falsedad (y consecuentemente cayera el precio de los mismos). Se trató pues de una clásica burbuja en la que se infla el precio y luego se descargan los títulos desde ese nivel inflado. Fenomenológicamente, este curso de acción se asemeja al moderno pump and dump ${ }^{22}$.

refers generally to practices, such as wash sales, matched orders, or rigged prices, that are intended to mislead investors by artificially affecting market activity." (judge Byron White en sentencia de la Corte Suprema de los Estados Unidos, Santa Fe Indus., Inc. v. Green, 430 U.S. 462, [1977], III).

${ }^{15}$ THEL, Steve, "The Original Conception of Section 10(b) of The Securities Exchange Act", 42 Stan. L. Rev. 385, 1989-1990, p. 393.

${ }^{16}$ Con esta expresión se quiere aludir al género, como sinónimo de mercado financiero. Las especies son el mercado de capitales de tipo bancario y el mercado de oferta pública de valores: cfr. arts. $1^{\circ}$ y $4^{\circ}$ de la LMV.

${ }^{17}$ Cfr. LOSS, Louis; SELIGMAN, Joel, Securities Regulation, versión digital Lexis.com, 2004 (3a. ed.), § 10A: "The practice is probably as old as the securities markets".

${ }^{18}$ Cfr. PENSO DE LA VEGA, José, Confusión de confusiones, Ámsterdam, 1688; cfr. LONDOÑO, "Ilícito de manipulación", cit. nota n 1 , p. 64 y notas 26 y 45.

${ }^{19}$ Rex v. De Berenger (1814) 3 M \& S 67, pp. 67-77 (pp. 536-540), sentencia del King's Bench a la que puede accederse desde http://www.worldlii.org/int/cases/EngR/1814/480.pdf.

${ }^{20}$ Cfr. FERNÁNDEZ, Pedro Javier, Código Penal de la República de Chile esplicado i concordado, T.II, 2 da. Santiago de Chile: Ed, Imprenta, litografía y encuadernación Barcelona, 1900, pp. 34-36, con referencias tomadas de la Historia Jeneral de Chile de Diego Barros Arana.

${ }^{21}$ Específicamente, se trataba de Public Government funds y Government Securities.

${ }^{22}$ Cfr. Comité de Autoridades Europeas Reguladoras de Valores (en adelante CESR, por su sigla en inglés), documento guía CESR 04-505b, emanado por la aludida entidad en sede de especificación del contenido de la Directiva 2003/6/CE sobre Abusos de Mercado. Cfr. al respecto, LONDOÑO, "Ilícito de manipulación", cit. nota $\mathrm{n}^{\circ} 1$, p. 87 (nota 58) y pp. 95-96. Aunque más bien de tipo informativa, la manipulación del caso 
El caso Rex v. De Berenger es una buena muestra de los límites de la figura común de fraude mediante engaño (fraud), a la vez que un anticipo de la autonomía del injusto de manipulación, de connotación institucional o supra-individual ${ }^{23}$.

Las inveteradas figuras de agio, agiotaje o alteración de precios ${ }^{24}$-como nuestro art. 285 $\mathrm{CP}$ y sus inmediatos antecedentes decimonónicos ${ }^{25}$ - ofrecían en cambio, a diferencia del fraude del derecho común, un espacio de adecuada cobertura para estos fenómenos defraudatorios, desde una perspectiva institucional o supra-individual. Con todo, esas figuras surgieron con una vocación dirigida a la tutela del adecuado abastecimiento de la población y la industria, con referencia por tanto a los precios y mercados en general $^{26}$, y no con un carácter especialmente orientado al mercado bursátil. Dichas figuras constituyen más bien un anticipo de lo que será más tarde la moderna prohibición de prácticas monopólicas o abusivas de una posición dominante de mercado.

Habría que esperar hasta la crisis bursátil de 1929 -en parte potenciada por los fenómenos manipulativos ${ }^{27}$ - para que, en el primer lustro de los años ' 30 del siglo pasado, surgiera una regulación moderna especializada en la prevención y sanción de la manipulación de mercado de valores ${ }^{28}$. Se trata de la Securities Exchange Act de 1934 de los Estados Unidos, especialmente de su sección $9\left(a^{29}\right.$. La prohibición de la manipulación bursátil constituye el corazón del régimen de prohibiciones del derecho federal estadounidense. Esta legislación servirá de modelo para las regulaciones contemporáneas en Europa y América. Sobre ella se volverá más tarde ${ }^{30}$, pues -como se ha anticipado- su tenor reverbera notablemente en nuestros artículos 52 y 53 LMV. Por de pronto bastará aquí con

Schwager se deja describir bajo esta categoría, como justamente lo hizo ver el tribunal en su sentencia en el considerando Decimotercero: cfr. condena penal por el $4^{\circ}$ Tribunal Oral en lo Penal de Stgo., RIT 67-2010 de 19 de octubre de 2010; Cfr. ROSENBLUT, "El caso Schwager", cit. nota ${ }^{\circ}$ 1, pp. 185-209.

${ }^{23}$ De interés resultan los problemas de subsunción por el contexto colectivo y anónimo en el que se introduce el engaño, lo que se traduce en una relativa indeterminación de los perjudicados. Cfr. Rex $v$ De Berenger (1814) 3 M \& S 67, especialmente pp. 69-73, incluyendo la lectura en clave individual o privatista de las defensas (pp. 69-71), así como la réplica de Lord Ellenborough (pp. 72-73), sensible en cambio a la dimensión pública del engaño o injusto en cuestión: cfr. pp. 67-77 (pp. 536-540).

${ }^{24}$ Un enlace ya con el derecho corporativo medieval y moderno (pre revolución industrial) es identificada por PEDRAZZI, Cesare, Problemi dell'aggiotaggio, Milano, 1958; reed. en Diritto Penale IV, Scritti di diritto penale dell'economia, Milano: Giuffrè, 2003, pp. 3-97, pp. 19 y ss., aunque más bien con fórmulas de evitación del ejercicio abusivo de un monopolio establecido; de ahí la prohibición de coaligaciones y pactos entre intervinientes en el mercado para elevar los precios. La ley Le Chapelier de 1791 castigaba ya estas coaligaciones. La perspectiva sería retomada y expandida en el Código Penal de Napoleón, de 1810, en su art. 419, más abajo comentado (cfr. infra sub apartado 1.2.2).

${ }^{25}$ Artículos 462 del CP Español de 1850 y 419 del CP Francés de 1810.

${ }^{26}$ Cfr. PACHECO, Joaquín Francisco, El Código penal concordado y comentado, $4^{\mathrm{a}}$ edición, Madrid: Imprenta de Manuel Tello, 1870, T. III, p. 386 con referencias al CP Francés de 1810 y los antecedentes en las Partidas.

${ }^{27}$ Cfr. TWENTIETH CENTURY FUND, INC., The Security Markets, New York: The Fund, 1935, cap. 13, pp. 443-508; LOSS/SELIGMAN, Securities Regulation, cit. nota n 17, Cap. 10.

${ }^{28}$ Cfr. AA.VV., "Illegality of Stock Market Manipulation (Note)", Colum. L. Rev., vol. 34 (1934), pp. 500 y ss.

${ }^{29}$ Como se verá más adelante (infra sub apartado 1.3.2), también la sección 10(b) de la SEA'34 cumple un rol importante en este contexto, si bien su tenor y aplicación sucesiva la llevaría más bien a desempeñar un rol decisivo en la prohibición del fraude y el uso de información privilegiada.

${ }^{30}$ Cfr. infra sub apartado 1.3. 
LONDOÑO, Fernando. “Aproximación histórico-comparada al Título VIII de la Ley de Mercado de Valores: bases para el reconocimiento de un contenido anti-manipulativo".

anticipar que la citada regulación federal estadounidense prohíbe, entre otras conductas manipulativas, la realización de transacciones con el propósito de inducir a la compra o venta de valores (9[a][2]), formulación que inmediatamente evoca a nuestro discutido artículo 53.

A partir de las décadas del ' 40 y ' 50 del siglo pasado las normas de prohibición y sanción de la manipulación bursátil se instalan en el centro de las regulaciones comparadas en materia de mercado de valores. No era de extrañar, por lo demás, desde que su lesividad ha estado desde siempre fuera de discusión (a diferencia de lo que ha acontecido con su "pariente más cercano", el insider trading o uso de información privilegiada) $)^{31}$. En efecto, la manipulación de mercado de valores afecta la correcta formación de los precios-demercado, mermando así su rol informativo, con la consecuente opacidad y pérdida de confianza de los inversores en dichos mercados. ${ }^{32}$ Con todo ello se pone en peligro la función distributiva de recursos financieros desde el ahorro hacia la inversión, propia de todo mercado de capitales y vital en un plano macroeconómico. ${ }^{33}$

Recién hacia los '80s comienza a cobrar mayor visibilidad en el debate político-legislativo y doctrinario comparado ${ }^{34}$ la -hoy muy conocida- prohibición y sanción del uso de información privilegiada ${ }^{35}$ (insider trading, en el contexto anglosajón), figura emparentada con la manipulación, si bien de signo opuesto, como se le ha caracterizado. En efecto, representando ambas hipótesis formas de explotación o abuso de un escenario de asimetría informativa (de allí el parentesco), en el primer caso (manipulación) el agente obtiene ventajas por la vía del dominio y ejercicio de una dosis de falsedad o irrealidad aplicada al mercado, mientras que en el segundo caso (información privilegiada), el agente obtiene ventajas a partir del dominio y ejercicio indebido de un conocimiento relativo a hechos o circunstancias reales (pero de cuyo conocimiento no podía extraerse riqueza mediante

\footnotetext{
${ }^{31}$ Un debate inaugurado por MANNE, Henry, "In Defense of Insider Trading”, Harvard Business Review, 1966 (Nov-Dec), pp. 113 ss.

${ }^{32}$ Cfr. PERRONE, Andrea, "Información en el mercado de valores y tutela del inversor". Polít. Crim. Vol. 4, No 7 (Julio 2009), Art. 7, pp. 197-229 (1-33), en http://www.politicacriminal.cl/Vol_04/n_07/Vol4N7A7.pdf. De interés en este contexto resulta la perspectiva crítica recientemente expuesta en GARCÍA, Gonzalo, "La idealización y la administrativización de la punibilidad del uso de Información Privilegiada. Un análisis de los discursos penales en la doctrina chilena". Política criminal Vol. 10, № 19 (Julio 2015), Art. 5, pp. 119-158, p. 151, en http://www.politicacriminal.cl/Vol 10/n_19/Vol10N19A5.pdf : tomando distancia de lo que identifica como una idealización neo-institucional de las funciones asociados al mercado de valores (en cuanto bien jurídico), con la subsecuente problemática del espacio que allí cabe a los mercados informales. Aunque las objeciones de García se plantean fundamentalmente a propósito de la (punibilidad) del uso de información privilegiada, el punto merece atención también en la presente sede; en efecto, la objeción resulta de interés de cara a la interpretación del objeto material de las conductas prohibidas en el art. 53 LMV. Al respecto, cfr. infra notas $\mathrm{n}^{\circ} 208$ y 215 , con reenvío a trabajo en proceso de publicación.

${ }^{33}$ Cfr. LONDONO, "Ilícito de manipulación", cit. nota n 1 , pp. 72 y ss. Cfr. además, TIEDEMANN, Manual de Derecho Penal Económico, cit. nota $\mathrm{n}^{\circ}$ 14, p. 380; EASTERBROOK, Frank H.; FISCHEL, Daniel, The Economic Structure of Corporate Law, Cambridge: Cambridge University Press, 1991, p. 324; ONADO, Marco, Economia e regolamentazione del sistema finanziario, Bologna: Il Mulino, 2004, pp. 24 y ss.

${ }^{34}$ Con los casos Chiarella, Dirks y O'Hagan en EEUU (cfr. infra 1.3.2) y la Directiva del '89 del Consejo Europeo para la coordinación de la regulación del insider trading (cfr. infra 1.4).

${ }^{35}$ No es de extrañar entonces que la versión original de la ley 18.045 no contemplara un régimen de prohibición y sanción del uso de información privilegiada, más allá del conciso art. 13 (cfr. infra 1.3.e)
} 
transacciones $\mathrm{u}$ otra actividad prohibida ${ }^{36}$. El efecto de sistema es, en ambos casos, comparable: el descrédito del mercado y el eventual éxodo de inversores ${ }^{37}$. Ambas figuras comprenden hoy la categoría conocida en Europa como Abusos de Mercado, fundamentalmente a partir de la decisiva Directiva 6 de 2003 (Market Abuse Directive) ${ }^{38}$. Por lo que toca a los Estados Unidos, ambas formas de ataque al mercado de valores resultan sancionadas bajo un mismo título de imputación ${ }^{39}$, si bien -como se verá- la manipulación bursátil cuenta con un contexto normativo más rico, de origen directamente legislativo-federal. ${ }^{40}$

Lo dicho hasta aquí permite extraer una conclusión provisional, de inmediata utilidad en sede hermenéutica; y esto es, que el contexto histórico-comparado (sobre todo aquel imperante hasta antes de los '80) hace naturalmente comprensible que el legislador nacional de 1980-1981 incluyera una sección dedicada a las actividades prohibidas en el mercado de valores (Título VIII, de las actividades prohibidas, arts. 52 y 53), y -más importante aúnque el contenido de dicha prohibiciones coincidiera precisamente (y exclusivamente) con el hasta entonces tópico dominante en cualquier regulación del sector: la prohibición de la manipulación del mercado de valores ${ }^{41}$.

\subsection{Desde el fraude común al agiotaje. Primeros esfuerzos de abordaje típico: emancipación respecto de los tipos de fraude tradicionales de referencia individual- patrimonial.}

Debe ser claro que los apartados siguientes no pretenden ofrecer una genealogía acabada de la figura contemporánea de manipulación de mercado de valores. Una reconstrucción semejante -que en sus detalles escapa con mucho a los propósitos de este artículo- debería hacerse cargo de los matices de diferencia entre los distintos contextos normativos y respectivas zonas de influencia (civil/administrativa/penal; Europa/EEUU). De todos modos, un bosquejo esquemático de tal genealogía puede anticiparse aquí en los términos que siguen.

Las tipologías contemporáneas de manipulación arrancarían todas, tanto en Europa como en Estados Unidos, de un remoto tronco común, como lo es el fraude, entendido en sentido estricto o en su subespecie, como fraude por engaño ${ }^{42}$. En lo que toca a los Estados Unidos, ello es claro en el recurso a la figura de fraude del common law para el tratamiento de los casos de manipulación anteriores a la legislación de 1934. A partir de esa legislación -la

\footnotetext{
${ }^{36}$ Cfr. LOSS/SELIGMAN, Securities Regulation, cit. nota ${ }^{\circ}$ 17, Cap. 10.

${ }^{37}$ Cfr. Preámbulo de la Directiva 2003/6/CE sobre Abusos de Mercado.

${ }^{38} \mathrm{Cfr}$. infra sub apartado 1.4.

${ }^{39}$ La conocida regla 10b-5 de la Securities Exchange Commission: cfr. infra 1.3.2.

${ }^{40}$ Fundamentalmente la sección 9(a) de la SEA '34, a diferencia del uso de información privilegiada, de elaboración fundamentalmente reglamentaria y jurisprudencial.

${ }^{41}$ Habría que esperar recién hasta la ley $\mathrm{N}^{\circ} 19.301$ de 1994 -acumulada ya una buena dosis de experiencia comparada en la prohibición del uso de información privilegiada- para que nuestro legislador incursionara en su tratamiento detallado y sanción.

${ }^{42}$ Cfr. GREEN, Stuart P., Lying, Cheating and Stealing, A moral Theory of White-Collar Crime, Oxford: Oxford Universitary Press, 2006, pp. 148 y ss., con referencia a la inconsistencia en el uso del concepto de fraude [fraud] en el common law. En Chile, cfr. especialmente MERA, Jorge, Fraude civil y penal. El delito de entrega fraudulenta, Santiago: Conosur, $2^{\text {a }}$ Ed., 1994, pp. 78-94, esp. pp. 88-94.
} 
LONDOÑO, Fernando. “Aproximación histórico-comparada al Título VIII de la Ley de Mercado de Valores: bases para el reconocimiento de un contenido anti-manipulativo".

Securities Exchange Act de 1934- la figura de manipulación de mercado adquiere vuelo propio, emancipándose del fraude de derecho común, y abriendo además un camino de influencia más allá del Atlántico. En Europa, justamente, puede decirse que en el camino entre el fraude por engaño y las figuras contemporáneas de manipulación del derecho comunitario europeo se ubica, en una estación intermedia, la figura decimonónica de agiotaje, a la cual se dedicará el apartado II.3.2. Es paradigmático en este sentido que algunas de las formulaciones europeas contemporáneas de manipulación se implanten tomando como base las figuras internas de agiotaje anteriores a la regulación comunitaria europea $^{43}$. En lo demás, en las figuras actuales del derecho europeo -sobre todo en el ámbito administrativo-regulatorio- se abre un camino propio, de cuño comunitariotecnocrático (Bruselas, el CESR y la ESMA), aunque se deja sentir la influencia de la legislación de matriz británica (la FSMA de 2000, secciones 118 y 397) ${ }^{44}$, así como aquella federal estadounidense (justamente la comentada de 1934). Con estas producciones normativas de matriz europeo-tecnocrática, se interrumpe parcialmente el nexo con las figuras de agiotaje ${ }^{45}$, volviéndose incluso problemática dicha vinculación ${ }^{46}$.

Por lo que se refiere al derecho nacional que aquí nos ocupa, un primer esbozo de reconstrucción genealógica se intentará más adelante (cfr. infra sub apartado 1.3). Considerando que la historia de la tramitación de la LMV original es más bien escasa en explicaciones, se trata de una tentativa no exenta de dificultades. Con todo, y según se expondrá en su momento, hay indicios que permiten colocar a dichas disposiciones bajo la órbita de influencia del derecho federal estadounidense, especialmente de las hipótesis 1), 2) y 6) de la sección 9 a) de la Securities Exchange Act de 1934.

\subsubsection{Fraude por engaño.}

"Relacionada al campo del fraude -pero en materia de análisis jurídico no enteramente reducible al mismo- se sitúa la manipulación de mercado". 47

Así abren Louis Loss y Joel Seligman su ya clásica exposición sobre la manipulación en el mercado de valores. El juicio es preciso: la manipulación está emparentada con el fraude (por engaño), si bien no se deja reducir completamente a dicha categoría. En teoría de

\footnotetext{
${ }^{43}$ El caso italiano es paradigmático en este contexto: aggiotaggio común (art. $501 \mathrm{CP}$ ), aggiotaggio societario (art. 2.628 C.C), aggiotaggio bancario (art. 138 d.lg. 385/1993), hasta el aggiotaggio sobre instrumentos financieros (art. 181 d.lg. 58/1998), figura esta última que - hasta las reformas introducidos a propósito de la recepción de la normativa europea - desempeñaba el rol de figura especial para los mercados de valores (hoy art. 185 d.lg. 58/1998). En España el art. 284, con su numeral $1^{\circ}$ de matriz tradicional, a la que se incorporan un numeral $2^{\circ}$ y un (inasible) numeral $3^{\circ}$. De interés, relacionando la situación española e italiana en sede de agiotaje, cfr. BRAGE, Santiago, Los delitos de alteración de precios, Granada: Comares, 2001, pp. 151-153.

${ }^{44}$ Cfr., especialmente, la secciones $118.5-8$ (por lo que toca a la regulación administrativa) y 397 (figuras penales) de la Financial Services and Markets Act 2000 (FSMA 2000). Al respecto, cfr. AVGOULEAS, The Mechanics, cit. nota $\mathrm{n}^{\circ} 13$, pp. 307 y ss.

${ }^{45}$ Aunque esto es más claro en la regulación administrativa-sancionatoria. Considérese el caso en España del art. 83 ter de la ley 24/1988 de Mercado de Valores, por lo que respecta al ilícito administrativo. Otro tanto en Italia, art. 187 ter d.lg. 58/1998.

${ }^{46}$ Como lo revela el caso del actual art. 284 CPE 1995.

${ }^{47}$ LOSS/SELIGMAN, Securities Regulation, cit. nota ${ }^{\circ} 17, \S 10 \mathrm{~A}-\mathrm{A} .:$ "Related to the field of fraud - but not altogether a part of it as a matter of legal analysis - is the matter of market manipulation."
} 
conjuntos, podría decirse que se comportan como dos categorías que se intersecan, compartiendo elementos en común.

Las manipulaciones no son entonces reconducibles a los tipos de estafa ${ }^{48} u$ otras formas tradicionales de fraude mediante engaño, por más que puedan identificarse puntos de conexión entre estas figuras.

El parentesco con las modalidades de fraude por engaño se halla en el input del hecho, en la medida que la alteración de los precios se suele alcanzar mediante el recurso a formas de engaño, generadoras de error en los operadores que, bajo su efecto, movilizan la oferta o la demanda (venden o compran), en el sentido buscado por el manipulador. Así, los manipulados comprarán o se abstendrán de vender, si el manipulador ha transmitido -ya con información pura, ya mediante las señales que se desprenden de transacciones reales o ficticias ${ }^{49}$ - falsas buenas noticias relativas al título-valor de que se trate; o bien, en sentido opuesto, venderán o se abstendrán de comprar, si el engaño se expresa en falsas malas noticias. Esta sintonía entre manipulación y engaño es perfecta en el caso de las manipulaciones informativas (cfr. infra apartado 2) ${ }^{50}$ que justamente operan mediante la introducción de información falsa en el mercado, lo que supone un impacto de la misma en los operadores manipulados; es decir, una interacción psíquica ${ }^{51}$ en términos de engaño/error.

Ahora bien, la relación o parentesco entre manipulación y fraude por engaño llega sólo hasta ahí. Dos dimensiones del fenómeno dan cuenta de sus diferencias: ya en el plano comisivo, ya en el plano del interés lesionado.

En cuanto a los medios comisivos, dos notas distintivas deben mencionarse. En primer lugar, si bien una forma de engaño concurre en la enorme mayoría de los casos de manipulación, éste no es de la esencia. Una alteración del precio-de-mercado puede también realizarse mediante el ejercicio (abusivo) de una posición de control o poder de mercado. Ello sucede paradigmáticamente en los casos de corners y squeezes, en los mercados de derivados y futuros ${ }^{52}$. Allí, el manipulador acapara un stock decisivo de los bienes subyacentes, de modo que fuerza a sus contrapartes -necesitadas de adquirirlos por una precedente obligación contractual- a comprarlos pagando un precio superior al de

\footnotetext{
48 Como figura central o paradigmática de defraudación mediante engaño. Al respecto, por todos, cfr. HERNÁNDEZ, Héctor, "Aproximación a la problemática de la estafa. Problemas actuales de Derecho Penal”, en: AAVV., Problemas actuales en Derecho Penal, Temuco: Universidad Católica de Temuco, 2003, pp. 147-190

${ }^{49}$ Como en los primeros casos reportados, Scott v. Brown; y Sanderson \& Levi v. British Westralian Mine \& Share Corporation: cfr. LOSS/SELIGMAN, Securities Regulation, cit. nota ${ }^{\circ}$ 17, Cap. 10.

${ }^{50}$ Cfr. LONDOÑO, "Ilícito de manipulación", cit. nota $n^{\circ} 1$, p. 103.

${ }^{51}$ Cfr. MAGRO, Beatrice, Manipolazioni dei mercati finanziari e diritto penale. Una critica al modello di razionalità economica, Milano: Giuffrè, 2012, p. 219, usando esta terminología.

52 Para una caracterización, cfr. FRIEDMAN, Richard D., "Stalking the squeeze: understanding commodities market manipulation", Mich. L. Rev., n. 89 (1990), pp. 30-68; MARKHAM, Jerry W., "Manipulation of Commodity Futures Prices - The Unprosecutable Crime", Yale J. Reg., n. 8 (1991), pp. 281 y ss.; PIRRONG, Craig, "Commodity Market Manipulation Law: A (Very) Critical Analysis and a Proposed Alternative", Wash. \& Lee L. Rev., n. 51 (1994), pp. 945 y ss. Véase también la sintética explicación del cornering en ESTRADA, “Alteración de precios”, cit. nota n 14, p. 28.
} 
LONDOÑO, Fernando. “Aproximación histórico-comparada al Título VIII de la Ley de Mercado de Valores: bases para el reconocimiento de un contenido anti-manipulativo".

mercado. La manipulación opera aquí por una vía emparentada con el abuso de una posición monopólica ${ }^{53}$ : el manipulador impone el precio-de-mercado, desde que controla el extremo de la oferta ${ }^{54}$. Otro tanto puede decirse de las manipulaciones que se realizan mediante transacciones disruptivas, por sí mismas alteradoras de los precios. De ahí que su mecanismo de actuación sobre los precios se caracterice como directo, en oposición a las formas de manipulación que operan mediante el recurso a alguna forma de engaño ${ }^{55}$.

Ahora -más importante aún desde un punto de vista de análisis dogmático- una segunda nota distintiva caracteriza al engaño propio de la manipulación; y es que éste no supone una concreta interacción individual, sino que opera en un contexto público y anónimo: en el mercado. Esto significa que el agente no dirige su acción engañosa a una contraparte u operador en particular. Es más, normalmente desconocerá por completo su identidad. Esta nota distintiva fue esgrimida por las defensas en el proto-caso ya comentado, Rex. v. De Berenger, justamente como argumento para sostener la (en palabras de hoy) atipicidad del hecho bajo una forma de fraude por engaño. El argumento subsecuente de las defensas pasaba por hacer ver que, considerado lo anterior, tampoco resultaban individualizados los perjudicados por el hecho. La respuesta que dio el tribunal a esta línea de defensa se revela muy moderna: un daño público [public mischief] constituye el objeto de la conducta ${ }^{56}$, cual fraude dirigido a todo el público, en la medida que no se dirige contra uno o más individuos en particular, sino contra todo aquel que haya de resultar comprador de los respectivos valores en el día en cuestión ${ }^{57}$. De allí entonces que resulte innecesario, para la acreditación del ilícito, individualizar a los compradores de tales valores.

La argumentación del tribunal parece insertarse en una dimensión intermedia de interés protegido. Es decir, en un estadio previo al pasaje decisivo hacia la tutela de un interés institucional o supra-individual. En efecto, entre la estricta tutela del interés patrimonial individual (propio de las figuras de fraude por engaño) y la más moderna tutela de un interés institucional o supra-individual (que más tarde aparecerá en las figuras de agiotaje o alteración de precios), la tutela se coloca aquí en un punto intermedio, con referencia a los intereses de un grupo indeterminado de sujetos $^{58}$. Con todo, en esta fase intermedia de desarrollo, la tutela debe todavía entenderse hecha a un interés individual, por más que se

\footnotetext{
${ }^{53}$ Cfr. ESTRADA, “Alteración de precios”, cit. nota ${ }^{\circ}$ 14, p. 30. De interés, EASTERBROOK, Frank H., "Monopoly, Manipulation, and the Regulation of Futures Markets", The Journal of Business, Vol. 59 (1986), n. 2, pp. 103-127, quien hace ver que aún en estos supuestos opera una forma de engaño en la fase de paulatina y sigilosa adquisición de los bienes subyacentes; es decir, de acceso a la posición de control del stock. Con todo, debe ser claro que se trata de un concepto de engaño distinto al que se utiliza aquí para explicar los mecanismos de injerencia en los precios y que supone alguna forma de interacción psíquica dirigida a condicionar (desorientando) el comportamiento de terceros.

${ }^{54}$ A esta categoría de manipulaciones se alude en LONDOÑO, "Ilícito de manipulación", cit. nota $\mathrm{n}^{\circ} 1$, p. 103, con formas "directas". Esta forma no mediada de alteración del precio puede también verificarse de manera puramente "mecánica", a consecuencia de compras o ventas voluminosas y disruptivas, que fijen precios-de-mercado por un determinado período, normalmente hacia el cierre del día bursátil ("marking the close"). Con mayor detalles, cfr. infra sub apartado 2.2 de este artículo.

${ }^{55}$ Sobre esto cfr. infra sub apartado 2.2.

${ }_{57}^{56}$ Juzgada a la luz del estatuto de la conspiracy.

${ }^{57}$ Rex v. De Berenger, cit. nota $\mathrm{n}^{\circ}$ 19, pp. 72-74, opiniones de jueces Ellenborough y Le Blanc, integrantes del King's Bench.

${ }^{58}$ Cfr., iluminante sobre el punto, PEDRAZZI, Problemi, cit. nota ${ }^{\circ} 24$, pp. 25 y ss.
} 
siga una diversa estrategia de protección (posiblemente forzando el sentido tradicional de la figura).

Lo dicho hasta aquí deja ya abierto el segundo plano diferenciador, en el campo del resultado. La lesión asociada a la figura de manipulación no coincide con el perjuicio patrimonial de un determinado operador o inversionista, sino con la afectación del mercado mismo y del mecanismo de formación de los precios ${ }^{59}$. De allí que, en las figuras contemporáneas de manipulación, el perjuicio individual no aparezca como elemento del tipo (ni aún la idea de un perjuicio económico a un grupo indeterminado de personas).

La manipulación del mercado no es entonces una estafa o un fraude por engaño colocado en un contexto bursátil. Dichas figuras no se encuentran en una relación de especialidad. Se trata de categorías distintas, por más que eventualmente compartan un aspecto tan vistoso o característico como es el engaño; y se dice aquí eventualmente, pues mientas aquel factor es de la esencia en tales fraudes, en el marco de la manipulación constituye un elemento esencial sólo de una categoría o grupo de manipulaciones (aquellas de injerencia indirecta mediante engaño, paradigmáticamente de tipo informativas). En cuanto al perjuicio patrimonial, su proyección es de la esencia en el fraude por engaño, como contrapartida del ánimo de lucro ${ }^{60}$, conformando un elemento necesario para su consumación. Aquello no se da en cambio en la manipulación de mercado. Hasta donde se alcanza a ver, no puede hallarse -en los ordenamientos de habitual referencia- un solo ejemplo en el que el perjuicio patrimonial figure en la descripción abstracta de una manipulación bursátil.

Por otra parte, resulta de interés destacar que si la relación entre fraude por engaño y manipulación cuelga de un hilo, es decir, se entabla apenas (y no siempre, en la praxis) en torno a un único elemento (el engaño), la conexión entre manipulación y fraude por abuso de confianza -el otro gran subconjunto de los fraudes- es ya derechamente inexistente. Nada tienen en común aquellas figuras. Esta observación es relevante como argumento adicional para descartar una posible lectura extensiva del art. 53, que ya no sólo lo interprete como coincidente con una figura con la que sólo comparte un elemento eventual (el fraude por engaño), sino con una categoría con la que ya derechamente nada tiene en común.

\subsubsection{Agiotaje o alteración de precios.}

Si la relación entre fraude por engaño y manipulación de mercado puede describirse mediante la imagen de conjuntos que se intersecan, ligados por la dimensión del engaño, la relación entre las figuras de agiotaje y las de manipulación suele corresponder en derecho comparado a una de género-especie.

Las decimonónicas figuras de agiotaje dan en efecto cobertura a las manipulaciones del mercado de valores, aunque, como se dirá a continuación, su enfoque o preocupación

\footnotetext{
${ }^{59}$ Cfr. LONDOÑO, "Ilícito de manipulación”, cit. nota $\mathrm{n}^{\circ} 1$, pp. 72 y ss.

${ }^{60}$ Por más que tradicionalmente en nuestro medio al ánimo de lucro no se le reconozca como elemento constitutivo de la estafa, ello no se condice con la tendencia comparada: al respecto, cfr. HERNÁNDEZ, "Aproximación", cit. nota $n^{\circ} 48$, p. 188.
} 
LONDOÑO, Fernando. “Aproximación histórico-comparada al Título VIII de la Ley de Mercado de Valores: bases para el reconocimiento de un contenido anti-manipulativo".

central radica en la función desempeñada por otros mercados, fundamentalmente de artículos de primera necesidad o de insumos para la industria.

En nuestro medio, fue Alfredo Etcheberry el primero que colocó el contenido de los arts. 52 y 53 LMV (y 59 e]) en la órbita del tipo común de alteración de precios previsto en el Código Penal, en una relación de tendencial especialidad o de subsidiariedad tácita ${ }^{61}$.

Para facilitar la comprensión de la tesis expuesta en este pasaje, conviene antes que nada tener a la vista la figura de agiotaje o alteración de precios prevista en nuestro Código Penal. Ella reza:

“Art. 285. Los que por medios fraudulentos consiguieren alterar el precio natural del trabajo, de los géneros o mercaderías, acciones, rentas públicas o privadas o de cualesquiera otras cosas que fueren objetos de contratación, sufrirán las penas de reclusión menor en sus grados mínimo a medio y multa de seis a diez unidades tributarias mensuales". ${ }^{2}$

Conocida es la reciente polémica sobre el alcance de este tipo, especialmente sobre su aplicabilidad a hechos de ejercicio abusivo de una situación monopólica ${ }^{63}$, pero más allá de ello, interesa aquí destacar la pertinencia de esta figura para la sanción de supuestos de alteración de precios en el mercado de valores ${ }^{64}$.

La conclusión anterior supone una interpretación del art. 285 CP y de los artículos 52 y 53 LMV en línea con los términos que aquí se han expuesto; es decir, como figuras de

61 ETCHEBERRY, Derecho Penal, cit. nota ${ }^{\circ}$ 1, pp.280-281. Por lo que se refiere a la interpretación de Etcheberry, cfr. también HERNANDEZ, Héctor, "La punibilidad de la colusión (secreta) de precios en el derecho chileno". Política Criminal, Vol. 7, № 13 (2012), pp. 147-167, pp. 153-154. Se dice aquí "tendencial especialidad" porque una estricta relación lógico-jurídica de género (285) a especie (52-53+59 LMV) es discutible, en cuanto no es seguro que el art. 285 abarque todos los casos concretos subsumibles bajo dichas normas de la LMV. Podría en efecto sostenerse la mayor amplitud de las normas de la LMV en dos ámbitos: el objeto de la manipulación y la modalidad comisiva. El asunto es, como se ha dicho discutible (cfr. infra notas $n^{\circ} 69$ y 70). Si en cambio al art. 285 se da la interpretación más amplia posible -todavía en los márgenes de su tenor literal- entonces sí sería posible afirmar una relación de género a especie, en la medida que todos los casos concretos subsumibles bajo los arts. 52 y $53(+59)$ lo serían bajo el art. 285 CP. Posiblemente la existencia de una relación de subsidiariedad tácita, en la que prefiere la aplicación de la LMV por sobre la del CP es una solución más segura que la de la especialidad. En esto parece llevar razón MATUS, Jean Pierre, "De nuevo sobre la falta de punibilidad de los atenta dos contra la libre competencia, de conformidad con el Art. 285 del Código penal. Algunos aspectos de la discusión con Héctor Hernández en Política Criminal” en Política Criminal Vol. 8, № 15 (Julio 2013), Doc. 1, pp. 314-362, p. 340.

${ }^{62}$ Por su parte, el art. 286 dispone el comiso para el supuesto de alteración recaída sobre mantenimientos u otros objetos de primera necesidad.

63 Polémica suscitada con motivo del denominado "caso Farmacias". Al respecto, cfr. las tesis contrapuestas de HERNÁNDEZ, "Punibilidad de la colusión”, cit. nota n 61 y MATUS, Jean Pierre, "Acerca de la actual falta de punibilidad en Chile de los acuerdos de precios", Política Criminal, Vol. 7, No 14 (Diciembre 2012), Art. 3, pp. 318 - 356; luego reiteradas en MATUS, "De nuevo sobre", cit. nota $n^{\circ} 61$.

64 Cuanto menos de aquellos ejecutados por medios informativos; esto es, bajo formas de engaño. Es decir, estando aún a la más restrictiva de las tesis sobre el alcance del art. 285 (propugnada por MATUS, "Actual falta de punibilidad", cit. nota $\mathrm{n}^{\circ} 63$ ), sólo los supuestos de alteración de precios mediante injerencia directa quedarían excluidos. Véase al respecto lo dicho infra en el sub apartado 2.2 a propósito de las modalidades comisivas. 
Polít. crim. Vol. 10, No 20 (Diciembre 2015), Art. 1, pp. 390-467.

[http://www.politicacriminal.cl/Vol_10/n_20/Vol10N20A1.pdf]

manipulación de mercado. Ésta es ciertamente la opinión de Alfredo Etcheberry. Así, describiendo el alcance general del art. $285 \mathrm{CP}$, sostiene dicho autor que aquel "sanciona a los que por medios fraudulentos consiguieren alterar el precio natural del trabajo, de los géneros o mercaderías, acciones, rentas públicas o privadas o de cualesquiera otras cosas que fueren objeto de contratación"65 "Es una conducta semejante a lo que tradicionalmente se conoce como agio: hacer variar los precios del mercado de manera artificial y con engaño para lucrar con ello" ${ }^{\text {, }}$, agrega más abajo. Abordando implícitamente el problema concursal, hace ver que el $285 \mathrm{CP}$ prevé sanción "cuando lo que se pretende alterar artificialmente es el precio de las acciones", 67 para luego comentar, en el mismo contexto, que los arts. 52 y 53 LMV:

"son (...) prescripciones más minuciosas que las del Código [Penal], pero que se refieren a la misma finalidad: alterar artificialmente el precio resultante de las libres transacciones del mercado de valores" ${ }^{, 68}$.

De lo anterior se desprende una primera conclusión, que aquí se expone en perspectiva funcional: si por las razones que sea, se derogasen los arts. 52 y 53 de la LMV (tipificados en conexión con el art. 59 e]), amén del art. 61 de la misma ley, entonces el art. 285 CP sería en cualquier caso aplicable para sancionar penalmente un universo importante de conductas hoy abarcadas por dichas disposiciones de la $\mathrm{LMV}^{69}$.

Más allá de lo anterior, interesa destacar aquí que la lectura propuesta por Alfredo Etcheberry para el art. $285 \mathrm{CP}$ se apoya en tierra firme, encontrando sustento en la historia del precepto y en la tradición de la figura. Por otra parte, no se advierte que haya sido contradicha por la literatura nacional que se ha ocupado de la misma figura (antes o después de la ley $\left.\mathrm{N}^{\circ} 18.045\right)^{70}$.

${ }^{65}$ ETCHEBERRY, Derecho Penal, cit. nota n ${ }^{\circ}$ 1, p. 280.

${ }^{66}$ ETCHEBERRY, Derecho Penal, cit. nota n ${ }^{\circ}$ 1, p. 280 (el destacado en cursiva es mío).

${ }^{67}$ ETCHEBERRY, Derecho Penal, cit. nota n ${ }^{\circ}$ 1, p. 280

${ }^{68}$ ETCHEBERRY, Derecho Penal, cit. nota ${ }^{\circ}{ }^{1,}$, p. 281

${ }^{69}$ Cuanto menos lo anterior es seguro para los supuestos de manipulación que recaigan sobre títulos accionarios, con empleo de formas de engaño (paradigmáticamente las manipulaciones informativas, pero no sólo ellas, según se verá más abajo). Si acaso a la voz residual "cualesquiera otras cosas que fueren objetos de contratación" puede darse un sentido amplio, comprensivo de títulos no accionarios (bonos, por ejemplo) es algo que puede quedar aquí sin una solución definitiva, por más que en principio no se adviertan razones para rechazar ese alcance amplio. En lo demás, las dudas de cobertura penal estarían en los márgenes, según la interpretación que se asuma del art. 52 LMV y $285 \mathrm{CP}$ en cuanto a su capacidad para comprender modalidades manipulativas no consistentes en formas de engaño. En otras palabras, entre el tipo del art. 59 e] (en conexión con los artículos 52 y 53 LMV) y el art. $285 \mathrm{CP}$ se plantea un concurso aparente de normas, a resolverse por subsidiariedad tácita o especialidad (dependiendo del alcance que se les atribuya en el plano medial) a favor de la aplicación de las figuras de la LMV.

${ }^{70}$ Así, autores como Fuensalida, Fernández, Del Río, Labatut, Hernández y Matus (con referencias para los cuatro primeros, HERNÁNDEZ, "Punibilidad de la colusión", cit. nota ${ }^{\circ} 61$, pp. 148 y ss.). En cuanto a los últimos dos autores -los únicos junto a Etcheberry que originalmente escriben sobre el art. 285 ya bajo la vigencia de la LMV - más allá de la polémica en torno a los límites y posibilidades de cobertura de la hipótesis de ejercicio abusivo de una posición dominante o monopólica de mercado (extensivo, afirmándola, HERNÁNDEZ, "Punibilidad de la colusión", cit. nota n ${ }^{\circ} 61$; restrictivo, negándola, MATUS, "Actual falta de punibilidad", cit. nota $\mathrm{n}^{\circ} 63$ ), la zona nuclear del art. 285 permanece indiscutida y nada hay en las posiciones 
LONDOÑO, Fernando. “Aproximación histórico-comparada al Título VIII de la Ley de Mercado de Valores: bases para el reconocimiento de un contenido anti-manipulativo".

Por lo que se refiere a la historia del precepto, considérese en primer lugar el tenor del art. 462 del Código Penal Español de 1850, que sirvió de modelo para nuestro art. $285 \mathrm{CP}^{71}$, como por lo demás se advierte de la sola comparación de los textos, notoriamente similares. Ubicado en un capítulo que lleva por título De las maquinaciones para alterar el precio de las cosas, la disposición española reza:

"Art. 462. Los que esparciendo falsos rumores, o usando de cualquier otro artificio, consiguieren alterar los precios naturales que resultarían de la libre concurrencia en las mercancías, acciones, rentas públicas o privadas, o cualesquiera otras cosas que fueren objeto de contratación, serán castigados con las penas (...)". ${ }^{72}$ (las cursivas son nuestras)

El comentario de Joaquín Francisco Pacheco a esta disposición avala la lectura que aquí se hace:

"Una carta falsa leída en la Bolsa, un posta simulado que se haga entrar ostensiblemente para divulgar cierta noticia, un anuncio hábil inserto en un periódico, pueden en determinadas circunstancias causar un trastorno en los precios, que enriquezca y arruine a mil personas. En esto hay delito real y verdadero (...)".73

Considerados los ejemplos que aporta, podemos incluso sospechar que Pacheco tenía en mente el célebre caso Rex $v$. De Berenger al comentar el 462 CPE $1850^{74}$. Lo cierto es que su comentario da expresa cabida a la manipulación en el contexto bursátil, sobre todo a aquella de valencia informativa, basada en el engaño.

Las diferencias con nuestro art. 285 se encuentran principalmente en la descripción de los medios comisivos. Lo que nuestros comisionados sintetizaron bajo la amplia fórmula "medios fraudulentos", en el texto que le sirve de fuente se detalla con la referencia al esparcimiento de "falsos rumores", para recurrirse en lo demás a una fórmula descriptiva de los medios comisivos, también genérica: "cualquier otro artificio", voz que en todo caso parece también abarcar a las discutidas "coligaciones",75.

Mayor detalle en la descripción de las modalidades comisivas puede apreciarse en el art. 419 del Código Penal Francés de 1810, arquetipo europeo-continental de la figura de agiotaje del s. XIX:

de dichos autores que en principio contradiga lo que aquí se afirma; esto es, la cobertura bajo el art. 285 de los casos centrales de alteración de precios o manipulación mediante hipótesis de engaño.

${ }^{71}$ Cfr. sesión 61 de las Actas de la Comisión Redactora del CP 1874: en LAZO, Santiago, Código Penal, Orígenes, Concordancias, Jurisprudencia, Santiago: Poblete Cruzat Hnos. Ed., 1917, pp. 240-2141 (art. 285).

${ }^{72}$ PACHECO, El Código penal, cit. nota n ${ }^{\circ} 26$, p. 385.

${ }_{74}^{73}$ PACHECO, El Código penal, cit. nota n ${ }^{\circ} 26$, p. 386.

${ }^{74}$ La referencia al "posta simulado" evoca de inmediato el recurso empleado por los conspiradores en ese caso.

${ }^{75}$ Según por de pronto puede desprenderse del artículo 463 que le sigue, relativo a los mantenimientos y objetos de primera necesidad, el que en su inciso segundo señala que "para la imposición de estas penas bastará que la coligación haya comenzado a ejecutarse." 
“Art. 419. El que por hechos falsos o calumniosos divulgados intencionalmente entre el público, por medio de ofertas hechas a los mismos vendedores, por la reunión o coligación entre los principales tenedores de una misma mercancía o artículo, formada para no venderla, o venderla sólo a cierto precio, o por otras vías o medios fraudulentos, hicieren subir o bajar el precio de géneros, mercancías, documentos o efectos públicos, en más o menos suma de la que hubiere resultado de la libre y natural concurrencia del comercio, será castigado con las penas (...)".76 (los subrayados son nuestros)

Es interesante notar que esta figura - conocida por nuestra Comisión Redactora a través de los Comentarios de Pacheco y cuya influencia para la redacción de nuestro precepto no puede descartarse ${ }^{77}$-ofrece una enumeración de medios comisivos que viene a anticipar, avant la lettre y de modo embrionario, las taxonomías de manipulación bursátil presentes hoy en derecho comparado y reconocidas por la literatura especializada. Aunque más abajo (infra apartado 2) se dará cuenta de esas taxonomías, valga aquí un apretado adelanto.

Pues bien, la referencia a "hechos falsos" se corresponde con las manipulaciones efectuadas mediante hechos o actividad fuera del mercado (action based manipulation), como por ejemplo, un caso en el que se aparente el cierre de la planta de una empresa cotizada en Bolsa, con el solo propósito de provocar alarma entre los inversionistas, induciéndolos así a vender y con ello provocando una baja en el precio de mercado del respectivo título (ello, por ejemplo, con la oculta finalidad del controlador de incrementar su participación pagando menos por ella) ${ }^{78}$. La alusión a la divulgación de tales hechos conecta esta modalidad comisiva con su género, la manipulación informativa (causalmente hablando, todo "hecho" se traduce en información) ${ }^{79}$. La referencia a "ofertas hechas a los mismos vendedores" instala ya el fraude en el marco de actividades en el mercado (por oposición a la action based manipulation). Se trata de un supuesto que parecería anticipar la categoría de cotizaciones u ofertas ficticias conocida en derecho comparado contemporáneo. Por otra parte, las aludidas coligaciones se emparentan con las formas de manipulación que operan mediante poder de mercado ${ }^{80}$, a las que nos hemos referido más arriba. Por último, cerrando la enunciación particularizada de medios, aparece una fórmula amplia, residual (“otras vías o medios fraudulentos"), de tenor equivalente al de nuestro art. $285^{81}$.

Algunas consideraciones finales para concluir este apartado.

\footnotetext{
${ }^{76}$ Traducción ofrecida en PACHECO, El Código penal, cit. nota n 26, p. 386.

${ }^{77}$ Cfr. en ese sentido HERNÁNDEZ, "Punibilidad de la colusión", cit. nota $n^{\circ} 61, \mathrm{p} .151$.

${ }^{78}$ Cfr. el caso de la American Steel and Wire Company, referido por ALLEN, Franklin; GALE, Douglas, "Stock-Price Manipulation", Rev. Fin. Stud. (1992), n. 5, pp. 503-529, p. 504, justamente al explicar esta categoría.

${ }^{79}$ Cfr. infra apartado 2.

${ }^{80}$ Cfr. infra apartado 2.

${ }^{81}$ De interés es también la figura de aggiotaggio del Código Penal del Reino de Italia, de 1889, conocido como Código Zanardelli: art. 293: "Chiunque, col diffondere false notizie o con altri mezzi fraudolenti, produce sul pubblico mercato o nelle borse di commercio un aumento o una diminuzione nei prezzi di salarii, derrate, merci o titoli negoziabili sul pubblico mercato o ammessi nelle liste di borsa, è punito con (...) Se il delitto sia commesso da pubblici mediatori o da agenti di cambio, la pena è (...)."
} 
LONDOÑO, Fernando. “Aproximación histórico-comparada al Título VIII de la Ley de Mercado de Valores: bases para el reconocimiento de un contenido anti-manipulativo".

En primer lugar, nótese que en todos los casos el objeto de la conducta coincide con el precio en un mercado libre. Esto es particularmente claro en el caso del antecedente español ("consiguieren alterar los precios naturales que resultarían de la libre concurrencia en las mercancías"), así como en el modelo francés ("hicieren subir o bajar el precio [...] en más o menos suma de la que hubiere resultado de la libre y natural concurrencia del comercio"). En el caso de nuestro art. 285, la referencia es oblicua, pero de todos modos reconocible bajo la fórmula "consiguieren alterar el precio natural" (que otro no puede ser fuera de aquel que resulte de la libre contratación en un mercado). Resulta así confirmado que el interés directo de tutela no es aquí el patrimonio de uno o más comerciantes o inversionistas -por más que en su Comentario Pacheco aluda a un "trastorno en los precios, que enriquezca y arruine a mil personas ${ }^{82, " ~ s i n o ~ l a ~ i n s t i t u c i o ́ n ~ d e l ~ p r e c i o-d e-m e r c a d o ~ y ~ e l ~}$ mercado (libre), como un todo ${ }^{83}$. En esto se aprecia nuevamente la sintonía con las figuras contemporáneas y especiales de manipulación del mercado de valores.

Ahora bien, más allá de la anterior correspondencia, las diferencias son también notorias, tanto si se considera nuestro art. $285 \mathrm{CP}$ como si se atiende a otras figuras de agiotaje similares; y es que en ellas la tutela del precio-de-mercado o del mercado libre aparece en buena medida instrumental a un interés de protección ulterior, mediatizado mediante dichas instituciones: el interés en el adecuado abastecimiento de los habitantes de la República (por lo que se refiere a los mantenimientos y bienes de primera necesidad), así como de la economía y la industria (por lo que toca a los demás bienes que sirven de insumos). Son las necesidades de abastecimiento (material) de la población y de la industria las que insuflan vida a esta figura, principalmente de cara a conductas de acaparamiento y especulación ${ }^{84}$.

En ese cuadro decimonónico, la preocupación por el abastecimiento financiero -la correcta asignación de recursos financieros, como dimensión últimamente subyacente a la tutela de los mercados de capitales y valores en general- ocupa un rol más bien modesto. Será función de las figuras especiales de manipulación de mercado surgidas en el $\mathrm{s}$. XX redimensionar la importancia de ese interés ${ }^{85}$, en perspectiva macroeconómica. Con ello toca entonces dar paso al tratamiento de estas figuras, comenzando con las arquetípicas normas contenidas en la legislación federal de los Estados Unidos: la sección 9 a) de Securities Exchange Act de 1934.

Una nota final, que servirá también para introducir las diferencias que se aprecian en el plano de técnica legislativa entre las figuras comunes aquí comentadas y aquellas especiales de manipulación de mercado que serán tratadas a continuación; y es que, por lo que toca a la dimensión penal, las primeras pueden aparecer construidas como figuras de resultado,

\footnotetext{
${ }^{82}$ PACHECO, El Código penal, cit. nota n 26 , p. 386 (las cursivas son mías).

${ }^{83}$ Cfr. PEDRAZZI, Problemi, cit. nota ${ }^{\circ} 24$, pp. 24 y ss.; MUÑOZ CONDE, Francisco, Derecho Penal. Parte Especial, Valencia: Tirant Lo Blanch, 14 a ed., 2002, p. 495, identificando en la política económica de precios el bien jurídico protegido en el delito de alteración de precios del CP Español de 1995, art. 284.

${ }^{84}$ Emblemáticos y de antigua data son los casos de acaparamiento de alimentos y manipulación de precios de mantenimientos. El tumultuario episodio de la "revuelta del pan", tan magistralmente descrito por Alessandro Manzoni en sus I Promessi Sposi (Los Novios, en la trad. castellana), es un excelente testimonio del tipo de preocupaciones de las sociedades modernas, a partir del s. XVII.

${ }^{85}$ Con todo, ya en el Código Penal italiano "Zanardelli" de 1889 (art. 293).
} 
para cuya consumación se supone entonces una efectiva alteración del precio ${ }^{86}$. Por plausibles razones simplificadoras de la siempre ardua acreditación del precio manipulado, aquella exigencia de resultado es en general eludida por el derecho comparado contemporáneo, adelantándose la punibilidad al tiempo de la sola acción manipulativa. Aquí, el déficit de resultado (no requerido para la configuración plena del tipo) se compensa por dos vías alternativas, en sede subjetiva u objetiva; es decir, ya exigiendo un plus en sede subjetiva (una intención trascendente del agente, encaminada a la alteración del precio), ya exigiendo una especial idoneidad manipulativa como cualidad de la acción tipificada. Estos dos derroteros "arquitectónicos" representan los modelos seguidos por el legislador comparado en este sector; tendencialmente de cuño estadounidense, el primero; más cercano al europeo, el segundo.

\subsection{Las fórmulas anti-manipulativas en el sistema federal de los EE.UU: $§$ 9(a) y 10(b) $S E A$ '34. A la vez, notas sobre la pertinencia y límites de una comparación con el derecho chileno.}

Habría que esperar hasta después de la violenta caída de la Bolsa de Nueva York en 1929 (el famoso martes negro del 29 de octubre de 1929) y con ella, en los '30, la que resultaría la mayor depresión económica del siglo XX, para que el Congreso de los Estados Unidos de América se decidiera a poner freno a las prácticas abusivas que hasta entonces proliferaban impunes en sus Bolsas de Valores. Las investigaciones conducidas por el Congreso de EE.UU para estudiar las causas del desplome bursátil y proponer los correspondientes remedios llegarían así a una conclusión unívoca: entre otras causas, una de las principales que explicaban el crac del '29 era la presencia de auténticas asociaciones de manipuladores (pools) que lucraban a partir de la alteración artificial de los precios de los títulos transados en las Bolsas ${ }^{87}$. Se demostró que estos agentes dominaban a su amaño la demanda y oferta de valores, induciendo al público inversionista a transar en un sentido u otro con títulos respecto de los cuales los manipuladores habían previamente tomado una determinada posición. Esta inducción al público -provocadoras de burbujas bursátiles: episodios de euforia-alcista, seguidos de pesimismo-depresivo- se realizaba mediante ardides como la difusión de información falsa, la simulación de mercados activos a través de operaciones aparentes o ficticias, entre otras maniobras manipulativas.

Nihil novum sub sole, pues -como se indicó al comienzo de este trabajo- la manipulación bursátil era tan antigua como las bolsas mismas: maniobras de este género eran ampliamente conocidas en el contexto europeo, fundamentalmente en las bolsas de Londres y Ámsterdam, con reportes de prácticas manipulativas ya desde fines del s. XVII. Lo novedoso entonces fue la toma de conciencia acerca de la lesividad general o macroeconómica del fenómeno y la decisión de ponerle atajo mediante una regulación enteramente nueva, que justamente asumiera la perspectiva institucional o supra-individual

\footnotetext{
${ }^{86}$ Lo anterior es válido sobre todo para las versiones del s. XIX: nuestro art. 285 CP desde ya, pero por cierto ya antes el art. 419 del CP Francés de 1810, el art. 462 del CPE 1850 y el art. 293 del CP italiano "Zanardelli" de 1889. El legislador del s. XX ya da el vuelco hacia la mera puesta en peligro como injusto suficiente: así, el art. 501 del CP italiano "Rocco" de 1930 (aunque contempla el resultado como agravante) y desde ya el art. 284 del CP español de 1995.

${ }^{87}$ Cfr. TWENTIETH CENTURY, The Security Markets, cit. nota $n^{\circ} 27$, cap. 13. Una versión sintética puede leerse en LOSS/SELIGMAN, Securities Regulation, cit. nota $\mathrm{n}^{\circ} 17$. cap. 10.
} 
LONDOÑO, Fernando. “Aproximación histórico-comparada al Título VIII de la Ley de Mercado de Valores: bases para el reconocimiento de un contenido anti-manipulativo".

de la dañosidad en juego. Ya no podía bastar con los remedios ex post que ofrecía, en clave individual-patrimonial, el common law a través de la figura de fraude ${ }^{88}$.

Así, tras los Hearings parlamentarios y bajo los nuevos aires del New Deal Rooseveltiano, el Congreso de los EE.UU daría a luz a sendos cuerpos reguladores del mercado de valores, de rango federal: la Securities Act de 1933 (en adelante $S A$ '33) y, más importante para los propósitos de este artículo, la Securities Exchange Act de 1934 (en adelante SEA '34).

\section{Según comentan Loss y Seligman:}

"El problema de la manipulación fue atacado por el Congreso de diversas maneras: mediante prohibiciones específicas, mediante la atribución a la Comisión $\left.{ }^{89}\right] \mathrm{de}$ competencia reguladora en determinadas áreas, y mediante una prohibición general contra toda negociación ejecutada con fines manipulativos" $"$.

Por lo que toca al régimen federal de prohibiciones de transacciones realizadas con finalidades manipulativas y de la manipulación en general, éste se descompone en prohibiciones específicas (sección 9a] SEA '34 fundamentalmente) y una prohibición general (sección 10b] SEA '34). Más tarde y sobre la base de un desarrollo jurisprudencial, la prohibición general asumirá un carácter genéricamente anti-fraude y anti-abuso de mercado, extendiéndose más allá del sentido anti-manipulativo original ${ }^{91}$.

Antes de pasar revista a la regulación federal de los EE.UU en materia de manipulación y fraude en el mercado de valores, es importante destacar que para los fines de este trabajo ella se estudia con un doble propósito demostrativo:

(a) En primer lugar, dar cuenta de la estrecha sintonía entre las fórmulas específicas de prohibición del derecho estadounidense (sección 9[a] de la $S E A$ '34) y el Título VIII de

\footnotetext{
${ }^{88}$ Por más que de dicho modelo regulativo ex post - fundamentalmente compensatorio y retributivo - se adoptasen elementos en la nueva regulación marco, con orientación fuertemente preventivas. Cfr. LOSS/SELIGMAN, Securities Regulation, cit. nota ${ }^{\circ} 17, \S 10-\mathrm{C}$.

${ }^{89}$ Se refiere a la Securities Exchange Commission (en adelante, SEC), autoridad reguladora del mercado de valores en los EE.UU.

90 LOSS/SELIGMAN, Securities Regulation, cit. nota $\mathrm{n}^{\circ} 17$, $10-\mathrm{C}$ Manipulation of the Securities Exchanges Under the SEC Statutes: "The problem of manipulation was attacked by Congress in a number of ways - by specific prohibitions, by giving the Commission rulemaking authority in certain areas, and by a general prohibition against any trading for a manipulative purpose".

${ }_{91}$ El cuadro de prohibiciones de manipulación, abusos y fraude en el mercado de valores se deja reconstruir del siguiente modo: SEA'34: Sección 9(a) = prohibición especial de manipulación en bolsa de valores nacional (nivel federal de EEUU), incluyendo seis hipótesis prohibidas. Sección 10(b) [+ Regla SEC 10b-5] = figura amplia anti-manipulación y anti-fraude en el mercado secundario (así como originalmente concebida), jurisprudencialmente ampliada (alcanzando al insider trading) en relación con valores en mercado secundario. La sección 10(b) contiene un reenvío a la regulación de nivel SEC, justamente lo que a partir de 1942 sería la Regla 10b-5. Es aplicable a manipulaciones over the counter (fuera de bolsa de valores nacional). Existe además una Regla 10b-18 = safe harbour para corporate repurchases (compras de acciones por el propio emisor, tendencialmente manipulativas bajo la §9(a)(2) y la regla 10b-5, de no enmarcarse en la autorización de la §10b-18). Sección 14(e) = fraude en tender offers (por ejemplo, en defensa de un take over tentativo). Sección 15(c)(1) y 15(c)(2) = relativa a maniobras de brokers. SA’33: sección 17(a) = en materia de ventas u ofertas de valores (mercado primario); y la Regulation M (rules 100-105) en materia de estabilizaciones.
} 
Polít. crim. Vol. 10, No 20 (Diciembre 2015), Art. 1, pp. 390-467.

[http://www.politicacriminal.cl/Vol_10/n_20/Vol10N20A1.pdf]

nuestra LMV. La captación de esa sintonía echa luz sobre el sentido anti-manipulativo de nuestro art. 53. En este contexto, especial atención se dará a las hipótesis (1), (2) y (6) de la aludida sección 9(a), como correlatos de los arts. 53 (= §9[a][1] y [2]) y 52 $(=\S 9([a][6])$. Se espera satisfacer este primer objetivo mediante el sub apartado 1.3.1.

(b) En seguida, demostrar la impertinencia de la fórmula general anti-fraude del derecho federal de EEUU (la sección 10b] SEA '34 y su "complementaria" Regla 10b-5) como hipótesis a la luz de la cual leer el derecho nacional (y las consecuencias antisistemáticas y contraproducentes de una tal pre-comprensión). Se espera satisfacer este segundo objetivo mediante el sub apartado 1.3.2.

Este apartado se divide en dos partes (1.3.1 y 1.3.2), en cada una de las cuales se tratarán las secciones del derecho federal estadounidense recién aludidas. En cada caso se plantean primero consideraciones generales sobre las secciones, para luego ofrecerse mayor detalle allí donde resulte pertinente. Cada sub apartado se cierra con un comentario a modo de conclusión, en el que se anticipa una valoración de nuestros arts. 52 y 53 LMV, a la luz del derecho federal estadounidense comentado. Se trata entonces de una valoración comparada de nuestras disposiciones, ofreciéndose puntos de apoyo para trazar paralelismos y diferenciaciones.

\subsubsection{La §9(a) SEA ’34: prohibiciones específicas de manipulación en el mercado de valores.}

Como se decía, las fórmulas específicas anti-manipulativas se desarrollan en la sección 9(a) de la $S E A$ ' $34 .^{92}$ Se prohíben allí seis modalidades de manipulación, las que en términos generales coinciden con las prácticas manipulativas que las investigaciones parlamentarias post crac del '29 reconocieron presentes en los mercados de valores de los EE.UU. La sección lleva por título el explícito Prohibition against manipulation of security prices y declara ilícitas las siguientes maniobras relativas a valores, ejecutadas en el contexto de una bolsa de valores de alcance nacional ${ }^{93}$.

Se ofrece de inmediato una síntesis de las hipótesis prohibidas, dejándose en nota el texto íntegro, en idioma original. Se destacan en cursiva algunos extremos o elementos de especial interés de cara a un contrapunto con nuestra legislación. Una traducción literal in extenso se ofrecerá en los sub apartados siguientes, sólo para las hipótesis 1), 2) y 6) de la $\S 9$ (a). Pues bien, las seis hipótesis que componen la §9(a) SEA’34 pueden sintetizarse del siguiente modo.

(1) Transacciones ficticias [auto-operaciones $u$ operaciones coordinadas], ejecutadas con el propósito de crear la apariencia de un mercado activo para el respectivo valor [wash sales/purchases y matched orders] ${ }^{94}$;

\footnotetext{
${ }^{92}$ Esta sección de la Securities Exchange Act de 1934 puede consultarse como sección 78i en el Capítulo 15 del Código Federal: 15 USCS \& 78i Manipulation of security prices.

${ }^{93}$ El encabezado de la sección 9 reza: It shall be unlawful for any person, directly or indirectly, by the use of the mails or any means or instrumentality of interstate commerce, or of any facility of any national securities exchange, or for any member of a national securities exchange.

${ }^{94}$ Véase texto en original, infra nota ${ }^{\circ} 135$.
} 
LONDOÑO, Fernando. “Aproximación histórico-comparada al Título VIII de la Ley de Mercado de Valores: bases para el reconocimiento de un contenido anti-manipulativo".

(2) La ejecución de una serie de transacciones con valores, que creen o aparenten la existencia de un mercado activo para dichos valores o bien que eleven o rebajen el precio de tales valores, en ambos supuestos con el propósito de inducir a otros a la compra o venta de tales valores ${ }^{95}$;

(3) La inducción a la compra o venta de valores mediante la diseminación de rumores sobre la existencia de asociaciones manipulativas [pools] activas en el mercado ${ }^{96}$,

(4) La entrega de información relevante falsa o engañosa, por intermediarios, vendedores o compradores de valores, con el propósito de inducir a la compra o venta de valores ${ }^{97}$

(5) La inducción a la compra de valores por propagandistas pagados, mediante la difusión de los rumores a que se refiere el punto $(3)^{98}$;

(6) La ejecución de transacciones con el propósito de fijar, mantener o estabilizar el precio de determinados valores, en contravención a la normativa que el Regulador (SEC) dicte para la protección de los inversionistas o en el interés público (pegging, fixing o stabilizing $)^{99}$.

Antes de abordar con mayor detalle las fórmulas de la $\$ 9(a)$, interesa hacer notar algunos aspectos comunes de especial interés, en cuanto en sintonía con la técnica empleada en nuestros arts. 52 y 53 LMV.

Nótese en primer lugar que el contenido (e incluso el orden de los contenidos) de las hipótesis 1 y 2 de la sección 9(a) coincide, respectivamente, con los incisos $1^{\circ}$ y $2^{\circ}$ de nuestro art. 53 LMV. Transacciones ficticias, por una parte; la ejecución de transacciones inductivas a la compra o venta, por la otra.

\footnotetext{
${ }^{95}$ Véase texto en original, infra nota $\mathrm{n}^{\circ} 109$.

96 (3) "If a dealer, broker, security-based swap dealer, major security-based swap participant, or other person selling or offering for sale or purchasing or offering to purchase the security, a security-based swap, or a security-based swap agreement with respect to such security, to induce the purchase or sale of any security registered on a national securities exchange, any security not so registered, any security-based swap, or any security-based swap agreement with respect to such security by the circulation or dissemination in the ordinary course of business of information to the effect that the price of any such security will or is likely to rise or fall because of market operations of any one or more persons conducted for the purpose of raising or depressing the price of such security."

97 (4) "If a dealer, broker, security-based swap dealer, major security-based swap participant, or other person selling or offering for sale or purchasing or offering to purchase the security, a security-based swap, or security-based swap agreement with respect to such security, to make, regarding any security registered on a national securities exchange, any security not so registered, any security-based swap, or any security-based swap agreement with respect to such security, for the purpose of inducing the purchase or sale of such security, such security-based swap, or such security-based swap agreement any statement which was at the time and in the light of the circumstances under which it was made, false or misleading with respect to any material fact, and which that person knew or had reasonable ground to believe was so false or misleading."

${ }^{98}$ (5) "For a consideration, received directly or indirectly from a broker, dealer, security-based swap dealer, major security-based swap participant, or other person selling or offering for sale or purchasing or offering to purchase the security, a security-based swap, or security-based swap agreement with respect to such security, to induce the purchase of any security registered on a national securities exchange, any security not so registered, any security-based swap, or any security-based swap agreement with respect to such security by the circulation or dissemination of information to the effect that the price of any such security will or is likely to rise or fall because of the market operations of any 1 or more persons conducted for the purpose of raising or depressing the price of such security."

${ }^{99}$ Véase texto en original, infra nota $\mathrm{n}^{\circ} 146$.
} 
Nótese en segundo lugar la frecuencia e importancia descriptiva asumida por la fórmula subjetiva "con el propósito de inducir a otros a la compra o venta de valores" [for the purpose of inducing the purchase or sale of such security by others], incorporada en las hipótesis 2, 4 y 5. Como se sabe, una fórmula similar (aunque objetivada) constituye la médula del inciso segundo de nuestro art. 53 LMV. Repárese además que la anotada fórmula subjetiva va acompañada de elementos de resultado como "alzando o rebajando el precio del respectivo valor" [raising or depressing the price of such security] o "creando un mercado activo -real o aparente- para dicho valor" [creating actual or apparent active trading in such security]. Como se sostendrá más adelante, esos elementos -no explicitados en nuestro art. 53- tienen un alto valor hermenéutico. Esos elementos explicitan el marco o contexto desde el que se capta adecuadamente el sentido (manipulativo) de la "inducción a la compra o venta de valores". Nuestra LMV optó por una perífrasis sintética, pero no por ello menos rotunda en su valencia anti-manipulativa, al menos una vez que se capta el contexto teleológico y sistemático de los arts. 52 y 53, según se expondrá más abajo.

Repárese por último en la 6a hipótesis de la sección 9(a) y cómo su contenido coincide casi perfectamente con nuestro art. $52 \mathrm{LMV}$. Si además se considera que en el proyecto original de la LMV los artículos 52 y 53 se aglutinaban en una sola disposición (art. 48 del proyecto) y que, además, el orden de las prohibiciones era inverso al actual (primero se prohibían las transacciones ficticias, luego otras formas manipulativas por vía de inducción a compra y venta, para cerrar el artículo con la prohibición de estabilización), entonces se tiene una imagen muy clara de la sintonía de técnica-legislativa. Para graficar este aspecto considérese el art. 48 del proyecto original de nuestra LMV:

"Artículo 48 .- (Prácticas engañosas y fraudulentas; estabilización) Es contrario a la presente ley efectuar cotizaciones o transacciones ficticias respecto de cualquier valor, ya sea que las transacciones se lleven a cabo en el mercado de valores o a través de negociaciones privadas.

Ninguna persona podrá efectuar transacciones o inducir o intentar inducir a la compra o venta de valores, regidos o no por este [SIC] ley, por medio de cualquier acto, práctica, mecanismo o artificio engañoso o fraudulento.

Las actividades de estabilización efectuadas con el objeto de llevar adelante una distribución de valores en el público, podrán realizarse sólo de acuerdo a reglas de carácter general que la Superintendencia emita al efecto"100.

Se puede captar la estructura del diseño normativo con toda claridad: una primer inciso dedicado a las transacciones ficticias (análogo al 9[a][1]); un segundo dedicado a las demás manipulaciones operativas e informativas (análogo al 9[a][2], principalmente), para cerrar con el tratamiento de las problemáticas manipulaciones estabilizadoras en los mercados primarios (análogo al 9[a][6]).

El diseño del art. 48 es lógico, diáfano bajo este prisma: un primer inciso que ataca de inmediato una forma especial y "poco problemática" de manipulación; a saber, aquella

${ }^{100}$ Proyecto de ley de 30 de diciembre de 1980, en Compendio de Historia de la Ley $\mathrm{N}^{\circ} 18.045$ (BCN), p. 28. 
LONDOÑO, Fernando. “Aproximación histórico-comparada al Título VIII de la Ley de Mercado de Valores: bases para el reconocimiento de un contenido anti-manipulativo".

ejecutada mediante transacciones ficticias; un segundo inciso que, mediante una cláusula amplia y que objetiva la fórmula de inducción conocida en el derecho federal estadounidense, comprende el resto de las manipulaciones, incluyendo en principio las manipulaciones operativas (cuanto menos aquellas que se valen de engaño o de injerencia indirecta, según se verá); para luego, en un tercer inciso, disponer el espacio regulatorio para sustraer del inciso anterior una forma de manipulación-operativa eventualmente legítima o justificada; a saber, las estabilizaciones en el mercado primario, coincidiendo también en esto en el modelo de la §9(a) SEA'34.

Por cierto no es éste el espacio para analizar en detalle el contenido de las disposiciones de nuestra LMV, pero pareció conveniente dejar sentada desde ya la conexión entre el abordaje nacional anti-manipulativo y el modelo de las prohibiciones especiales del derecho federal estadounidense. Toca ahora continuar la revisión de ese modelo, advirtiendo que el paralelismo anticipado se hará aún más claro en lo sucesivo, en la medida que se desarrollen los contenidos de las citadas hipótesis de la §9(a).

Dos observaciones generales sobre su diseño pueden ser de utilidad.

En primer lugar, debe observarse que la técnica empleada es la del establecimiento de prohibiciones o definición de actividades prohibidas, como base común para la procedencia de responsabilidad civil, administrativa o penal. La concreta identificación de ese conjunto de prohibiciones está orientada empírica y criminológicamente (casuística), en la medida que, como se ha dicho, se condice con la evidencia hallada en las investigaciones parlamentarias post crac del '29.

En seguida, es importante observar que la caracterización de las actividades manipulativas descansa de manera importante en la faz subjetiva, mediante el recurso a un elemento subjetivo de intención trascendente ${ }^{101}$. Esto es claro en cada una de las tipologías de la $\S 9$ (a). Así, por lo que toca a la hipótesis (1), no basta la sola transacción ficticia, sino que es preciso que ella se ejecute con el propósito de crear una apariencia falsa o engañosa de mercado activo o bien, más en general, de crear una apariencia falsa o engañosa con respecto al mercado de un determinado valor. ${ }^{102}$ Por su parte, en las hipótesis (2) y (4) la intención manipulativa transcendente aparece descrita con el propósito para inducir a la compra o la venta de valores, misma fórmula indirectamente presente en las hipótesis (3) y (5), caracterizadora de la actividad desplegada por las asociaciones de manipuladores

\footnotetext{
${ }^{101}$ Conocido también en una tradición como la italiana como dolo específico: por todos, cfr. ROMANO, Mario, Commentario Sistematico del Codice Penale, I, Milano: Giuffrè, $3^{\circ}$ ed., 2004, art. 43, num. lat. 33, p. 446 y MARINUCCI, Giorgio; DOLCINI, Emilio, Manuale di Diritto Penale. Parte Generale, Milano: Giuffrè, 2004, p. 192. Al respecto, en nuestro medio, cfr. POLITOFF, Sergio, MATUS, Jean Pierre y RAMÍREZ, María Cecilia, Lecciones de Derecho Penal Chileno, Parte General, Santiago: Ed. Jurídica de Chile, 2da. ed., 2003, pp. 191-193 y p. 281, con referencia en este último caso al dolo específico, dando cuenta de su progresivo abandono por la doctrina dominante.

${ }^{102}$ Esto significa que ni aún las operaciones simuladas como las wash sales o las matched orders (9[a][1]) están prohibidas por sí mismas en esta sección, sino sólo en la medida que concurra la específica finalidad manipulativa. Más allá del texto, que es expreso en tal sentido, cfr. In re Batterman (1976) 46 SEC 303; e In re Edward J. Mawood \& Co. (1977) 46 SEC 865.
} 
(pools). En fin, también la hipótesis (6) contiene un elemento de intención trascendente, allí donde se alude al propósito de fijar, mantener o estabilizar el precio.

Que no baste entonces la operación engañosa, la noticia falsa o la transacción estabilizadora, sino que se reconozca una actividad prohibida sólo allí donde aquellas se realicen con finalidades de tipo manipulativas (inducir a la compra o venta; crear la apariencia de un mercado activo, etc.), es una nota característica del diseño seguido en la $\S 9$ (a) de la SEA '34. Aunque tratándose de manipulaciones informativas -como la noticias falsas o engañosas, por ejemplo- el recurso a esta intención trascendente pueda considerarse de importancia secundaria (más allá del rigor taxonómico, necesario para evitar una confusión con conductas guiadas por otro tipo de finalidades: elusivas de impuestos, societarias, etc.), tratándose de definir manipulaciones operativas el recurso a dichos elementos subjetivos tiene la mayor importancia. Su sentido es de garantía, especialmente dirigido a evitar un efecto de sobre-disuasión (overdeterrence) de conductas lícitas. Lo anterior se explica habida cuenta de la -a veces- escurridiza frontera entre operaciones manipulativas y operaciones lícitas idóneas para afectar los precios. En el diseño de la política federal anti-manipulación, es el elemento intencional el que en principio permite distinguir entre operaciones lícitas $-\mathrm{y}$ que sin embargo tienen o pueden tener un impacto relevante en los precios de mercado- y operaciones prohibidas, manipulativas. En suma, el legislador federal estadounidense optó por recurrir a la faz subjetiva para una diferenciación que ha sido desde siempre problemática ${ }^{103}$.

Casi setenta años después, en 2003, el legislador europeo-comunitario ${ }^{104}$ seguiría un modelo distinto para abordar este mismo problema: buscando una diferenciación ya en la faz objetiva, mediante el recurso a la idoneidad manipulativa, según se explicará más abajo $^{105}$.

a) $\quad \S 9(a)(2):$ efectuar transacciones sobre valores, alterando el mercado o el precio, con el propósito de inducir a otros a la compra o venta de tales valores.

Conviene ahora detenerse en la hipótesis $2^{\text {a }}$ de la sección 9(a) $S E A$ '34, pues, además de ser aquella que más afinidad presenta con el inciso $2^{\circ}$ del art. $53 \mathrm{LMV}$, constituye el centro de las prohibiciones anti-manipulativas, como tempranamente sostendría la propia autoridad reguladora federal de los EEUU. En palabras de Louis Loss y Joel Seligman:

"El objetivo de la § 9(a)(2) - tempranamente denominada por la Comisión [la $S E C$ ] como 'el verdadero corazón de la ley' $\left[{ }^{106}\right]$ - es declarar ilegal no sólo operaciones ejecutadas por asociaciones de manipuladores [pools], sino también 'cualquier otro

${ }^{103}$ Cfr. los trabajos de PERDUE, "Manipulation of futures", cit. nota ${ }^{\circ} 14$, pp. 345 y ss.; PIRRONG, "Commodity Market Manipulation", cit. nota n ${ }^{\circ}$ 52; y MARKHAM, "Manipulation of Commodity", cit. nota $\mathrm{n}^{\circ} 52$.

${ }^{104}$ Directiva 2003/6/CE sobre Abusos de Mercado: cfr. infra su apartado 1.4.

${ }^{105}$ Cfr. infra 1.4.2. Como es obvio, al tiempo de la versión original de la LMV (cuyos arts. 52 y 53 son originales de 1981 y no han sufrido cambios desde entonces), este modelo objetivista del legislador comunitario-europeo aún no existía.

${ }^{106}$ Citado por LOSS/SELIGMAN, Securities Regulation, cit. nota ${ }^{\circ} 17$, cap. 10, de SEC, Report on Proposals for Amendments to the Securities Act of 1933 and the Securities Exchange Act of 1934, House Comm. on Interstate \& Foreign Commerce, 77th Cong., 1st Sess. 50 (Comm. Print 1941). 
LONDOÑO, Fernando. “Aproximación histórico-comparada al Título VIII de la Ley de Mercado de Valores: bases para el reconocimiento de un contenido anti-manipulativo".

mecanismo usado para persuadir al público de que la actividad sobre un valor es el reflejo de una demanda genuina en lugar de un espejismo' $\cdot\left[{ }^{107}\right]$. Esto es válido para el lenguaje general de la sección [9]".

Pues bien, en lo que aquí nos ocupa, la sección 9(a)(2) reza:

\section{“9(a) Prohibición contra la manipulación de los precios de los valores}

Será ilegal para cualquier persona, directa o indirectamente, mediante el uso de los correos o cualquier medio o instrumento de comercio interestatal, o de cualquier instalación de cualquier bolsa de valores nacional, o para cualquier miembro de una bolsa de valores nacional":

(...)

(2) Efectuar, solo o con una o más personas distintas, una serie de transacciones sobre cualquier valor registrado en una bolsa nacional o en relación a cualquier acuerdo swap basado en un valor de ese tipo, creando un mercado activo real o aparente para ese valor, o bien elevando o deprimiendo el precio de ese valor, con el propósito de inducir a la compra o venta de tal valor por otros. ${ }^{109,}$

De esta disposición vale la pena comentar aquello que pueda ser de interés en nuestra sede, ofreciendo sintéticamente los puntos de conexión o diferencia con el inciso $2^{\circ}$ del art. 53 LMV. De estos paralelismos se dará cuenta al terminar la explicación de la $\S 9(a)(2)$, para no interrumpir el hilo del comentario.

Como puede apreciarse, la disposición consta de tres grupos de elementos: (a) la conducta misma, (b) los efectos o manifestaciones de la conducta y (c) la finalidad o propósito de la conducta (c). De ellos, dos segmentos coinciden con la faz objetiva de la tipología, mientras que el tercero es de naturaleza subjetiva. Figura en primer lugar (a) la nuda conducta: efectuar una serie de transacciones. Esa conducta es cualificada por el segundo extremo objetivo, a la vez que por la dimensión subjetiva. Así, (b) de la conducta se espera que, alternativamente, ${ }^{110}$ cree un mercado activo real o aparente o bien que eleve o deprima el precio. Como se verá más adelante, esos efectos cumplen una función medial con respecto a la manipulación. En fin, no basta con la concurrencia de dichos efectos, sino que es

\footnotetext{
${ }^{107}$ Citado por LOSS/SELIGMAN, Securities Regulation, cit. nota $\mathrm{n}^{\circ} 17$, cap.10 de Senate Reports No. 1455 , 73d Cong., 2d Sess. 54 (1934).

${ }^{108}$ Cit. de LOSS/SELIGMAN, Securities Regulation, cit. nota ${ }^{\circ} 17, \S 10-C$ : "The object of $\S 9(\mathrm{a})(2)-$ which the Commission early termed "the very heart of the act" - is to outlaw not only pool operations, but "every other device used to persuade the public that activity in a security is the reflection of a genuine demand instead of a mirage." This accounts for the general language of the Section".

${ }^{109}$ La traducción y los destacados en cursiva son míos. El texto original reza: "It shall be unlawful for any person, directly or indirectly, by the use of the mails or any means or instrumentality of interstate commerce, or of any facility of any national securities exchange, or for any member of a national securities exchange. (...) (2) To effect, alone or with one or more other persons, a series of transactions in any security registered on a national securities exchange or in connection with any security-based swap agreement with respect to such security creating actual or apparent active trading in such security, or raising or depressing the price of such security, for the purpose of inducing the purchase or sale of such security by others."

${ }^{110}$ Así, LOSS/SELIGMAN, Securities Regulation, cit. nota ${ }^{\circ} 17, \S 10-\mathrm{C}$, notando que no existen casos reales (reportados) sin que se verifiquen cambios en los precios, lo que por cierto no impide que en abstracto aparezca como disyuntivo, junto al efecto de creación de mercado activo.
} 
preciso que ellos aparezcan como manifestación de una conducta finalizada a (c) inducir a la compra o venta de valores.

Por otra parte, debe observarse que la $\$ 9(a)(2)$ plantea un escenario de exclusiva manipulación operativa, esto es, una manipulación realizada únicamente mediante transacciones en el mercado de valores. En principio ha de tratarse de transacciones reales (ya de compra, ya de venta) ${ }^{111}$ por oposición a la $\S 9(a)(1)$, que prohíbe operaciones ficticias. El número mínimo de operaciones constitutivo de la serie de transacciones es discutible, pero por de pronto se descarta que baste una única operación ${ }^{112}$.

En cuanto a (b) los efectos manipulativos, ellos cumplen una función caracterizadora de la conducta. Se comprende que efectuar una serie de transacciones no podría prohibirse per se, sin con ello proscribir la entera fisiología del mercado. Algo más se requiere para caracterizar adecuadamente la conducta prohibida. Aquí es donde aparecen los efectos (y el propósito). Como se ha dicho, los efectos descritos son disyuntivos: o bien se crea un mercado activo real o aparente o bien se eleva o deprime el precio. El sentido funcional de estos efectos se capta a su vez si se considera la variable subjetiva; a saber, el propósito de inducir con ello a la compra o venta de valores. Bajo esa óptica se capta que estos efectos no constituyen la estación terminal de la conducta manipulativa, sino más bien una fase intermedia, desde la cual se propicia o potencia la manipulación. La apariencia de un mercado activo o bien el alza/baja de los precios constituyen los espejismos que reclamarán la atención de los operadores en el mercado. Estas manifestaciones son las que los engañarán, induciéndolos a negociar con los respetivos valores, en el sentido que corresponda a la información implícita en esos cambios del mercado. Al hacerlo, contribuirán -cual instrumentos del manipulador- a que aquel alcance su propósito. Esto es, que se alcance un precio-de-mercado desde el cual puedan obtenerse los beneficios esperados (por más que la realización de dichos beneficios no constituya un elemento de la tipología $)^{113}$. De paso, vale la pena decir que en esta instrumentalización radica toda la fuerza semántica del concepto de manipulación, como ya se ha dicho en otro trabajo ${ }^{114}$.

Avanzando en el comentario de los elementos de la $\S$ 9(a)(2), nótese que la correspondencia funcional entre efecto y propósito resulta prístina si se coordinan las respectivas secciones de la disposición. Así, al efecto de alza le corresponde un propósito de inducción a la compra de valores, mientras que al efecto depresivo le corresponde un propósito de inducción a las ventas ${ }^{115}$. Dicho en términos más claros: mediante un alza del precio-de-mercado se induce al público a comprar los respectivos valores; mientras que mediante la depresión del precio-de-mercado se induce al público a vender los respectivos valores. Esto es así en la medida que los precios -y el comportamiento del mercado en general- tienen valencia informativa: transmiten información, cuanto menos aquella

\footnotetext{
${ }^{111}$ Así, LOSS/SELIGMAN, Securities Regulation, cit. nota n ${ }^{\circ} 17, \S 10-\mathrm{C}$.

112 Alcance sobre el número mínimo (3 en principio; 2 eventualmente), en LOSS/SELIGMAN, Securities Regulation, cit. nota $\mathrm{n}^{\circ} 17, \S 10-\mathrm{C}$, con referencia a Kidder, Peabody \& Co., 18 SEC 559, 568 (1945).

${ }^{113}$ Este precio-buscado y este lucro-esperado son excéntricos a la tipología, no requiriéndose su concurrencia (ni acreditación, por tanto) para que se configure la hipótesis prohibida, por más que - empírica y estadísticamente hablando - aparezcan acompañando a toda tentativa de manipulación.

${ }^{114}$ LONDOÑO, "Ilícito de manipulación", cit. nota $\mathrm{n}^{\circ} 1$, pp. 91 y ss.

${ }^{115}$ Como justamente comentan LOSS/SELIGMAN, Securities Regulation, cit. nota $n^{\circ} 17, \S 10-\mathrm{C}$, ii).
} 
LONDOÑO, Fernando. “Aproximación histórico-comparada al Título VIII de la Ley de Mercado de Valores: bases para el reconocimiento de un contenido anti-manipulativo".

disponible en el preciso contexto ${ }^{116}$. Así, el precio-de-mercado se comporta como una señal y, como tal, es "interpretado" por los operadores; para decirlo muy esquemáticamente: como buenas noticias relativas al título o al emisor, si hay alzas; como malas noticias, si hay bajas. Un alza del precio-de-mercado hablará de una probable infravaloración retrospectiva, conforme a un juicio como el siguiente: hasta aquí el mercado habría estado equivocado al cotizar tan bajo los respectivos títulos (de allí entonces una oportunidad de ganancia en la compra o mantención en cartera de los mismos); una baja del precio dará en cambio señales de una probable sobrevaloración retrospectiva, conforme a un juicio en sentido opuesto: hasta aquí el mercado habría estado equivocado al cotizar tan alto los títulos (de allí entonces una oportunidad de ganancia en su venta). Más detalles sobre la mecánica manipulativa pueden apreciarse en el apartado 2 del presente artículo. Toca ahora decir algo más sobre el último elemento de la $\S 9(a)(2)$.

Como explican Loss y Seligman, la provocación de una alteración de un precio-demercado no constituye un ilícito per $s e^{117}$, sino en la medida que concurra la finalidad manipulativa, que el legislador del '34 expresa con el ya aludido (c) propósito de inducción a la compra o venta de valores. Con ello no se quiere indicar otra cosa más que un designio voluntario o premeditado [willfulness] ${ }^{118}$ en orden a valerse de la conducta para incidir en la oferta o la demanda, sin que se requiera la acreditación de una suerte de voluntad de perjudicar o un ánimo de lucro ${ }^{119}$. Así, en principio es también ilícita la manipulación para conducir los precios hacia un nivel considerado correcto o adecuado al valor de inversión. Ello se condice con un paradigma de mercado libre (= no controlado $)^{120}$, en el que no toca a ningún agente particular (ni aún al más entendido) decidir, por todos, cuál es precio “correcto", erigiéndose en el árbitro del mercado ${ }^{121}$.

Una nota final, especialmente pertinente para captar el sentido de nuestro art. 53: y es que al definir el propósito manipulativo en términos de inducción a la compra o venta de valores, la $\S 9(\mathrm{a})(2)$ emplea una no del todo clara perífrasis (que nuestro art. 53 hace suya también, aunque en un plano distinto, según se dirá de inmediato, comentando la segunda modalidad típica de dicha norma). La misma finalidad manipulativa habría podido expresarse, de manera directa y menos equívoca, como un propósito de incidir en la oferta $o$ demanda por el título. La fórmula empleada representa una perífrasis, pues es induciendo a las compras que se favorece el aumento de la demanda (y con ello el ulterior aumento del precio), mientras que es induciendo a las ventas que se aumenta la oferta (y con ello la ulterior rebaja del precio). Como se ha dicho, el circunloquio habría podido evitarse aludiendo a la demanda y a la oferta, instancias que representan la unidad agregada de las compras y ventas para un determinado período. Ese lenguaje se adecua mejor al carácter

\footnotetext{
116 Sobre los mecanismos de transmisión o flujo de información en el mercado de valores, cfr. el trabajo clásico de GILSON, Ronald; KRAAKMAN, Reinier, "The Mechanism of Market Efficiency", Va. L Rev. (1984), vol. 70, pp. 549 y ss.

${ }_{117}$ Algo que el dictum en Rex v. de Berenger (cit. nota ${ }^{\circ} 19$ ) ya advertía: p. 73 (p. 539 de 3 Maule \& S. 67, 74, 105 Eng. Rep. 536), según hacen ver LOSS/SELIGMAN, Securities Regulation, cit. nota $\mathrm{n}^{\circ} 17, \S 10-\mathrm{C}$,iii.

${ }^{118}$ Así, LOSS/SELIGMAN, Securities Regulation, cit. nota n ${ }^{\circ} 17, \S 10-\mathrm{C}$,iii.

${ }^{119}$ Así, LOSS/SELIGMAN, Securities Regulation, cit. nota $n^{\circ} 17, \S 10-\mathrm{C}$,iii.

${ }^{120}$ Cfr. LONDOÑO, "Ilícito de manipulación", cit. nota $n^{\circ} 1$, p. 102 (notas 105 y 106), con referencia al tampering with the free market $\mathrm{y}$ al paradigma del fraud in the market de la doctrina estadounidense.

${ }^{121}$ Una excepción la constituyen las estabilizaciones justificadas, según se explicará más abajo: infra 1.3.1.c).
} 
institucional de los intereses en juego. Con todo, es importante hacer presente que al propósito de inducción se le ha entendido pacíficamente como una cláusula de finalidadmanipulativa, de modo consistente con lo aquí indicado.

De la revisión hecha resulta el siguiente esquema sintético:

\begin{tabular}{|l|l|}
\hline \multirow{2}{*}{$\begin{array}{l}\text { Estructura } \\
\text { (descriptor) }\end{array}$} & \begin{tabular}{l} 
\$ 9(a)(2), SEA'34 \\
\cline { 2 - 2 }
\end{tabular} \\
\cline { 2 - 2 } & $\begin{array}{l}\text { (b) conducta (= efectuar una serie de transacciones) } \\
\text { precio) }\end{array}$ \\
\cline { 2 - 2 } $\begin{array}{l}\text { (c) calificante subjetiva explícita (= propósito de inducir a la compra o venta de } \\
\text { valores) }\end{array}$ \\
\hline $\begin{array}{l}\text { Cobertura } \\
\text { Manipulación operativa por vía de engaño - operativa impropia (apariencia de } \\
\text { mercado activo o apariencia informativa implícita en alteración de precio) }\end{array}$ \\
\hline $\begin{array}{l}\text { Mecanismo } \\
\text { manipulativo }\end{array}$ & $\begin{array}{l}\text { Indirecto: creación de apariencia engañosa para el mercado: apariencia de mercado } \\
\text { activo o apariencia informativa implícita en alteración del precio. }\end{array}$ \\
\hline
\end{tabular}

- $\quad$ Conclusiones preliminares de utilidad para una valoración comparada de nuestro art. 53.2 LMV.

Antes de abordar la siguiente hipótesis de la $\S 9(a)$, conviene adelantar algunas conclusiones provisorias para una valoración comparada del inciso segundo de nuestro art. 53 LMV, a la luz de la $\$ 9(a)(2)$ recién tratada. Servirá a la vez para profundizar en su comprensión.

- $\quad$ Primera modalidad típica del art. 53.2 LMV: efectuar transacciones [...] por medio de cualquier acto, práctica, mecanismo o artificio engañoso o fraudulento.

Nótese en primer lugar que nuestro art. 53.2 prohíbe también -al igual que la §9(a)(2)efectuar transacciones, aunque no como única modalidad de conducta (como en cambio prevé la aludida \$9[a][2]), sino como hipótesis alternativa al intento de inducción a la compra o venta de valores. Esta diferencia será abordada en su momento, pero lo que interesa adelantar aquí es que las transacciones prohibidas en el art. 53.2 deben necesariamente estar connotadas de una valencia engañosa o fraudulenta, al tenor de la segunda parte del inciso, que viene a adjetivar a las transacciones objeto de la conducta. No podría ser de otro modo, por lo demás, pues mal podría la ley prohibir las transacciones a secas, sin cualificación alguna: de lo contrario, la fisiología misma de los mercados de valores quedaría proscrita (y otro tanto puede decirse respecto de la inducción a la compra $o$ venta de valores: que de otro modo toda promoción o publicidad estaría prohibida, per se, aún si correcta o ajustada a la información disponible).

Aunque todo esto es obvio y se desprende del propio tenor literal del 53.2, lo que es menos obvio es qué ha de entenderse por transacciones engañosas o fraudulentas o por

\footnotetext{
122 En las sucesivas tablas esquemáticas, por "cobertura" se quiere indicar la tipología de conducta en principio alcanzada por la prohibición.

${ }^{123}$ Por "mecanismo manipulativo" se quiere indicar el medio que posibilita la manipulación prohibida por la norma, de acuerdo a las tipologías conocidas. Al respecto, más detalle puede verse infra sub apartado 2.2
} 
LONDOÑO, Fernando. “Aproximación histórico-comparada al Título VIII de la Ley de Mercado de Valores: bases para el reconocimiento de un contenido anti-manipulativo".

"transacciones [efectuadas mediante] cualquier acto, práctica, mecanismo o artificio engañoso o fraudulento", para estar al tenor literal del 53.2. Responder a esta interrogante es central para una correcta interpretación del discutido inciso. ${ }^{124} \mathrm{Al}$ respecto, aquí puede adelantarse una observación importante, cuya elaboración se ve justamente auxiliada por el tenor del $\S 9(a)(2)$.

Pues bien, como se ha visto, el legislador federal estadounidense se vio también en la necesidad de cualificar las transacciones prohibidas (a riesgo de proscribir toda transacción incidente en los precios). Podría muy bien haberse conformado con adjetivar las transacciones en sede subjetiva, mediante el propósito manipulativo (lo que en efecto hace: con el propósito de inducir a la compra o venta de tal valor por otros, según ya se ha visto). Pero quizás una dependencia exclusiva en lo subjetivo no pudo bastarle, sobre todo en un estadio en el que faltaba un desarrollo jurisprudencial significativo. De allí entonces la importancia del segundo segmento objetivo de la $\S 9(\mathrm{a})(2)$, que cualifica las transacciones por sus efectos. Como se vio más arriba, este segmento opera a modo de bisagra entre la conducta prohibida (efectuar una serie de transacciones) y el propósito exigido (inducir a la compra o venta de valores). Así, no todas las transacciones-inductivas están prohibidas, sino aquellas que, alternativamente, (a) creen un mercado activo real o aparente o bien (b) eleven o depriman el precio. Esta cualificación objetiva de las transacciones prohibidas cumple una función hermenéutica de la mayor importancia, ofreciendo un escenario adecuado para captar -ahora en nuestro contexto- qué ha de entenderse por transacción engañosa o fraudulenta ${ }^{125}$.

En este punto debe recuperarse lo dicho arriba, comentando estas exigencias de la $\S 9(a)(2)$ y su vinculación con el propósito inductivo. Se dijo que estos efectos (la alteración del precio o la creación de un mercado activo) no constituyen la manipulación en sí, sino que los medios manipulativos; se dijo que no son la estación terminal de la manipulación, sino la estación intermedia, desde la cual es posible una manipulación ventajosa para el agente. Así, por lo que toca a la primera variable calificante de las transacciones, es la apariencia de mercado activo la que atraerá a inversionistas, quienes, inducidos a comprar o vender, incrementarán la demanda o la oferta por el título, respectivamente, elevando o deprimiendo con ello el precio-de-mercado. Por lo que toca a la segunda variable calificante, puede decirse otro tanto: es el alza o rebaja del precio la que persuadirá (inducirá) a los inversionistas a comprar o a vender, respectivamente.

De lo dicho puede concluirse lo siguiente: que las transacciones prohibidas deben tener una cualidad tal que, a partir de ellas o de sus efectos (la apariencia creada en su virtud), los intervinientes puedan verse motivados a adoptar decisiones de inversión o desinversión en línea con la variación de precio con la que el manipulador busca inocular al mercado. De un

\footnotetext{
124 Para una toma de posición detallada, se reenvía a un trabajo posterior, en proceso de publicación: véase supra la nota $\mathrm{n}^{\circ} 10$.

${ }^{125}$ Dejando por ahora de lado la pregunta sobre si acaso ambos términos se explican por mero defecto de redundancia o desprolijidad, o bien pudieren tener un contenido diferenciado. Algo se adelantará a continuación; en lo demás, se reenvía al trabajo a que se alude supra en nota $\mathrm{n}^{\circ} 10$.
} 
tipo semejante de transacciones podrá decirse que son manipulativas, en los términos de la $\S 9(\mathrm{a})(2)^{126}$.

Ahora, si nuestro art. 53 constituye una cláusula anti-manipulativa -como aquí se ha defendido y se defenderá- entonces lo dicho recién a propósito de las operaciones prohibidas por la $\S 9(\mathrm{a})(2)$, es de utilidad para captar el posible sentido de la enrevesada formulación que hace suya nuestra LMV: "ninguna persona podrá efectuar transacciones [...] por medio de cualquier acto, práctica, mecanismo o artificio engañoso o fraudulento"; o bien, en términos más concisos: ninguna persona podrá efectuar transacciones engañosas o fraudulentas.

Pues bien, con lo dicho hasta aquí se está ya en condiciones de responder la pregunta con la que se abre este sub-apartado. Dicho por ahora en extrema síntesis: sólo pueden ser consideradas engañosas o fraudulentas en los términos del art. 53.2 aquellas transacciones que, por sus características, aparezcan idóneas para distorsionar la realidad del mercado o de los precios-de-mercado, de modo que, en virtud de su consideración, pudieren conducir (inducir) a los intervinientes en el mercado a adoptar decisiones de inversión contradictorias con la mejor información disponible al tiempo de los hechos (transacciones fraudulentas, como hipótesis de manipulación especial) ${ }^{127}$, o bien, a lo menos, en línea con el tipo de incidencia que el manipulador se ha propuesto conseguir para los precios-demercado del título respectivo (transacciones engañosas, como hipótesis de manipulación general) ${ }^{128}$. En este segundo caso, serán transacciones engañosas aquellas que tengan la capacidad para "incidir en los precios" en el sentido buscado por el manipulador, aunque no por sí mismas (que para ese evento basta con el tipo o prohibición de estabilización o variación de los precios del art. 52), sino en cuanto puedan afectar la apreciación de terceros en el mercado, quienes a su turno realizan las transacciones necesarias para condicionar los precios en el sentido buscado por el manipulador. Estos terceros son así, precisamente, manipulados $^{129}$.

A modo de cierre de este apartado, es posible ofrecer la siguiente conclusión comparativa, sintética; y es que existiría una relativa equivalencia funcional entre el recurso a las nociones de engaño y fraude empleadas por la LMV en el art. 53.2 y las calificantes objetivas del segundo segmento de la $\S 9(a)(2)$, relativas a los efectos de las transacciones. Así, mientras que nuestro art. 53.2 circunscribe el universo de transacciones prohibidas

\footnotetext{
${ }^{126}$ Aquí se tornan nuevamente pertinentes las palabras de LOSS/SELIGMAN, Securities Regulation, cit. nota $\mathrm{n}^{\circ} 17$, ya citadas más arriba (nota $\left.\mathrm{n}^{\circ} 108\right)$ : "El objetivo de la $\S 9(\mathrm{a})(2)$ - tempranamente denominada por la Comisión [la SEC] como 'el verdadero corazón de la ley' - es declarar ilegal no sólo operaciones ejecutadas por asociaciones de manipuladores [pools], sino también 'cualquier otro mecanismo usado para persuadir al público de que la actividad sobre un valor es el reflejo de una demanda genuina en lugar de un espejismo'. Esto es válido para el lenguaje general de la sección [9].” (op. cit., 10-C)

127 Cfr. LONDOÑO, "Ilícito de manipulación", cit. nota $\mathrm{n}^{\circ}$ 1, pp. 92-93, 100-103, para un concepto de manipulación especial.

${ }^{128}$ Cfr. LONDOÑO, "Ilícito de manipulación", cit. nota $\mathrm{n}^{\circ}$ 1, pp. 92-93, 100-103, para un concepto de manipulación general.

${ }^{129}$ Con lo dicho, no puede por cierto darse por resuelta la pregunta sobre el contenido preciso de la fórmula típica indicativa de los mecanismos de actuación de la manipulación en el art. 53.2; a saber, "por medio de cualquier acto, práctica, mecanismo o artificio engañoso o fraudulento". Como se ha anticipado, ello constituye la materia de un trabajo posterior, en proceso de publicación (cfr. supra nota $\mathrm{n}^{\circ} 10$ ).
} 
LONDOÑO, Fernando. “Aproximación histórico-comparada al Título VIII de la Ley de Mercado de Valores: bases para el reconocimiento de un contenido anti-manipulativo".

recurriendo a un elemento medial como "acto, práctica, mecanismo o artificio engañoso o fraudulento", la $\S 9(\mathrm{a})(2)$ echa mano, para igual propósito, a los posibles efectos de las transacciones; a saber, que creen un mercado activo real o aparente o bien que eleven o depriman el precio del respectivo valor. Ello es claro si se considera que, como se ha dicho, los efectos del segundo segmento de la $\S 9(\mathrm{a})(2)$ se comportan no tanto como efectos, sino como instancias o medios manipulativos. Aquí se ha sostenido una equivalencia funcional en la medida que a ambas fórmulas se atribuye una valencia manipulativa ${ }^{130}$.

Ahora bien, siempre en el plano de la función de la tipicidad, la diferencia parecería estar dada por el empleo de una calificación adicional por la § 9(a)(2): el ya aludido propósito de inducir a la compra o venta de valores. Como se sabe, en su segunda parte nuestro art. 53.2 contiene una referencia similar, pero no como calificante subjetiva.

Lo dicho en los últimos párrafos puede sintetizarse mediante el siguiente esquema:

\begin{tabular}{|c|c|}
\hline §9(a)(2), SEA'34 & $53.21^{a}$ parte, LMV \\
\hline \multicolumn{2}{|c|}{ Estructura (descriptor) } \\
\hline $\begin{array}{l}\text { (a) conducta } \quad(=\text { efectuar una serie } \mathrm{de} \\
\text { transacciones })\end{array}$ & (a) conducta (= efectuar transacciones) \\
\hline $\begin{array}{l}\text { (b) calificante objetiva }(=\text { efectos/medios: } \\
\text { apariencia de mercado } o \text { alteración del precio })\end{array}$ & $\begin{array}{l}\text { (b) calificante objetiva (= medios: mediante } \\
\text { modalidad engañosa o fraudulenta) }\end{array}$ \\
\hline $\begin{array}{l}\text { (c) calificante subjetiva explícita (= propósito de } \\
\text { inducir a la compra o venta de valores) }\end{array}$ & (c) ¿calificante subjetiva? (no explícita al menos) \\
\hline \multicolumn{2}{|c|}{ Cobertura } \\
\hline $\begin{array}{l}\begin{array}{l}\text { Manipulación operativa por vía de engaño } \\
\text { (impropia) }\end{array} \\
\end{array}$ & $\begin{array}{l}\text { Manipulación operativa por vía de engaño } \\
\text { (impropia) }\end{array}$ \\
\hline \multicolumn{2}{|c|}{ Mecanismo Manipulativo } \\
\hline $\begin{array}{l}\text { Indirecto. Creación de apariencia engañosa para el } \\
\text { mercado: apariencia de mercado activo o o } \\
\text { apariencia informativa implícita en alteración del } \\
\text { precio. }\end{array}$ & $\begin{array}{l}\text { Indirecto. "Cualquier acto, práctica, mecanismo o } \\
\text { artificio engañoso o fraudulento" }\end{array}$ \\
\hline
\end{tabular}

- $\quad$ Segunda modalidad típica del art. 53.2 LMV: inducir o intentar inducir a la compra o venta de valores, por medio de cualquier acto, práctica, mecanismo o artificio engañoso o fraudulento.

Valorada en comparación a la recién tratada $\$ 9(a)(2)$, algo puede también anticiparse aquí sobre la segunda modalidad de conducta del art. 53.2; a saber: "inducir o intentar inducir a la compra o venta de valores, por medio de cualquier acto, práctica, mecanismo o artificio engañoso o fraudulento."

Recuérdese que en la $§ 9(a)(2)$-y en otras hipótesis de la misma sección- la inducción a la compra o venta de valores figura en la faz subjetiva, como propósito de inducción de tipo manipulativo. En nuestro art. 53.2 dicha inducción aparece en cambio objetivada, como

${ }^{130}$ Como se verá al tratar el derecho de la Unión Europea, una distinción similar puede hacerse entre la primera variante de la letra a) y la hipótesis de la letra b) del art. 1.2) de la Directiva 2003/6/CE (o bien del art. 12 del Reglamento 596/2014). Cfr. infra sub apartado 1.4. 
segunda variante del inciso. Lo que en la legislación federal estadounidense es un propósito de inducción a comprar o vender valores, en nuestra LMV es una inducción o tentativa de inducción a comprar o vender valores.

Si la atención se pone en esta conversión -lo que es subjetivo en la $\S 9(a)(2)$, aparece objetivado como conducta en el art. 53- entonces lo que se tiene es una considerable ampliación del alcance de la prohibición en nuestro art. 53.2. En efecto, dado que la conducta misma consiste en inducir (o intentar inducir) a la compra de valores, entonces en principio caben tantos medios comisivos como resulten idóneos para dicha inducción. De este modo, bajo este segundo segmento, nuestro art. 53.2 daría cabida también a manipulaciones informativas en sentido estricto (por ejemplo realizadas a través de la comunicación de noticias falsas). Cubriría igualmente modalidades que combinen lo operativo (transacciones) y lo informativo, así como manipulaciones llevadas a cabo mediante acciones o actividades extra bursátiles (action based manipulation).

De este modo, nuestro art. 53.2 cubriría tanto manipulaciones operativas impropias (bajo la primera fórmula: efectuar transacciones engañosas o fraudulentas), como manipulaciones informativas y otras modalidades complejas o basadas en actividades extra bursátiles (todo ello bajo la segunda fórmula: inducir o intentar inducir a la compra o venta).

Lo dicho se ha limitado a una comparación entre la § 9(a)(2) y la segunda parte del art. 53.2 en términos de alcance o cobertura. Con todo, metodológicamente hablando, una comparación semejante no puede constituir el punto de arranque; y es que nada se ha dicho sobre una cuestión previa, sin cuyo tratamiento la comparación se hace imposible. Me refiero al contenido mismo de la fórmula inducir o intentar inducir a la compra o venta de valores, por medio de cualquier acto, práctica, mecanismo o artificio engañoso o fraudulento. En términos concisos: (tentativa de) inducción engañosa o fraudulenta a la compra o venta de valores.

Al respecto, pueden adelantarse contenidos tributarios de la comparación con la $\S 9(a)(2)$, conforme se propusiera al inicio de este apartado. En este contexto, interesa adelantar tres consideraciones.

En primer lugar, también aquí resulta decisiva la cualificación de la inducción mediante el recurso a las nociones de engaño o fraude. Pues, como se ha dicho, mal podría la ley haber prohibido la inducción a comprar o vender valores a secas (que de otro modo toda publicidad o propaganda estaría prohibida, per se, aún si correcta o ajustada a la información disponible) $)^{131}$.

En seguida, cabe reiterar lo sostenido supra al comentar el elemento subjetivo de la $\S$ 9(a)(2); y es que también aquí, aún tratándose de una reconversión objetivada, la fórmula en comento se revela una perífrasis. En efecto, en el contexto del art. 53 la inducción a comprar o vender sólo puede hacer sentido como modalidad de injerencia en las fuerzas de

\footnotetext{
${ }^{131}$ Que la mera inducción a comprar o vender valores no está proscrita por sí misma, lo demuestra con eficacia una lectura a contrario sensu del art. 65 de nuestra LMV, justamente en materia de publicidad o propaganda.
} 
LONDOÑO, Fernando. “Aproximación histórico-comparada al Título VIII de la Ley de Mercado de Valores: bases para el reconocimiento de un contenido anti-manipulativo".

la oferta y la demanda, y -con ello- en los precios-de-mercado. En lo demás, vale aquí todo lo que se dijo supra 1.3.1.a).

Con todo -y ésta es la consideración de mayor valor en este apartado- el juicio anterior podría muy bien ponerse en discusión por quien postule que la fórmula inducción a comprar o vender valores no cumple en el art. 53.2 una función (exclusivamente) antimanipulativa; es decir, por quien pretenda ver en ella una referencia a otros sentidos de protección. Lo anterior, en contraste al sentido anti-manipulativo que inequívocamente se le reconoce a su variable subjetiva en la $\S 9(\mathrm{a})(2)$. A aquella objeción debe hacérsele frente. Lo hacen obligatorio tanto el confuso tenor literal del art. 53.2, como su (hasta ahora) escasa aplicación jurisprudencial y nula atención doctrinaria.

Sin duda una referencia directa a la incidencia en la oferta/demanda -en lugar del circunloquio empleado- habría ayudado a evitar cualquier equívoco interpretativo. Hasta donde se alcanza a ver, al menos otras dos lecturas alternativas podrían plantearse para la fórmula en cuestión; a saber, entender que inducir o intentar inducir a la compra o venta de valores importa:

(a) una referencia a una forma de autoría de la parte general del Código Penal (art. 15.2), como en su momento planteara Alfredo Etcheberry ${ }^{132}$;

(b) una incitación a la inversión especulativa, abusiva del operador inexperto (como en el tipo del derecho alemán: $\S 23.1$ y 61 BörsG) u a otro tipo de figuras de engaño dirigido a un círculo más o menos amplio de potenciales inversionistas, prioritariamente reconducibles a intereses patrimoniales (como la mal denominada estafa de inversión del art. 264a del StGB Alemán o su símil del art. 282 bis CPEspañol y aún la falsedad de prospecto del art. 2.623 CCitaliano).

Ninguna de esas interpretaciones es adecuada. Mientras que la primera se coloca derechamente fuera del alcance posible de la disposición (pues no hace sentido alguno como equivalente a la inducción a cometer delitos a que se refiere el Código Penal en su art. 15, en circunstancias que en el art. 53 se trata de inducir a realizar inversiones o desinversiones perfectamente lícitas [ise trata de comprar o vender valores!]), la segunda línea interpretativa es inconsistente con la reconstrucción histórico-comparada aquí propuesta, así como con la sistemática de nuestra LMV. Por de pronto puede decirse que la LMV contiene figuras capaces de anticipar la tutela frente a resultados semejantes, de manera más cómoda y directa, cuanto menos por lo que se refiere a las formas de falsedad en contexto de inversión (art. 59 f] LMV). Con todo, la segunda interpretación merece una atención especial, en cuanto hablan a su favor aspectos de la literalidad del inciso ${ }^{133}$.

De la comparación efectuada en este apartado, relativa al segundo segmento del art. 53.2 LMV, puede extraerse el siguiente esquema sintético:

\footnotetext{
${ }^{132}$ ETCHEBERRY, Derecho Penal, cit. nota $\mathrm{n}^{\circ} 1, \mathrm{p} .280$.

${ }^{133}$ Esa atención es objeto de un artículo posterior, en proceso de publicación (cfr. supra nota $\mathrm{n}^{\circ} 10$ ).
} 
Polít. crim. Vol. 10, No 20 (Diciembre 2015), Art. 1, pp. 390-467.

[http://www.politicacriminal.cl/Vol_10/n_20/Vol10N20A1.pdf]

\begin{tabular}{|c|c|}
\hline §9(a)(2), SEA'34 & $53.22^{\text {a }}$ parte, LMV \\
\hline \multicolumn{2}{|c|}{ Estructura (descriptor) } \\
\hline (a) conducta (= efectuar una serie de transacciones) & $\begin{array}{l}\text { (a) conducta (= "inducir o intentar inducir a la } \\
\text { compra o venta de valores") }\end{array}$ \\
\hline $\begin{array}{l}\text { (b) calificante objetiva }(=\text { efectos/medios: } \\
\text { apariencia de mercado } o \text { alteración del precio })\end{array}$ & $\begin{array}{l}\text { (b) calificante objetiva (= medios: mediante } \\
\text { modalidad engañosa o fraudulenta) }\end{array}$ \\
\hline $\begin{array}{l}\text { (c) calificante subjetiva explícita (= propósito de } \\
\text { inducir a la compra o venta de valores) }\end{array}$ & (c) ¿calificante subjetiva? (no explícita al menos) \\
\hline \multicolumn{2}{|c|}{ Cobertura } \\
\hline $\begin{array}{l}\text { Manipulación operativa por vía de engaño } \\
\text { (impropia) (otras formas de manipulación son } \\
\text { cubiertas por las demás subsecciones de la } \S 9([\mathrm{a}]) \text {. }\end{array}$ & $\begin{array}{l}\text { Manipulación informativa }{ }^{134} \\
\text { Manipulación mixta (informativas }+ \text { operativas) } \\
\text { Manipulación mediante actividades o acciones } \\
\text { extra bursátiles (action based manipulation) }\end{array}$ \\
\hline \multicolumn{2}{|c|}{ Mecanismo Manipulativo } \\
\hline $\begin{array}{l}\text { Indirecto. Creación de apariencia engañosa para el } \\
\text { mercado: apariencia de mercado activo o apariencia } \\
\text { informativa implícita en alteración del precio }\end{array}$ & $\begin{array}{l}\text { Indirecto. "Cualquier acto, práctica, mecanismo o } \\
\text { artificio engañoso o fraudulento" }\end{array}$ \\
\hline
\end{tabular}

b) $\$ 9(a)(1):$ Transacciones ficticias [wash sales/purchases y matched orders], ejecutadas con el propósito de crear la apariencia de un mercado activo para el respectivo valor.

Toca ahora continuar la revisión de otras dos hipótesis de la sección 9(a) de la Securities Exchange Act, que son también de interés para la captación del sentido posible del Título VIII de nuestra LMV. En lo que sigue se abordarán las subsecciones (1) y (6) de la § 9(a). $\mathrm{Su}$ tratamiento será relativamente más conciso, en la medida que las necesidades del presente artículo lo requieran.

La sección 9(a)(1) de la SEA '34 dispone:

"Será ilegal para cualquier persona, directa o indirectamente, mediante el uso de los correos o cualquier medio o instrumento de comercio interestatal, o de cualquier instalación de cualquier bolsa de valores nacional, o para cualquier miembro de una bolsa de valores nacional:"

(1) "Con el propósito de crear una apariencia falsa o engañosa de negociación activa en cualquier valor registrado en una bolsa de valores nacional, o una apariencia falsa o engañosa con respecto al mercado de un valor semejante, (A) efectuar cualquier operación con semejante valor, que no implique un cambio en la titularidad beneficiada por ella, o (B) ingresar una orden u órdenes para la compra de tal valor con el conocimiento de que una orden u órdenes de sustancialmente el mismo tamaño, sustancialmente al mismo tiempo, y sustancialmente al mismo precio, para la venta de tal valor, ha sido o será ingresada por o para la misma parte o por o para diferentes partes, o (C) ingresar cualquier orden u órdenes de venta de tal valor, con el conocimiento de que una orden $\mathrm{u}$ órdenes de sustancialmente el mismo tamaño, sustancialmente al mismo tiempo, y

${ }^{134}$ De aplicación preferente respecto al art. 61 LMV, según se justificará con detalle en otro trabajo (cfr. supra nota $\left.\mathrm{n}^{\circ} 10\right)$. 
LONDOÑO, Fernando. “Aproximación histórico-comparada al Título VIII de la Ley de Mercado de Valores: bases para el reconocimiento de un contenido anti-manipulativo".

sustancialmente al mismo precio, para la compra de tal valor, ha sido o será ingresada por o para la misma parte o por o para diferentes partes"135.

Esta disposición prohíbe las dos formas de transacción ficticia manipulativa más conocidas en el sector en general, tanto en derecho comparado ${ }^{136}$ como en la literatura ${ }^{137}$ : wash sales (A) y matched orders (B y C). En el primer caso - wash sales- se trata de transacciones con valores en las que no se verifica un cambio en la titularidad de los valores, normalmente realizadas por un mismo titular (actuando desde cuentas separadas) ${ }^{138}$. En el caso de las matched orders, la alteración engañosa del mercado opera mediante transacciones coordinadas para tal propósito, ya realizadas por una misma parte, ya -más comúnmentepor parte coludidas. Como se ha visto, la $\S 9(a)(1)$ las define como órdenes para la compra o venta de un valor con el conocimiento de que otras tantas órdenes de sustancialmente el mismo tamaño y precio serán ingresadas básicamente a la misma hora, ya por para la misma persona, ya por o para otras partes. Ambas tipologías pueden usarse para crear una falsa apariencia de mercado activo en el valor de que se trate ${ }^{139}$.

La propia Corte Suprema de los Estados Unidos coloca a estas prácticas en el ámbito que nos ocupa declarando que:

"el término [manipulación] se refiere a prácticas como las wash sales [o] matched orders, que son realizadas con la intención de engañar a los inversionistas mediante una alteración artificial de la actividad del mercado" $"$.

De acuerdo a lo detectado en las investigaciones parlamentarias post crisis del '29, estas prácticas abundaban en las Bolsas de los Estados Unidos. Tenían como propósito llamar la

${ }^{135}$ La traducción es mía. El texto original reza: "It shall be unlawful... (1) For the purpose of creating a false or misleading appearance of active trading in any security registered on a national securities exchange, or a false or misleading appearance with respect to the market for any such security, (A) to effect any transaction in such security which involves no change in the beneficial ownership thereof, or (B) to enter an order or orders for the purchase of such security with the knowledge that an order or orders of substantially the same size, at substantially the same time, and at substantially the same price, for the sale of any such security, has been or will be entered by or for the same or different parties, or $(C)$ to enter any order or orders for the sale of any such security with the knowledge that an order or orders of substantially the same size, at substantially the same time, and at substantially the same price, for the purchase of such security, has been or will be entered by or for the same or different parties."

${ }^{136}$ Como se verá (infra sub apartado 1.4) de ellas también se ocupará el legislador europeo-comunitario, reconociéndose allí prácticas manipulativas subsumibles bajo la normativa dedicada a los abusos de mercado. Cfr. documento guía CESR 04-505 b, parag. 4.10 (véase supra nota n²2).

${ }^{137}$ Cfr. AVGOULEAS, The Mechanics, cit. nota $\mathrm{n}^{\circ}$ 13, pp. 118 y ss.; LOSS/SELIGMAN, Securities Regulation, cit. nota $\mathrm{n}^{\circ} 17, \S 10-\mathrm{C}$.

${ }^{138}$ Desde esta hipótesis hace sentido la prohibición formulada en parágrafo 27.920, aparatado 7.I.1 del Manual de Operaciones en Acciones de la Bolsa de Comercio, allí donde se lee: "Los corredores que reciban de un mismo cliente una orden de venta y otra de compra sobre una misma acción, por igual número de unidades y con las mismas condiciones de precio y liquidación, no podrán ejecutar ambas órdenes ya sea mediante una operación directa $(\mathrm{OD})$ en rueda o remate, o mediante dos o más operaciones en las que participe como contraparte el propio corredor o un tercero". Sobre esto se volverá en un trabajo posterior, en proceso de publicación (cfr. supra en nota $\mathrm{n}^{\circ} 10$ )

${ }^{139}$ Así, STEINBERG, Understanding Securities, cit. nota ${ }^{\circ} 14$, p. 259, sobre la base del contenido de la sección 9(a)(1) de la SEA'34.

${ }^{140}$ Santa Fe Industries, Inc. v. Green, 430 U.S. 462, 476 (1977). 
atención al mercado sobre un determinado título; así, la notable actividad sobre el título que no era representativo de un interés real del mercado sino fruto de innumerables transacciones realizadas por un mismo sujeto o por sujetos coludidos- movía a quienes observaban el mercado a invertir en esos valores. En otras palabras, estas prácticas operaban justamente como formas engañosas de inducción a la compra o venta de valores, lo que las coloca en el radio tipológico del resto de las disposiciones de la sección 9, especialmente de aquella central hipótesis \$9(a)(2) ya revisada. Puede aún considerársele un caso especial de la $\S 9(a)(2)^{141}$.

Como nota de cierre, interesa destacar que la SEA '34 no prohíbe estas prácticas en sí mismas, sino sólo cuando ellas se realizan con "con el propósito de crear una apariencia falsa o engañosa de negociación activa en cualquier valor registrado en una bolsa de valores nacional, o una apariencia falsa o engañosa con respecto al mercado de un valor semejante" 142 . En otras palabras, ni aún las en principio ilícitas wash sales o matched orders están proscritas por sí mismas, sino en la medida que concurra la específica finalidad manipulativa.

- Conclusiones preliminares de utilidad para una valoración comparada de nuestro art. 53.1 LMV.

Como se sabe, también la LMV prohíbe las transacciones ficticias, en virtud del inciso primero de su art. 53:

"Es contrario a la presente ley efectuar cotizaciones o transacciones ficticias respecto de cualquier valor, ya sea que las transacciones se lleven a cabo en el mercado de valores o a través de negociaciones privadas".

La interpretación detallada de esta disposición nos ocupará en otra sede ${ }^{143}$, pero también a su respecto puede ser útil anticipar algunos comentarios, aprovechando el punto de apoyo comparado. Pues bien, saltan a la vista a lo menos tres aspectos de contraste respecto a la $\S 9(\mathrm{a})(1)$.

Por una parte, nuestro art. 53.1 no define las modalidades de transacción ficticia -como en cambio sí lo hace la legislación estadounidense comentada. En su lugar se conforma con aludir genéricamente al carácter ficticio de las transacciones. En este sentido puede considerársele más amplia-pero también más indeterminada.

En segundo lugar, no califica estas transacciones ficticias mediante el recurso a un propósito manipulativo, como sí lo hace la §9(a)(1). Una cualificación adicional pudo parecerle innecesaria a nuestra LMV -quizás por parecerle intrínseca una idoneidad

\footnotetext{
141 "Transactions that violate $15 \operatorname{USCS} \S 78 \mathrm{i}(a)(1)$ can serve as basis for violation of $\S 78 \mathrm{i}(\mathrm{a})(2)$; however, transactions such as wash sales and matched orders, which constitute violations of $\S 78 \mathrm{i}(\mathrm{a})(1)$, are per se manipulative": cit. de In re Sharon M. Graham, et al. (1995) 1995 SEC LEXIS 3457 (cfr. Legislación anotada en Lexis, com. 15 USCS $\S 78 \mathrm{i}=9$ A SEA ' 34 ).

${ }^{142}$ Más allá del texto, que es expreso en tal sentido, cfr. Southern Brokerage Co. v Cannarsa (1966, Tex Civ App Texarkana) 405 SW2d 457 (en Legislación anotada Lexis, com. 15 USCS $\S 78$ i = 9 A SEA '34).

${ }^{143}$ Cfr. supra nota $\mathrm{n}^{\circ} 10$.
} 
LONDOÑO, Fernando. “Aproximación histórico-comparada al Título VIII de la Ley de Mercado de Valores: bases para el reconocimiento de un contenido anti-manipulativo".

engañadora como cualidad del carácter ficticio de las conductas- pero su falta es lamentable, en cuanto su literalidad concede algo de espacio a interpretaciones (textualistas) que contrarían el sentido de protección de la norma y la sistemática del título VIII y de la LMV en general. Antes que nada existe el riesgo de dar espacio a interpretaciones "patrimonialistas", en clave individual. Así, por ejemplo, quien pretenda ver en esta disposición la prohibición (y punibilidad con pena de crimen vía 59 e]) de una hipótesis no especialmente diversa al mero contrato simulado patrimonialmente perjudicial, como por ejemplo el que castiga nuestro Código Penal en el art. 471 N.2 o bien una hipótesis de engaño instrumental a una estafa común ${ }^{144}$. Aquí ya se ha adelantado la inconsistencia de una reinterpretación "patrimonialista-individual" de las prohibiciones del Título VIII LMV. El caso del inciso $1^{\circ}$ del art. 53 ofrecerá un nuevo espacio para reafirmar esa posición.

Pues bien, la propuesta interpretativa que aquí se defiende se ve favorecida, entre otros elementos, por una tercera nota de interés comparativo: y es que nuestro art. 53.1 utiliza en sentido disyuntivo la voz "cotizaciones", junto a la más obvia de "transacciones". Una referencia tal no existe en la $\S 9(a)(1)$. En una primera aproximación, puede parecer oscura la expresión "efectuar (...) cotizaciones ficticias"; desde ya porque las cotizaciones no son tanto algo que se "efectúa" (a diferencia de las transacciones), como algo que "resulta de" las transacciones. Sin embargo, como se verá, esta voz cumple una función hermenéutica vital para la captación del sentido general de la prohibición, una vez que se la considera en su acepción especial. Se aprecia entonces que su introducción no se debió a un descuido. Consideradas las cotizaciones como el reflejo público (publicado) de los precios de los valores transados en la bolsa, ${ }^{145}$ se capta el sentido de la prohibición y cómo, a la vez, su objeto coincide con un interés supra-individual. Baste aquí con señalar que la falsación de las cotizaciones resulta perfectamente idónea para inducir a error al mercado y, desde allí, para condicionar los precios-de-mercado reales a partir de decisiones de inversión o desinversión que descansen en dicha falsación.

De la comparación efectuada en este apartado puede extraerse el siguiente esquema sintético:

\footnotetext{
144 Piénsese por ejemplo en quien simule una transacción para aparentar desprenderse de un paquete accionario, con el sólo propósito de rebajar sus obligaciones en sede de alimentos del derecho de familia. Una conducta semejante es claramente típica y punible en sede de Ley de Familia (o bien del propio 471 N. 2 $\mathrm{CP}$ ), pero ciertamente no puede contar como manipulativa del mercado de valores, al menos no en la medida que la transacción en sí misma no tenga la idoneidad para llevar a error al mercado (por ejemplo porque insignificante en el universo de transacciones). Puede también pensarse en el caso de transacciones ficticias realizadas por el agente de un corredor con el propósito de generar mayores comisiones por concepto de intermediación (contra el cliente y/o contra el empleador, en su caso). Aquí la conducta podría configurar en principio una hipótesis de estafa común en perjuicio del cliente y/o del empleador (desde que pueda considerarse engañosa la solicitud de pago de comisiones basada en un presupuesto falso), pero no podrá verse como un supuesto de manipulación bursátil, salvo que por las características y entidad de las operaciones ficticias ellas puedan reputarse idóneas para conducir a error al mercado en general (y ya no sólo al cliente o al empleador para el cobro de unas comisiones).

${ }^{145}$ Este es el inequívoco sentido que le atribuye la LMV; entre otras disposiciones, considérese en particular la letra d) del art. 43. Por su parte, de acuerdo a la RAE cotizar significa, en el ámbito mercantil: "Publicar en la bolsa el precio de los efectos públicos allí negociados".
} 
Polít. crim. Vol. 10, No 20 (Diciembre 2015), Art. 1, pp. 390-467.

[http://www.politicacriminal.cl/Vol_10/n_20/Vol10N20A1.pdf]

\begin{tabular}{|c|c|}
\hline §9(a)(1), SEA'34 & 53.1 LMV \\
\hline \multicolumn{2}{|l|}{ Estructura (descriptor) } \\
\hline $\begin{array}{l}\text { (a) conducta (= efectuar transacciones sin cambios } \\
\text { de titularidad - wash sales - o bien bajo un } \\
\text { supuesto de colusión en el calce - matched orders) }\end{array}$ & $\begin{array}{l}\text { (a).- conducta (="efectuar cotizaciones o } \\
\text { transacciones ficticias") } \\
\text { (1.1) falsación de las cotizaciones } \\
\text { (1.2) efectuar transacciones ficticias }\end{array}$ \\
\hline (no prevé calificante objetiva) & (no prevé calificante objetiva) \\
\hline $\begin{array}{l}\text { (b) calificante subjetiva explícita (= propósito de } \\
\text { crear apariencia falsa o engañosa de mercado } \\
\text { activo) }\end{array}$ & (b) ¿calificante subjetiva? (no explícita al menos) \\
\hline \multicolumn{2}{|c|}{ Cobertura } \\
\hline $\begin{array}{l}\text { Manipulación operativa impropia }=\text { mediante } \\
\text { transacciones ficticias (otras formas de } \\
\text { manipulación son cubiertas por las demás } \\
\text { subsecciones de la } \S 9[\mathrm{a}] \text { ). }\end{array}$ & $\begin{array}{l}\text { Manipulación operativa impropia (o manipulación } \\
\text { informativa en el caso de las cotizaciones ficticias) } \\
=\text { mediante transacciones ficticias o bien mediante } \\
\text { falsación de las cotizaciones (otras formas de } \\
\text { manipulación son cubiertas por art. } 52 \text { y 53.2) }\end{array}$ \\
\hline \multicolumn{2}{|c|}{ Mecanismo Manipulativo } \\
\hline $\begin{array}{l}\text { Indirecto. Precio-de-mercado generado por la } \\
\text { operación ficticia y/o la información trasmitida por } \\
\text { la operación ficticia (apariencia engañosa para el } \\
\text { mercado). }\end{array}$ & $\begin{array}{l}\text { Indirecto. Precio-de-mercado reportado por la } \\
\text { cotización falsa o bien generado por la operación } \\
\text { ficticia y/o la información trasmitida por la } \\
\text { operación ficticia. }\end{array}$ \\
\hline
\end{tabular}

c) $\$ 9(a)(6)$ : transacciones con el propósito de fijar, mantener o estabilizar el precio de valores.

La sección 9(a)(6) de la SEA '34 dispone:

"Será ilegal para cualquier persona, directa o indirectamente, mediante el uso de los correos o cualquier medio o instrumento de comercio interestatal, o de cualquier instalación de cualquier bolsa de valores nacional, o para cualquier miembro de una bolsa de valores nacional:

$(\ldots)$

(6) Efectuar, ya sea solo o con una o más personas cualquier serie de transacciones para la compra y /o venta de cualquier valor distinto a uno emitido por el gobierno, con el propósito de fijar, mantener o estabilizar el precio de aquel valor, en contravención a las normas y regulaciones que la Comisión [SEC] pueda dictar, en cuanto necesarias o apropiadas para el interés público o para la protección de los inversores" $"$ "146.

La hipótesis en comento constituye un caso especial respecto a la hipótesis general de la $\S$ 9(a)(2). Establece la prohibición de la estabilización, una práctica manipulativa comúnmente operativa en los mercados de primera emisión (mercado primario). El legislador de la SEA '34 sustrajo esta hipótesis manipulativa de la regla general de la § 9(a)(2), entregándola a la competencia regulativa de la autoridad administrativa

\footnotetext{
${ }^{146}$ La traducción es mía. El texto original reza: "It shall be unlawful... (6) To effect either alone or with one or more other persons any series of transactions for the purchase and/or sale of any security other than a government security for the purpose of pegging, fixing, or stabilizing the price of such security in contravention of such rules and regulations as the Commission may prescribe as necessary or appropriate in the public interest or for the protection of investors."
} 
LONDOÑO, Fernando. “Aproximación histórico-comparada al Título VIII de la Ley de Mercado de Valores: bases para el reconocimiento de un contenido anti-manipulativo".

fiscalizadora del sector (la SEC) ${ }^{147}$, como puede advertirse de la segunda parte de la formulación. ${ }^{148}$ La razón para ello es que, bajo determinadas condiciones y contextos, la estabilización de los precios puede ser admisible, en interés de los emisores y del sistema de oferta pública de valores en general.

Sucede que en contextos de primera emisión es posible que la oferta de valores supere de modo significativo a la demanda por los mismos, con el consecuente riesgo de desplome de los precios. A ello contribuye la saturación producida por la gran cantidad de títulos incorporados de golpe al mercado, así como la presencia de especuladores a la baja (short sellers), quienes contribuyen a incrementar las presiones desde el lado de la oferta. Dejadas las cosas al libre juego del mercado, las bajas en los precios de primera emisión implicarían un desincentivo para el recurso al mercado de oferta pública de valores como opción de financiamiento de las empresas. De allí entonces que, bajo determinadas condiciones se autoricen estabilizaciones "en defensa" del precio de salida.

La propia SEC habría definido la estabilización como "aquel proceso en virtud del cual el precio de mercado de un valor es fijado o mantenido para el limitado propósito de prevenir o retardar una baja del precio en vista de una oferta pública de valores o durante la misma." "149 Básicamente, este proceso de estabilización del precio consiste en un suplemento desde el lado demanda, mediante ofertas y compras al precio en cuestión, todo ello bajo precisas restricciones temporales ${ }^{150}$. Así, se declara ilegal toda oferta, compra o inducción a la compra realizada en dichos períodos restringidos por los propios emisores ${ }^{151}$ o bien por los responsables o participantes ${ }^{152}$ de la emisión ${ }^{153}$. Esas conductas quedan por tanto bajo el imperio de las reglas generales en materia de prohibición y sanción de las prácticas manipulativas $^{154}$.

Por cierto, no es necesario estabilizar valores fuertes, espontáneamente bien cotizados por el mercado, así como tampoco es posible sostener indefinidamente valores débiles, mal apreciados por el mercado. La propia SEC ha afirmado que "la estabilización es considerada necesaria sólo en el caso de emisiones que no constituyan ni éxitos notables ni notables fracasos"

Cabe en fin tener presente que la práctica de estabilización (lícita) es conocida en los mercados y como tal ampliamente regulada para determinar el límite entre lo manipulativo-

\footnotetext{
${ }^{147}$ Cfr. LOSS/SELIGMAN, Securities Regulation, cit. nota ${ }^{\circ} 17, \S 10-\mathrm{E}-1$.

148 Así en la Regulation M, Reglas 100 y ss.

${ }^{149}$ Cit. por LOSS/SELIGMAN, Securities Regulation, cit. nota $n^{\circ}$ 17, §10-E-1, de Sec. Ex. Act Rel. 4163 (1948).

${ }^{150}$ En las definiciones de la regla 100, la Regulation M define una serie de períodos restringidos dependiendo del tipo de emisión o instrumento de que se trate - en los cuales no están permitidas prácticas manipulativas para mantener los precios.

${ }^{151}$ Cfr. la regla 102 de la Regulation $\mathrm{M}$.

${ }^{152}$ Cfr. la regla 101 de la Regulation M. Entiéndase por ellos suscriptores (underwriters) e intermediarios en general comprometidos en la distribución de los valores en primera emisión.

${ }^{153}$ Cfr., principalmente, las reglas 101 y 102 de la Regulation M.

154 Por de pronto la propia $\S 9(a)(2)$ podría resultar aplicable.

155 Cit. por LOSS/SELIGMAN, Securities Regulation, cit. nota n ${ }^{\circ} 17$, §10-E-1, de Sec. Ex. Act Rel. 2446 (1940).
} 
Polít. crim. Vol. 10, No 20 (Diciembre 2015), Art. 1, pp. 390-467.

[http://www.politicacriminal.cl/Vol_10/n_20/Vol10N20A1.pdf]

permitido y lo manipulativo-ilegal. Como se verá más adelante (infra II.5), es también conocida y regulada en el derecho europeo-comunitario, contexto en el que se ha señalado que "las operaciones de estabilización tienen principalmente el efecto de proporcionar apoyo para el precio de una oferta de los valores de que se trate durante un tiempo limitado, si se producen bajo presión de las ventas, aliviando de este modo esa presión generada por los inversores a corto plazo y manteniendo un mercado ordenado de los valores de que se trate" 156 .

- Conclusiones preliminares de utilidad para una valoración comparada de nuestro art. 52 LMV.

Nuestro art. 52 LMV encuentra en la $\S 9(a)(6)$ un inmediato correlato:

"Artículo 52.- Es contrario a la presente ley efectuar transacciones en valores con el objeto de estabilizar, fijar o hacer variar artificialmente los precios.

Sin perjuicio de lo dispuesto en el inciso anterior, podrán efectuarse actividades de estabilización de precios en valores de acuerdo a reglas de carácter general que imparta la Superintendencia y únicamente para llevar adelante una oferta pública de valores nuevos o de valores anteriormente emitidos y que no habían sido objeto de oferta pública”.

Mientras que el primer inciso afirma la prohibición de manipulaciones operativas como regla general, el inciso segundo entrega a la regulación de la Superintendencia el marco de autorización para estabilizaciones, limitadamente para el mercado primario. La inmediatez de este paralelo era también clara en el inciso final del art. 48 del proyecto de ley de la LMV original, apartado que durante la tramitación sería parcialmente reelaborado para convertirse en el actual art. 52. Así:

Artículo $48^{\circ}$.-

(...)

"Las actividades de estabilización efectuadas con el objeto de llevar adelante una distribución de valores en el público, podrán realizarse sólo de acuerdo a reglas de carácter general que la Superintendencia emita al efecto"157.

Como puede advertirse, el art. 48 del proyecto original se ocupaba exclusivamente de las estabilizaciones. Ello contrasta con el actual art. 52, que a la idea de estabilización de los precios agrega, de modo disyuntivo, las voces fijar y hacer variar artificialmente los precios. Al menos con esta segunda voz parece ir más allá de la sola estabilización, comprendiendo toda forma de manipulación operativa propia; esto es, aquella ejecutada mediante operaciones reales e idóneas para afectar los precios de modo directo. En este punto existiría una diferencia con la $\S 9(a)(6)$, que se concentra solo en el fenómeno de la estabilización, por más que ocupe voces auxiliares como fijar (o sujetar = pegging) y mantener (fixing). En este punto entonces podría apreciarse una nota de diferenciación comparativa en el pasaje desde el art. 48 original al art. 52 actual.

\footnotetext{
${ }^{156}$ Considerando 11 del Reglamento (CE) No. 2273/2003.

${ }^{157}$ Proyecto de ley de 30 de diciembre de 1980, en Compendio de Historia de la Ley 18.045 (BCN), p. 28
} 
LONDOÑO, Fernando. “Aproximación histórico-comparada al Título VIII de la Ley de Mercado de Valores: bases para el reconocimiento de un contenido anti-manipulativo".

Ahora bien, en ese pasaje desde el art. 48 del proyecto original de LMV al art. 52 definitivo también se aprecia una nota de aproximación comparativa. En efecto, el art. 52 asume un modelo de descripción basado en el recurso a la faz subjetiva, a la usanza de la $§ 9(a)(6)$. Aparece así el propósito estabilizador como elemento caracterizador de las transacciones prohibidas. Es interesante notar que este giro hacia un modelo descriptivo sobre base subjetiva (como el imperante en el modelo de la sección 9) sólo se da en nuestra LMV en este pasaje desde el art. 48 del proyecto original hacia el art. 52 definitivo ${ }^{158}$. El inciso segundo dedicado a la autorización de la estabilización asume en cambio una perspectiva objetiva, aludiendo a las "actividades de estabilización", en los mismos términos que lo hiciera el inciso final del art. 48 del proyecto original.

Para culminar este comentario comparado sólo resta aludir a la técnica de excepción o autorización de las estabilizaciones. Ambas disposiciones aquí comparadas plantean un espacio de delegación complementaria en regulación de segundo orden por la autoridad administrativa del sector. En lo demás, las diferencias de técnica no parecen ser sustantivamente decisivas, más allá del distinto énfasis: mientras la $\S 9(\mathrm{a})(6)$ integra la referencia a la regulación complementaria en la propia prohibición a modo de ley en blanco (de modo que la excepcional justificación resulta implícita), nuestro art. 52 describe íntegramente la prohibición, para luego, en un plano diferenciado, reconocer un espacio de autorización para las solas estabilizaciones, delegando su configuración a la regulación complementaria. Con todo, es en la implementación de esta regulación complementaria donde se aprecia una diferencia decisiva. Mientras la SEC estadounidense se dio a la tarea de dar con una regulación para la estabilización, terminando el proceso en 1996 con un detallado set de reglas ${ }^{159}$, nuestra Superintendencia de Valores no habría dictado una regulación pertinente. En consecuencia, hasta donde alcanzamos a ver, en nuestro medio no existiría base normativa para plantear una autorización o justificación de las actividades de estabilización $^{160}$.

\footnotetext{
${ }^{158}$ Recordemos que los incisos primero y segundo del art. 48 - que más tarde se convertirán en el actual art. 53 - obedecen, por el contrario, a un modelo descriptivo de tipo objetivo, coincidente con el que más de veinte años después llegaría también a ser característico del diseño europeo-comunitario en la Directiva 2003/6/CE.

${ }^{159}$ La ya aludida Regulation M. Cfr. LOSS/SELIGMAN, Securities Regulation, cit. nota $\mathrm{n}^{\circ} 17, \S 10$-E, dando cuenta de cómo la Regulation M de 1996 cierra un proceso de regulación, de manera "más simple y flexible", respecto de las anteriores Reglas 10b-6, 10b-7, y 10b-8, así como las Reglas 10b-6A y 10b-21.

${ }^{160}$ La regulación de los Market Makers - antes contenida en la derogada Circular SVS No 1644 de enero 2003 y ahora detallada en la Norma de Carácter General SVS n. 327 de enero de 2012 - no parece pertinente para la autorización de las actividades de estabilización en el mercado primario de que aquí se trata. En consecuencia, cuando en el documento "Reglas para prevenir y combatir el uso de información privilegiada y la manipulación de mercado", emanado por el Comité de Regulación de la Bolsa de Comercio de Santiago y Comité de Autorregulación de la Bolsa Electrónica de Chile (abril de 2009, V2), se dispone una concordancia entre el inciso segundo del art. 52 LMV y la Circular № 1644 sobre Market Makers, debe entenderse más bien como una referencia a considerar de cara a otras formas de manipulación operativa, distintas a aquellas a que se refiere el inciso segundo del art. 52 (a justificar eventualmente en atención a las reglas generales, como por de pronto el N.10 del art 10 del CP, de ejercicio legítimo de deber, oficio o cargo). En efecto, la regulación de los Market Makers - y los contratos de Market Maker a que dan lugar - no tienen por finalidad asegurar condiciones de interés en un mercado primario, sino asegurar la adecuada liquidez del mercado secundario. Esto último, de acuerdo a nuestra LMV, en consonancia con el carácter de "presencia bursátil" descrito en su art. 4 bis, y como alternativa al estándar de "presencia ajustada". Según reza el art. 4 bis LMV, la condición de presencia bursátil podrá darse por establecida "en virtud de contratos que aseguren la
} 
Polít. crim. Vol. 10, № 20 (Diciembre 2015), Art. 1, pp. 390-467.

[http://www.politicacriminal.cl/Vol_10/n_20/Vol10N20A1.pdf]

De la comparación efectuada en este apartado puede extraerse el siguiente esquema sintético:

\begin{tabular}{|c|c|}
\hline §9(a)(6), SEA'34 & $52 \mathrm{LMV}$ \\
\hline \multicolumn{2}{|c|}{ Estructura - (=descriptor) } \\
\hline $\begin{array}{l}\text { (a) conducta }(=\text { efectuar }(\ldots) \text { cualquier serie de } \\
\text { transacciones para la compra o venta de } \\
\text { valores) }\end{array}$ & (a).- conducta (= efectuar transacciones en valores) \\
\hline (no prevé cualificante objetiva) & (no prevé cualificante objetiva) \\
\hline $\begin{array}{l}\text { (b) calificante subjetiva explícita (= propósito de } \\
\text { fijar, mantener o estabilizar el precio del valor) }\end{array}$ & $\begin{array}{l}\text { (b) calificante subjetiva explícita (= con el objeto } \\
\text { de estabilizar, fijar o hacer variar artificialmente } \\
\text { los precios) }\end{array}$ \\
\hline \multicolumn{2}{|c|}{ Cobertura } \\
\hline $\begin{array}{l}\text { Manipulación operativa específicamente de tipo } \\
\text { estabilizadora, en contravención a normativa } \\
\text { complementaria SEC (otras formas de manipulación } \\
\text { son cubiertas por las demás subsecciones de la } \S \\
9[\text { a]). }\end{array}$ & $\begin{array}{l}\text { Manipulación operativa propia en general, } \\
\text { incluyendo las manipulaciones estabilizadoras } \\
\text { (otras formas de manipulación son cubiertas por el } \\
\text { art. 53) }\end{array}$ \\
\hline \multicolumn{2}{|c|}{$\begin{array}{ll} & \text { Mecanismo Manipulativo } \\
\end{array}$} \\
\hline $\begin{array}{l}\text { Directo. Precio-de-mercado generado por las } \\
\text { transacciones estabilizadoras. }\end{array}$ & $\begin{array}{l}\text { Directo (aunque no incompatible con mecanismo } \\
\text { indirecto). Precio-de-mercado generado por las } \\
\text { transacciones manipulativas. }\end{array}$ \\
\hline
\end{tabular}

1.3.2. La § 10(b) SEA ’34 y la Regla 10b-5 SEC: prohibición general de manipulación y fraude en el mercado de valores.

El sub apartado anterior habría debido satisfacer el primer objetivo que el ejercicio de comparación con el derecho federal estadounidense se proponía: dar cuenta de la estrecha sintonía entre las fórmulas específicas de prohibición del derecho estadounidense (sección 9[a] de la $S E A$ '34) y el Título VIII de nuestra LMV. La captación de esa sintonía permitiría echar luz sobre el sentido anti-manipulativo de los arts. 52 y 53 LMV.

Toca ahora hacerse cargo del segundo objetivo adelantado; a saber, demostrar la impertinencia de la fórmula general anti-fraude del derecho federal de EEUU (la sección 10b] SEA '34 y su “complementaria” Regla 10b-5) como hipótesis normativa a la luz de la cual leer nuestro Título VIII. Al mismo tiempo, hacer ver las consecuencias antisistemáticas de una semejante pre-comprensión.

Como en cualquier ejercicio de comparación, el análisis no sólo confirma y precisa los contornos de "lo que hay" (algo en lo que puede haber contribuido la comparación con la sección 9[a]), sino que también devela "lo que no hay". La tesis aquí defendida es que nuestra LMV carecería de una figura de fraude común u otra figura de defraudación en el mercado de valores comparable o similar a la Regla 10b-5, así como aplicada en concreto. En compensación, nuestra LMV contiene figuras muy amplias de falsedad informativa que,

existencia diaria de ofertas de compra y venta de los valores, por la cuantía, tiempo y condiciones que defina la Superintendencia". 
LONDOÑO, Fernando. “Aproximación histórico-comparada al Título VIII de la Ley de Mercado de Valores: bases para el reconocimiento de un contenido anti-manipulativo".

con una técnica diversa, cubrirían un campo no menor de los supuestos comprendidos por la Regla 10b-5, con enormes ventajas en términos de simplificación típica y probatoria. Se alude principalmente a las falsedades informativas sancionadas en el art. 59 (principalmente las de las letras a] y f]).

a) Aspectos generales.

En comparación a la detallada sección 9(a), la sección 10(b) de la SEA’34 se pensó desde el principio como una fórmula amplia, a modo de "catch-all provision", para toda forma de manipulación y engaño al mercado que en futuro pudiera desarrollarse en los mercados secundarios y que no fuese conocida por el legislador de 1934. La técnica empleada es, justamente por ello, la de una ley en blanco, entregándose un importante poder regulatorio a la autoridad administrativa del sector $(\text { la } S E C)^{161}$.

Así, la sección 10(b) de la SEA '34 dispone:

“§ 10. Regulación del uso de dispositivos manipulativos y engañosos

Será ilegal para cualquier persona, directa o indirectamente, mediante el uso de cualquier medio o instrumento de comercio interestatal o de los correos, o de cualquier instalación de cualquier bolsa de valores nacional:

(...)

b) Utilizar o emplear, en relación con la compra o venta de cualquier valor registrado en una bolsa de valores nacional o de cualquier valor no inscrito, o cualquier acuerdo de canje de valores [swap agreement], cualquier dispositivo manipulativo o engañoso o artificio en contravención a las normas y regulaciones que la Comisión [SEC] pueda dictar, en cuanto necesarias o apropiadas para el interés público o para la protección de los inversores"

En 1942 la $S E C$ se dio a la tarea de dictar la regulación complementaria a que se refería la sección 10b. El resultado fue la Regla 10b-5, disposición cuyo lenguaje se advierte parcialmente excéntrico al marco fijado por la ley delegante.

La regla 10b-5 reza:

"Empleo de dispositivos manipulativos y engañosos.

Será ilegal para cualquier persona, directa o indirectamente, mediante el uso de cualquier medio o instrumento de comercio interestatal o de los correos, o de cualquier instalación de cualquier bolsa de valores nacional:

\footnotetext{
${ }^{161}$ En esta línea de lectura, cfr. especialmente, THEL, "The Original", cit. nota ${ }^{\circ} 15$.

${ }^{162}$ La traducción es mía. El texto en original reza: $\S 10$. "Regulation of the use of manipulative and deceptive devices.

It shall be unlawful for any person, directly or indirectly, by the use of any means or instrumentality of interstate commerce or of the mails, or of any facility of any national securities exchange: (...) (b) To use or employ, in connection with the purchase or sale of any security registered on a national securities exchange or any security not so registered, or any securities-based swap agreement any manipulative or deceptive device or contrivance in contravention of such rules and regulations as the Commission may prescribe as necessary or appropriate in the public interest or for the protection of investors."
} 


\section{Polít. crim. Vol. 10, № 20 (Diciembre 2015), Art. 1, pp. 390-467. [http://www.politicacriminal.cl/Vol_10/n_20/Vol10N20A1.pdf]}

(a) Emplear cualquier dispositivo, esquema o artificio para defraudar,

(b) Hacer cualquier declaración falsa de un hecho esencial [material] u omitir declarar un hecho esencial, necesario para hacer no engañosas las declaraciones formuladas, a la luz de las circunstancias en que fueron hechas,

(c) Participar en cualquier acto, práctica o curso de negocio que opere o pueda operar como un fraude o engaño a cualquier persona, en relación con [in connection with] la compra o venta de cualquier valor" ${ }^{\prime 63}$.

De las tres hipótesis de la Regla 10b-5, es la hipótesis (b) -relativa a las declaraciones falsas y engañosas- la que concentra la atención de la praxis y la doctrina ${ }^{164}$, hasta el punto que cierta jurisprudencia ha considerado aplicable la Regla 10b-5 sólo si se da un supuesto de emisión de información falsa o engañosa, careciendo las hipótesis (a) y (c) de autonomía aplicativa, al menos para fundar demandas de privados ${ }^{165}$. Dicho sea de paso, es fácil advertir que en nuestra LMV el correlato de la hipótesis (b) de la Regla 10b-5 no se encuentra en el artículo 53, sino en las hipótesis de falsedad informativa del art. 59, distintas a la letra e). Sobre esta comparación se dirá algo más adelante (cfr. infra 1.3.2.e).

Por lo que toca a la cobertura de la manipulación, el estatuto de la sección 10(b) y su regla 10b-5 se ubica en posición residual respecto a la detallada sección 9(a) ya analizada ${ }^{166}$. Lo anterior, siempre en el marco del mercado secundario. Con todo, a diferencia de la sección 9(a), sería pacífico que la sección aquí en estudio ofrecería cobertura para casos de manipulación (y fraude) en contextos extra-bursátiles o fuera de bolsa (over-the-counter), muchas veces relativos a títulos de pequeños emisores no registrados (penny stocks) ${ }^{167}$.

${ }^{163}$ La traducción es mía. El texto en original reza: "Rule 10b-5. Employment of manipulative and deceptive devices. It shall be unlawful for any person, directly or indirectly, by the use of any means or instrumentality of interstate commerce, or of the mails or of any facility of any national securities exchange (a) To employ any device, scheme, or artifice to defraud; (b) To make any untrue statement of a material fact or to omit to state a material fact necessary in order to make the statements made, in the light of the circumstances under which they were made, not misleading, or (c) To engage in any act, practice, or course of business which operates or would operate as a fraud or deceit upon any person; in connection with the purchase or sale of any security."

${ }^{164}$ Es notable que en la manualística consultable y que se ocupa de la sección 10b o de la Regla 10b-5 apenas se mencionen las otras dos hipótesis y que en general la reconstrucción de los elementos se limite a la hipótesis (b), cual si ésta coincidiera con la regla completa. Al respecto, cfr. la tesis crítica de PRENTICE, Robert A., "Scheme liability: Does it have a future after Stoneridge?", Wis. L. Rev. (2009), pp. 351 y ss.

${ }^{165}$ Crítico de esa posición, PRENTICE, "Scheme liability", cit. nota n ${ }^{\circ} 164$, pp. 377 y ss. Este autor hacer ver que "al decidir que una conducta fraudulenta no es castigable bajo la sección 10(b) a menos que coincida con la noción clásica de manipulación del mercado, las cortes han querido negar la existencia de las subsecciones (a) y (c)": op. cit, p. 378.

${ }^{166}$ Por más que la praxis de la litigación privada demuestre un importante impacto de la Regla 10b-5, éste parece concentrarse más en casos de fraude y uso de información privilegiada que en casos de nítida manipulación. La importancia de la Regla 10b-5 se explica por cierto por su derecho implícito para obtener resarcimiento por perjuicios. Considérese en este contexto que se ha ido asentando una doctrina que ve "fraude" en toda manipulación, en la medida que se hayan verificado transacciones sin advertir a los adquirentes/vendedores que el precio en cuestión se ha debido a la manipulación del agente: cfr. ampliamente, LOSS/SELIGMAN, Securities Regulation, cit. nota $n^{\circ} 17, \S 10-\mathrm{D}$, especialmente nota 3.

${ }^{167}$ Cfr. STEINBERG, Understanding Securities, cit. nota ${ }^{\circ}$ 14, p. 260; LOSS/SELIGMAN, Securities Regulation, cit. nota $\mathrm{n}^{\circ} 17, \S 10-\mathrm{D}$. 
LONDOÑO, Fernando. “Aproximación histórico-comparada al Título VIII de la Ley de Mercado de Valores: bases para el reconocimiento de un contenido anti-manipulativo".

Dado que la Regla 10b-5 no puede exceder el radio de cobertura de la Sección 10b, la jurisprudencia superior aprecia una infracción a la Regla 10b-5 sólo si se prueba la existencia de una manipulación o bien alguna forma de engaño (deceit)-especialmente de tipo informativo-, no bastando la mera infracción de un deber fiduciario ${ }^{168}$. Esta doctrina fue sentada por la Corte Suprema de los Estados Unidos en el muy conocido caso Santa Fe Industries $^{169}$, en el que los accionistas de minoría demandaron la infracción de la Regla 10b-5 argumentando que la notable pérdida de valor de sus acciones en el contexto de una polémica operación de fusión constituía por sí misma un fraude, en el sentido de la sección 10(b) y la citada regla. La Corte rechazó el argumento, sosteniendo que la operación no había sido engañosa ni manipulativa, y que por tanto no habría violado la normativa en cuestión. En este contexto la Corte Suprema agregaría que:

"el lenguaje de la sección 10(b) no da ninguna indicación en orden a que el Congreso hubiese tenido la intención de prohibir alguna conducta que no involucre manipulación o engaño, así como tampoco se ha ofrecido evidencia en la historia legislativa que pueda justificar apartarse del tenor de la ley" ${ }^{, 170}{ }^{171}$.

En esta línea, cierta doctrina ve en el estatuto conformado por la Sección 10(b) y la Regla 10b-5 dos presupuestos básicos, que justamente lo colocan en la óptica recién apuntada: (1) la idea de que el fraude se dirija al valor intrínseco del instrumento en cuestión; y (2) que el fraude se haga calculadamente para influenciar al público inversionista ${ }^{172}$.

En fin, es importante tener en cuenta que la Regla 10b-5 ha sido objeto de una doble tensión. Por un lado, se aprecia una tendencia a favorecer una dilatación de su alcance, valiéndose de su poroso lenguaje, especialmente de su segunda hipótesis en materia de declaraciones falsas y declaraciones engañosas. A lo anterior han contribuido fundamentalmente los litigantes privados $\mathrm{y}$ en parte la misma SEC, aunque en determinados períodos la propia Corte Suprema ha favorecido esa tendencia. De este modo se daría cabida al insider trading o uso de información privilegiada (según se verá con más detalle a continuación), a la vez que se buscaría perseguir la responsabilidad de ejecutivos y

168 STEINBERG, Understanding Securities, cit. nota ${ }^{\circ} 14$, pp. 243-244, con referencia al caso Santa Fe Industries, Inc. V. Green, 430 U.S. 462 (1977). Ulterior detalle, en STEINBERG, Understanding Securities, cit. nota $\mathrm{n}^{\circ} 14$, pp. 254 y ss. Crítico y con referencia a jurisprudencia de tribunales inferiores, cfr. PRENTICE, "Scheme liability", cit. nota $\mathrm{n}^{\circ} 164$, p. 377.

${ }^{169}$ Santa Fe Industries, Inc. V. Green, 430 U.S. 462 (1977).

${ }^{170}$ Santa Fe Industries, Inc. V. Green, 430 U.S. 462 (1977), 473. De especial interés resultan las pp. 472 y 473 del fallo: "Rule 10b-5 was adopted pursuant to authority granted the [Securities and Exchange] Commission under 10 (b). The rulemaking power granted to an administrative agency charged with the administration of a federal statute is not the power to make law. Rather, it is "the power to adopt regulations to carry into effect the will of Congress as expressed by the statute."' (. . " The scope of the Rule cannot exceed the power granted the Commission by Congress under 10 (b)." (...) The language of 10 (b) gives no indication that Congress meant to prohibit any conduct not involving manipulation or deception. Nor have we been cited to any evidence in the legislative history that would support a departure from the language of the statute. "When a statute speaks so specifically in terms of manipulation and deception, . . . and when its history reflects no more expansive intent, we are quite unwilling to extend the scope of the statute (...)"

${ }^{171}$ En todo caso una línea diversa se abriría con la tendencia "Goldberg" o la teoría de la lost state remedy: cfr. STEINBERG, Understanding Securities, cit. nota $\mathrm{n}^{\circ}$ 14, pp. 256-257.

${ }^{172}$ Así, CHOI, Stephen J.; PRITCHARD, Adam C., Securities Regulation. Essentials. New York: Aspen Publishers, 2008, pp. 109-110. 
directores por eventuales infracciones a deberes fiduciarios, perjudiciales para los accionistas. A este movimiento "dilatador", se opondría otro de signo opuesto, fuertemente restrictivo. Liderada por la Corte Suprema, esta tendencia restrictiva habría tenido por finalidad poner atajo al insostenible crecimiento de demandas de litigantes privados (no siempre fundadas), globalmente perjudiciales para las sociedades y, con ello, para los propios accionistas $^{173}$. Desde esta perspectiva se explican los exigentes requisitos que paulatinamente se han ido reconociendo por la Corte Suprema como necesarios para validar demandas por presuntas infracciones a la regla $10 \mathrm{~b}-5^{174}$. De estos requisitos nos ocuparemos más abajo, pero vale la pena anticipar aquí que ellos dan cuenta de una reconstrucción de la Regla 10b-5 que la acercan al (restrictivo) campo de los fraudes cometidos mediante engaño, más que a la técnica caracterizadora de las manipulaciones ${ }^{175}$.

\section{b) El giro jurisprudencial hacia la cobertura del insider trading.}

Ahora bien, no obstante esta importante restricción, la noción de engaño es todavía lo suficientemente amplia como para posibilitar una dilatación del alcance de la sección 10(b), principalmente bajo el tenor de la hipótesis (b) de la Regla 10b-5. Esa dilatación no demoraría en llegar, siendo la más notable aquella que se alcanzaría mediante la inclusión en su seno de la prohibición del insider trading ${ }^{176}$ o uso de información privilegiada, como es conocida entre nosotros. Por cierto no es éste el espacio para ocuparnos de esta figura y de su articulada construcción jurisprudencial, pero pueden bastar algunas pocas líneas para conectar su génesis con la sección que aquí nos ocupa.

Ya desde los '60 -fundamentalmente a partir de los casos In re Cady (1961) ${ }^{177}$ y luego SEC v. Texas Gulf (1968) ${ }^{178}$ - la jurisprudencia de tribunales inferiores había dado razón a la SEC y a su teoría del acceso igualitario a la información, conforme a la cual, al transar valores del respectivo emisor, los insiders tenían el deber de (i) revelar la información substantiva y no divulgada al público de que estuvieren en posesión, o bien -en su defecto(ii) abstenerse de negociar con los respectivos valores. Este deber se resume en la conocida máxima "revela o abstente". Pues bien, si un deber semejante existe, entonces podría en principio verse una infracción a la hipótesis (b) de la Regla 10b-5 allí donde se transen valores sin que la parte obligada (insider) hubiere revelado su conocimiento sobre una información esencial, relativa a los respectivos valores. Así, el deber de revelar actuaría como presupuesto para la tipicidad de la omisión a que alude la hipótesis (b) de Regla 10b5 .

\footnotetext{
${ }^{173}$ En este sentido, CHOI/PRITCHARD, Securities Regulation, cit. nota $\mathrm{n}^{\circ} 172$, pp. 105 y ss. En similar sentido, cfr. STEINBERG, Understanding Securities, cit. nota n 14, p. 247 (3).

${ }^{174}$ Destacan en este contextos los pronunciamientos de la Corte Suprema en Blue Chip Stamps, et al. V. Manor Drug Stores 421 U.S. 723 (1975); y Santa Fe Industries, Inc. V. Green, 430 U.S. 462 (1977). Cfr. CHOI/PRITCHARD, Securities Regulation, cit. nota $\mathrm{n}^{\circ}$ 172, pp. 105 y ss.; STEINBERG, Understanding Securities, cit. nota $\mathrm{n}^{\circ} 14$, pp. 243 y ss.

${ }^{175}$ Al tratar el contexto histórico-comparado de la figura de manipulación se expuso sobre las diferencias entre los fraudes cometidos mediante engaño y las manipulaciones bursátiles: cfr. supra sub apartado 1.2.

${ }^{176}$ Cfr. la interesante reconstrucción ofrecida por SEMINARA, Sergio, Insider Trading e Diritto Penale, Milano: Giuffrè, 1989, pp. 91-130.

${ }^{177}$ In re Cady, Roberts \& Co., 40 S.E.C. 907 (1961)

${ }^{178}$ SEC v. Texas Gulf Sulphur Co., 401 F.2d 833 (2d. Cir. 1968).
} 
LONDOÑO, Fernando. “Aproximación histórico-comparada al Título VIII de la Ley de Mercado de Valores: bases para el reconocimiento de un contenido anti-manipulativo".

Tres importantes pronunciamientos de la Corte Suprema de los Estados Unidos terminarían por consolidar esta doctrina, constituyendo hoy el estado de la cuestión en la materia. En 1980, en el caso Chiarella v. United States, la Corte Suprema de los EE.UU. tomaría por primera vez posición sobre aquella lectura de la $S E C$, ratificándola, al afirmar que cabe responsabilidad bajo la Sección 10(b) y la Regla 10b-5 allí donde se realicen transacciones sobre la base de información-esencial-no-divulgada (material nonpublic information), aunque sólo en la medida que exista un deber fiduciario de revelar tal información (a la contraparte $)^{179}$. Esa doctrina sería básicamente ratificada por la Corte Suprema en 1983, en el caso Dirks v. Sec. ${ }^{180}{ }^{181}$, para ser considerablemente ampliada en 1997, en el caso United States vs. O'Hagan ${ }^{182}$, afirmándose un deber fiduciario ya no sólo para con la contraparte en la transacción, sino para con la fuente de la información. Con ello se daría cabida a la conocida misappropiation theory o teoría de la apropiación indebida de la información ${ }^{183}$. En la base de toda esta reconstrucción jurisprudencial estaría la idea-fuerza de que el propósito fundamental de la SEA'34 -y por ende de la sección 10(b)- coincidiría con la imposición de una filosofía de "revelación total" o full disclosure ${ }^{184}$.

Pueden desde ya extraerse las siguientes conclusiones útiles para los fines del presente artículo, siempre en clave comparativa. A saber, que mientras en los EE.UU una misma disposición, originalmente concebida para la prohibición de la manipulación y otros engaños afines, da cobijo - sobre la base de una histórica reconstrucción jurisprudencial - a la prohibición del uso de información privilegiada, ello no acontece en nuestro ordenamiento. En efecto, nuestra LMV trata bajo estatutos claramente diferenciables la manipulación bursátil y el uso de información privilegiada, en los títulos VIII y XXI, respectivamente (amén de prever sanciones penales diferenciadas, fundamentalmente en el art. $60 \mathrm{LMV}$ ). Más importante aún, la detallada regulación y punibilidad del uso de información privilegiada no es originaria de la LMV, en su versión de 1981. Recordemos que en su versión original la LMV no preveía tipología penal ni administrativasancionatoria especial para el uso de información privilegiada, limitándose a disponer -en un escueto art. $13^{185}$ - un deber de reserva de información-esencial-no-divulgada, seguido

${ }^{179}$ Chiarella v. United States, 445 U.S. 222 (1980), descartándose la responsabilidad de un sujeto no-iniciado (no insider), en cuanto a su respecto no podía afirmarse semejante deber fiduciario.

${ }^{180}$ Dirks v. SEC , 463 U.S. 646 (1983), en el que se planteó el problema sobre la responsabilidad de quien "dateaba" a terceros con información relevante-no-divulgada, así como el status de estos terceros "dateados", que usaban dicha información para realizar transacciones.

181 A este pronunciamiento le seguirían leyes que dispondrían sanciones administrativas y penales para el Insider Trading, incluyendo medidas de enforcement a favor de la SEC: la Insider Trading Sanctions Act de 1984 y la Insider Trading and Securities Fraud Enforcement Act de 1988: cfr. 15. U.S.C. § 78ff(a).

${ }^{182}$ United States vs. O'Hagan, 521 U.S. 642 (1997), en el que se afirmó la responsabilidad de un iniciado secundario que usó (se apropió) una información que le había sido confiada por su mandante, adquiriendo valores emitidos por la empresa que el mandante se proponía escalar.

183 Cfr. para mayor detalle, STEINBERG, Understanding Securities, cit. nota $\mathrm{n}^{\circ} 14$, pp. 367 y ss.; CHOI/PRITCHARD, Securities Regulation, cit. nota ${ }^{\circ} 172$, pp. 149 y ss.

${ }^{184}$ Crítico de esta idea-fuerza, cfr. THEL, "The Original", cit. nota n 15 , esp. pp. 388 y 461 y ss.

185 “Artículo 13.- Los directores, administradores y, en general, cualquiera persona que en razón de su cargo o posición tenga acceso a información de la sociedad y de sus negocios, que aún no haya sido divulgada oficialmente al mercado por la compañía en cumplimiento de lo dispuesto en la presente ley y que sea capaz de incluir en la cotización de los valores de la misma, deberán guardar estricta reserva. // Asimismo, se prohíbe a las personas mencionadas en el inciso anterior valerse de la información reservada para obtener para sí o para otros, ventajas mediante la compra o venta de valores. Ellas deberán velar para que esto tampoco 
de una obligación de compensación a favor del emisor y una indemnización de perjuicios a favor de terceros, en supuestos de uso de tal información. El Título XXI que hoy regula detalladamente la información privilegiada, así como su tipificación penal bajo el art. 60, fueron incorporados recién en 1994 por la ley $19.301^{186}$.

En este contexto es decisivo advertir que, hasta donde se alcanza a ver, el inciso segundo del art. 53 de la LMV jamás ha sido postulado -por la SVS, la jurisprudencia o la doctrina, ni aún antes de la dictación de la ley 19.301- como un espacio bajo el cual pudiera subsumirse la prohibición del uso de información privilegiada ${ }^{187}$. Más allá de las variables institucionales e históricas, una razón es evidente: la notoria diferencia entre el tenor del art. 53.2 y la Regla 10b-5. Difícilmente podría pretenderse del primero lo que se ha encontrado en la segunda, especialmente bajo aquella hipótesis que sanciona como forma de engaño la omisión de declaración de un hecho esencial.

ocurra a través de subordinados o terceros de su confianza. // Las personas mencionadas en el inciso primero que hayan actuado en contravención a lo establecido en este artículo, deberán devolver a la caja social toda utilidad que hubieren obtenido a través de transacciones de valores de la sociedad. // Toda persona perjudicada por infracción a lo dispuesto en el presente artículo tendrá derecho a demandar indemnización en contra de las personas indicadas en el inciso primero, excepto si estaba en conocimiento de la información reservada."

${ }^{186}$ Lo anterior, sin perjuicio de las sucesivas reformas del Título XXI y del art. 60 por las leyes ${ }^{\circ} \mathrm{s} 19.705$ y 20.382. Anteriormente, la ley $\mathrm{n}^{\circ} 18.860$ de 1987 había incorporado la punibilidad para dos supuestos de revelación y uso de información reservada en contextos clasificación por sociedades clasificadoras (revelación $=$ art. 60 d] y; uso $=$ original inciso primero del art. 85 en relación con el art. 59 e]).

${ }^{187}$ La literatura nacional en materia de uso de información privilegiada se ha incrementado aceleradamente en los últimos años. Entre otros trabajos publicados en nuestro medio, pueden consultarse, ALCALDE, Enrique, "Uso de información privilegiada: algunas consideraciones sobre el sentido y alcance de la prohibición en relación con su sujeto, objeto y sanción", Revista Chilena de Derecho, Vol. 27 N$^{\circ} 1$ (2000), pp. 11-28; PRADO, Arturo. "Acerca del concepto de información privilegiada en el mercado de valores chileno: su alcance, contenido y límites", Revista Chilena de Derecho, Vol. 30 N (2003), pp. 237-269; RIED, José Miguel, "Fundamentos de la prohibición del uso de la información privilegiada en Chile: una visión crítica", Revista Chilena de Derecho, Vol. 31 N 3 (2004), pp. 439-463; SALAH, María Agnes, Responsabilidad por uso de información privilegiada en el mercado de valores, Santiago: Lexis Nexis, 2004; ROSAS, Juan Ignacio, "El delito de abuso de información privilegiada en el mercado de valores: análisis crítico de la regulación contenida en la Ley N. 18.045”, Gaceta Jurídica N. 299 (2005), pp. 7-24; GUZMÁN, Francisco, lnformación privilegiada en el mercado de valores chileno, Santiago: Legal Publishing, 2009; PFEFFER, Francisco, "Concepto de información privilegiada y deberes de conducta de quienes están en posesión de ella, a la luz de la jurisprudencia emanada de la Excma. Corte Suprema", Revista de Derecho Comercial, Año 1, $\mathrm{N}^{\circ} 1$ (2010), pp. 155-181; VÁSQUEZ, María Fernanda, "Revisión del ámbito de aplicación subjetivo y objetivo de la noción de uso de información privilegiada en Chile: un examen de la normativa a la luz de las tendencias doctrinales y jurisprudenciales", Revista de Derecho Universidad Católica del Norte, Año 17 - N. 2 (2010), pp. 239-297; PIÑA, Juan Ignacio, "Algunos problemas del delito de uso de información privilegiada", en: Regulaciones del Mercado de Valores, Cuadernos de Extensión jurídica, U. Andes, Santiago, 2010, pp. 113 y ss.; GASPAR, José Antonio; ARAYA, Fernando, "Uso de información privilegiada: Superintendencia de Valores y Seguros, 14 de abril de 2011, Resolución Exenta N $^{\circ} 229$ ", Revista Chilena de Derecho Privado, No 17 (2011), pp. 277-305; BASCUÑÁN R., Antonio, "La regulación de la información privilegiada en el mercado de valores después de la ley N. 20.382", en: WILLENMANN, Javier (Coord.), Gobiernos Corporativos. Aspectos esenciales de las reformas a su regulación, Santiago: Legal Publishing, 2011, pp. 87-137. GARCÍA, Gonzalo, "Modelo de protección en normas administrativas y penales que regulan el abuso de Información Privilegiada en la legislación chilena", Política criminal, Vol. 8, No 15 (2013), Art. 2, pp. 23 - 63 (http://www.politicacriminal.cl/Vol_08/n_15/Vol8N15A2.pdf). 
LONDOÑO, Fernando. “Aproximación histórico-comparada al Título VIII de la Ley de Mercado de Valores: bases para el reconocimiento de un contenido anti-manipulativo".

Límites y requisitos de procedencia.

Ya se ha aludido a la doble tensión - dilatadora y restrictiva- de la que ha sido objeto la Regla 10b-5. En lo sucesivo se ofrecerá una síntesis de los elementos que la jurisprudencia superior -en clave restrictiva- reconoce como necesarios, cuanto menos para el éxito de una demanda de indemnización por infracción a la Regla $10 b-5^{188}$. Aquí se dará cuenta de aquellos elementos que más contribuyen a delinear el semblante de la Regla y que, a la vez, son de mayor interés para los propósitos del presente trabajo.

En primer lugar, figura un requisito a modo de legitimación activa, conforme al cual el demandante debe tener la calidad de comprador o vendedor del respectivo valor (purchaseseller requirement $)^{189}$. Esto significa que la regla no protege a un tenedor cualquiera del valor, como por ejemplo el caso del inversionista que sólo mantuvo los respectivos valores en su portafolio ${ }^{190}$. Como puede apreciarse, este requisito anticipa la configuración de un presupuesto de interacción, característico del fraude por engaño. Los elementos siguientes complementan esta idea.

En segundo lugar, debe acreditarse la existencia de manipulación o engaño, no bastando el mero quiebre de un deber fiduciario. ${ }^{191}$ Ya se ha ofrecido una detallada exposición de este decisivo requisito, así como desarrollado por la Corte Suprema a partir del caso Santa Fe Industries $^{192}$. La caracterización del engaño supone a su turno que el déficit informativo sea substantivo (material, en el original) o esencial, para estar al término empleado por nuestra $\mathrm{LMV}^{193}$.

En tercer lugar, una serie de elementos se exigen en el plano de la causalidad, todos los cuales concurren a configurar la idea de una interacción entre agente y afectado, característica de todo fraude cometido mediante engaño. Así, el requisito de reliance, que

\footnotetext{
${ }^{188}$ En principio para la persecución de indemnización de perjuicios, pero algunos de estos elementos son también aplicables a acciones que buscan injunctive relief (en términos generales, órdenes de hacer o no hacer para el restablecimiento de una determinada situación). Cfr. STEINBERG, Understanding Securities, cit. nota $\mathrm{n}^{\circ} 14$, p. 248.

${ }^{189}$ Cfr. STEINBERG, Understanding Securities, cit. nota $\mathrm{n}^{\circ} 14$, p. 243 y pp. 247-248. Esto no significa que el hechor demandado deba a su turno aparecer como comprador o vendedor; cfr. también CHOI/PRITCHARD, Securities Regulation, cit. nota $\mathrm{n}^{\circ} 172$, p. 110.

${ }^{190}$ Ya en un pronunciamiento de 1952, del Segundo Circuito en Birnbaum v. Newport, 193 F 2 d 461 (2d Cir. 1952): cfr. HAZEN, Thomas Lee, Securities Regulation. In a nutshell, St. Paul (MN): West (Thomson Reuters), $10^{\text {th }}$ ed., 2009, pp. 16-164. En este caso accionistas de minoría cuestionaron la venta de un paquete accionario que daba control sobre sociedad, en la medida que por aquel se pagó un precio sobre mercado (el premio de control), con perjuicio para los demás accionistas. Nótese que una problemática semejante se ubica en nuestra LMV en el ámbito de la defraudación de OPA (=60f]), no hallando solución en nuestro art. 53 LMV. La restricción purchaser-seller sería posteriormente avalada y detallada por la Corte Suprema de los EE.UU en Blue Chip Stamps v. Manor Drug Stores, 421 U.S. 723 (1975), según se indicará luego.

${ }^{191}$ Así, STEINBERG, Understanding Securities, cit. nota ${ }^{\circ} 14$, p. 244, con referencia a Santa Fe Industries, Inc. V. Green, 430 U.S. 462 (1977).

192 Santa Fe Industries, Inc. V. Green, 430 U.S. 462 (1977).

${ }^{193}$ El concepto coincide en efecto con la idea de información que un inversionista razonable pueda considerar como importante para la adopción de sus decisiones de inversión: cfr. STEINBERG, Understanding Securities, cit. nota $\mathrm{n}^{\circ}$ 14, p. 244 (4), de acuerdo a la doctrina del importante caso Basic, Inc. v. Levinson, 485 U.S. 224 (1988). Se capta la inmediata sintonía con la definición contenida en el art. $9^{\circ}$ de nuestra LMV.
} 
supone la prueba de que el demandante confió o contó con (relied) en la alegada falsedad informativa $^{194}$ y que ejerció due diligence a su respecto ${ }^{195}{ }^{196}$. En seguida, se precisa acreditar la relación causal entre la conducta ilícita y el perjuicio del demandante ${ }^{197}$. Cierra este plano la exigencia de relación entre la conducta engañosa y la compra o venta del respectivo valor ${ }^{198}$. Esta exigencia se desprende por la jurisprudencia de la frase final de la Regla: en relación con [in connection with] la compra o venta de cualquier valor. Conforme a este requisito, la Regla sólo protegería civilmente a aquel que compró o vendió valores a causa o con motivo de la falsedad o de la conducta engañosa; no protegería por tanto, por ejemplo, a aquel que mantenía los respectivos valores en su portafolio (desde antes del fraude) y que se ve perjudicado vendiéndolos a bajo precio después de conocerse el fraude. En concreto, de acuerdo a esta exigencia -complementaria del presupuesto de legitimación activa o purchaser-seller requirement- la Regla no protegería ni a potenciales compradores o potenciales vendedores (will-be purchasers; will-be sellers), así como tampoco a accionistas, acreedores y terceros que hubieren sufrido pérdidas en el valor de sus inversiones, en la medida que no hubieren comprado o vendido las respectivas acciones durante el período relevante ${ }^{199}-{ }^{200}$.

En cuarto lugar, por lo que se refiere al tipo subjetivo, debe establecerse que el demandado actuó con scienter, elemento caracterizado por la jurisprudencia como "un estado mental

${ }^{194}$ Por cierto en el supuesto de invocación de la hipótesis (b) de la Regla 10b-5.

${ }^{195}$ Cfr. STEINBERG, Understanding Securities, cit. nota n 14 , pp. 244 y 260 y ss.

${ }^{196}$ Esta ardua exigencia se ve en todo caso simplificada por una presunción basada en la teoría de "fraude en el mercado", operativa en contextos de mercados eficientes, construida sobre la base de los modelos de eficiencia informativa del mercado. Ello supone afirmar que el afectado podía confiar en el precio de mercado, siendo el propio mercado - a través de sus innumerables interacciones - el que "procesaría" la información por el afectado. La reliance estaría así radicada en el propio mercado. Cfr. STEINBERG, Understanding Securities, cit. nota n ${ }^{\circ} 14$, pp. 261 y ss.

${ }^{197}$ Cfr. STEINBERG, Understanding Securities, cit. nota ${ }^{\circ} 14$, p. 244.

${ }^{198}$ Cfr. STEINBERG, Understanding Securities, cit. nota $\mathrm{n}^{\circ}$ 14, p. 245.

${ }^{199}$ Cfr. STEINBERG, Understanding Securities, cit. nota ${ }^{\circ}$ 14, p. 247, sobre la base del pronunciamiento en el caso Blue Chip Stamps v. Manor Drug Stores, 421 U.S. 723 (1975). En este caso, se entregó información falsamente pesimista por un emisor, para inducir a los demandantes a no comprar las acciones sobre las que tenían derecho de opción (cfr. HAZEN, Securities Regulation, cit. nota $\mathrm{n}^{\circ}$ 190, pp. 164-165). Estos potenciales compradores (will-be buyers) no fueron protegidos por la razón anotada arriba. En base a esta misma restricción tampoco se ha protegido a quien "habría vendido" de no haber contado con información optimista (falsa), como en el caso Merrill Lynch et al v. Dabit, 547 U.S. 71 (2006): cfr. HAZEN, Securities Regulation, cit. nota $\mathrm{n}^{\circ} 190$, p. 165.

${ }^{200}$ Para estar a un ejemplo concreto, si se tratase de un caso como "La Polar" - ubicable en el radio de cobertura de una regla como la 10b-5, si los hechos hubieren tenido lugar en su jurisdicción, por cierto - de acuerdo a los requisitos hasta aquí expuestos no podrían hallar protección civil aquellos inversionistas que tenían y mantuvieron en cartera acciones de La Polar desde antes de comenzar la entrega de estados financieros falsos (y tampoco si esos mismo inversionistas sufrieron pérdidas al vender acciones de su portafolio a precios ruinosos, una vez conocidos los hechos que hoy son de público conocimiento); mucho menos podrían accionar aquellos inversionistas que vendieron acciones de La Polar antes de conocerse los hechos. En cambio, en principio podrían accionar aquellos que compraron las acciones antes de conocerse los hechos, pero sólo en la medida que esas transacciones encuentren su causa en la información falsa o en la conducta fraudulenta. Lo anterior, sin perjuicio de la presunción conforme a la teoría del "fraude en el mercado": v. supra nota $\mathrm{n}^{\circ} 205$. Debe advertirse que el ejemplo se ofrece aquí con carácter hipotético, por cierto, estando sólo a los antecedentes hoy de público conocimiento y sin prejuzgar sobre el mérito del caso, estando aun pendiente el proceso. 
LONDOÑO, Fernando. “Aproximación histórico-comparada al Título VIII de la Ley de Mercado de Valores: bases para el reconocimiento de un contenido anti-manipulativo".

comprensivo de la intención de engañar, manipular o defraudar" ${ }^{201}$, no bastando la sola negligencia $^{202}$.

Una última restricción del alcance de derecho privado de la Regla 10b-5 merece una mención en este contexto. Se trata de la jurisprudencia superior conforme a la cual las acciones de resarcimiento por perjuicios sólo pueden dirigirse a los obligados principales por el deber de información infringido y no a los terceros (aiders, abetters) que aparecieren ejecutando conductas auxiliares o accesorias a la actividad de los principales, a menos que ellos mismos incurrieren en una conducta descrita por la Regla 10b-5. Esa restricción obedece a una distinción entre responsabilidad primaria y responsabilidad secundaria inaugurada por la Corte Suprema en el caso Central Bank of Denver de $1994^{203}$ y reafirmada por la misma en 2008, en el caso Stoneridge $e^{204}$.

\section{d) Sintesis acerca del sentido de la Regla 10b-5.}

De todo lo expuesto ${ }^{205}$ resulta que el estatuto conformado por la sección 10(b) y la Regla 10b-5 se comporta en el sistema federal estadounidense como una figura común, tendencialmente residual respecto de otras figuras especiales, y con alcance sobre toda manipulación y todo fraude cometido mediante engaño en el contexto del mercado secundario de valores. Bajo esta segunda modalidad de fraude por engaño -específicamente bajo la hipótesis (b) de la Regla 10b-5- se han comprendido los comportamientos de insider trading, así como otras conductas reconducibles a falsedades o abusos informativos, especialmente declaraciones falsas o engañosas por sujetos obligados por normas primarias (emisores y gatekeepers, en general), en contextos de comunicación de hechos esenciales. Con todo, más allá de su amplitud, la Corte Suprema ha precisado su alcance ${ }^{206}$,

201 Ernst \& Ernst v. Hochfelder, 425 U.S. 185 (1976), at. 193 nota 12. Posición reafirmada también para procedimientos de injunction de la SEC, en Aaron v. SEC 446 U.S. 680 (1980). Cfr. STEINBERG, Understanding Securities, cit. nota ${ }^{\circ} 14$, pp. 248-249.

202 Ernst \& Ernst, at. 201-206. Cfr. STEINBERG, Understanding Securities, cit. nota n ${ }^{\circ} 14$, p. 249. La Corte Suprema no afrontó la compatibilidad de la recklessness (una tipología que se mueve entre nuestro dolo eventual y la culpa grave) con la regla 10b-5 (cfr. Ernst \& Ernst, at. 193 nota 12), pero los tribunales federales inferiores han reconocido su compatibilidad: cfr. STEINBERG, Understanding Securities, cit. nota $n^{\circ} 14, \mathrm{pp}$. 249 y 250.

${ }^{203}$ Central Bank of Denver, N.A. v. First Interstate Bank of Denver, N.A., 511 U.S. 164 (1994): cfr. critico, PRENTICE, "Scheme liability", cit. nota n 164, pp. 394 y ss.

${ }^{204}$ Stoneridge Investment Partners v. Scientific-Atlanta, 552 U.S. 148 (2008); al respecto, cfr. PRENTICE, "Scheme liability", cit. nota $n^{\circ} 164$, dedicado a la crítica de esta decisión.

${ }^{205}$ Aunque un autor tan reputado como Steve Thel haya afirmado que "it would be very hard to define exactly what section 10(b) and rule 10b-5 forbid" y que "it is surely impossible to say it in a nutshell" (THEL, "The Original", cit. nota ${ }^{\circ} 15$, p. 386), aquí se intenta de todos modos ofrecer un noción sintética, estando a la concepción dominante, así como sentada por los pronunciamientos de la Corte Suprema de los Estados Unidos citados en pasajes anteriores, principalmente Santa Fe, Blue Chip, Ernst \& Ernst v. Holchfelder y Chiarella.

${ }^{206}$ Resulta de interés revisar la concepción alternativa (a la restrictiva-dominante, impulsada por la Corte Suprema de los Estados Unidos), defendida en THEL, "The Original”, cit. nota $n^{\circ} 15$, esp. pp. 388-394. Si bien esa concepción alternativa propone una lectura de la $\$ 10$ b más generosa para con los poderes reguladores de la SEC - sosteniendo que mediante ella se propiciaba no tanto la regulación de la manipulación en sentido estricto, como la regulación del uso de dispositivos manipulativos (aún si se empleados de buena fe) -, de ella no pueden desprenderse argumentos que contradigan en lo fundamental lo defendido aquí, cuanto más si la tesis central de Thel apunta a hacer ver que la preocupación del legislador del '34 coincidía con la tutela de 
Polít. crim. Vol. 10, No 20 (Diciembre 2015), Art. 1, pp. 390-467.

[http://www.politicacriminal.cl/Vol_10/n_20/Vol10N20A1.pdf]

restringiendo significativamente su aplicabilidad, especialmente para fines indemnizatorios. De estas limitaciones, las más importantes son aquellas que (1) exigen la existencia de una conducta intencional (scienter), así como (2) la concurrencia de una forma de manipulación (manipulation) o de engaño (deceit), descartándose con ello la tipicidad de otras conductas igualmente perjudiciales, como por ejemplo la infracción de deberes fiduciarios en contextos de mala administración societaria; amén de exigirse (3) que aquellas modalidades de conducta se conecten causalmente a una operación de compra o venta de los respectivos valores (purchase-seller requirement; in connection with the purchase or sale of any security).

e) El art. 53 LMV y la Regla 10b-5. Conclusiones en el plano comparativo.

Llegados a este punto corresponde afrontar la pregunta acerca de si puede identificarse en la sección 10(b) de la $S E A$ '34 y su Regla 10b-5 algún patrón de referencia para el art. 53 LMV. La pregunta plantea dos órdenes de cuestiones, lógicamente diferenciables: en primer lugar, la pregunta acerca de si el tenor de la Regla 10b-5 pudo ser tenido a la vista o haber influido en la redacción de nuestro art. 53, particularmente de su inciso segundo; la segunda cuestión, seguramente más importante, corresponde a la pregunta acerca de si el art. 53 pudo ser concebido - en el texto original de la LMV - de modo que desempeñara una función comparable a la de la Regla 10b-5. Esta segunda cuestión puede también ser respondida desde una perspectiva presente, considerando las reformas sucesivas y evolución de la sistemática de la LMV. Por cierto esta última perspectiva es la que resulta de mayor importancia de cara a la aplicación del inciso segundo del art. 53.

Pues bien, comencemos por constatar que nuestra LMV no empleó en el art. 53 la técnica de delegación o ley en blanco sobre la que se basa la sección 10(b) de la SEA'34. En otras palabras, aún si se postulase que la LMV original quiso concebir el art. 53 particularmente su inciso segundo- como una fórmula amplia, comprensiva de toda forma de manipulación y fraude mediante engaño en el mercado de valores, lo que parece seguro es que no habría confiado para ello en una elaboración normativa de segundo orden, a cargo de la autoridad administrativa del sector ${ }^{207}$. Esto significa que el texto mismo de la LMV debería bastar para esos fines.

Una vez que nos concentramos en el solo tenor del art. 53 (especialmente de su inciso segundo), no es descartable que su redacción pueda haber tomado inspiración en el tenor de la Regla 10b-5. Cuanto menos habrá que constatar una "coincidencia" en determinados extremos. Por cierto, de la historia de la ley no puede obtenerse siquiera un argumento a favor de dicha inspiración, pero hay elementos en el inciso segundo de nuestro art. 53 que la reclaman. Así, el recurso a voces como acto, práctica, mecanismo, así como las ideas de fraude o engaño mancomunadas en un contexto disyuntivo, encuentran eco en la Regla 10b-5, específicamente en las hipótesis (a) y (c) de la misma. Por otra parte la Regla 10b-5

los precios como mecanismo de mercado, buscando así mediante la sección 10(b) “empoderar a la SEC para regular toda práctica que pudiera contribuir a la especulación con valores o que tendiera a alejar los precios de los instrumentos transados del valor de inversión" (THEL, "The Original", cit. nota $\mathrm{n}^{\circ} 15$, pp. 385-386).

${ }^{207}$ Como en cambio puede asumirse quiso el Congreso de los EE.UU a través de la sección 10(b), estando sobre todo a la reconstrucción histórica ofrecida por THEL, "The Original", cit. nota n 15 , pp. 385 y ss. 
LONDOÑO, Fernando. “Aproximación histórico-comparada al Título VIII de la Ley de Mercado de Valores: bases para el reconocimiento de un contenido anti-manipulativo".

da cobertura a hipótesis de fraude incluso respecto de instrumentos no listados en bolsas (OTC), aspecto sobre el que podría advertirse una coincidencia con el art. 53, dependiendo de la interpretación que se adopte en materia de objeto material ${ }^{208}$.

Con todo, las semejanzas (o coincidencias) sólo pueden extenderse hasta aquí. Hay en efecto muy buenas razones para afirmar que el art. 53 no fue diseñado para cumplir una función comparable a la que desempeña la Regla 10b-5 en su propio sistema. Las reformas legislativas sucesivas, así como la jurisprudencia administrativa y judicial, confirman esta idea. Con todo, pueden hallarse suficientes pruebas ya en el propio texto original de la LMV.

En primer lugar, debe reiterarse lo que ya se ha dicho sobre el art. 48 del proyecto original de LMV, y que más tarde daría lugar a los actuales arts. 52 y 53; a saber, que en el art. 48 del proyecto de ley original la modalidad comisiva consistente en "efectuar transacciones" servía como fórmula comprensiva de las manipulaciones operativas (trade based manipulation), no directamente cubiertas por el inciso que más tarde daría lugar al actual art. 52, el que se limitaba a regular el caso de las estabilizaciones lícitas. Nótese entonces que sólo a partir de la elaboración del art. 52 -sobre la base del inciso tercero del original art. 48- se produce una eventual redundancia ${ }^{209}$ en el plano de la cobertura de las manipulaciones operativas, abriendo así la pregunta acerca de si este "efectuar transacciones mediante mecanismos engañosos o fraudulentos" puede tener un sentido no anti-manipulativo, comprensivo de otra índole de conductas (como por ejemplo el fraude por engaño de que trata también la Regla 10b-5). Esa pregunta carecería de peso de cara al texto del proyecto de ley original de 1980, texto que, salvo modificaciones puntuales, se convertiría en la LMV de $1981^{210}$.

En seguida, si se quiere ver una inspiración en la Regla 10b-5, entonces resulta paradójico que la LMV se haya cuidado de tomar elementos de las entonces casi inexploradas hipótesis (a) y (c) de dicha Regla, pero no haya asimilado allí los contenidos de la hipótesis que, con mucho, había constituido desde su dictación el corazón de su vigencia real (es decir, la law in action). Ya desde la década del '50 la Regla 10b-5 -su hipótesis (b), para mayor precisión- estaba siendo fuertemente explorada en la praxis y siendo debatida en doctrina. Para 1980 se conocían ya algunos pronunciamientos decisivos de la Corte Suprema. Podría todavía argumentarse que justamente se quiso excluir el contenido de la "muy dilatable" hipótesis (b), pero con ello no se hace más que confirmar lo que aquí se sostiene. En efecto, si la LMV se cuidó de no contaminar el art. 53 con aquello que pudiera emparentarse al uso de información privilegiada $u$ otra forma de fraude $\mathrm{o}$ abuso

\footnotetext{
${ }^{208}$ Cfr. infra nota ${ }^{\circ} 215$. Una toma de posición detallada sobre el punto será materia de un artículo en proceso de publicación, aludido supra en nota $\mathrm{n}^{\circ} 10$.

209 Se dice "eventual” porque según se explicará más adelante, es posible dar con interpretaciones que eviten la redundancia: cfr. infra Conclusiones, reenviando en lo demás a artículo en proceso de publicación (véase supra nota $\left.\mathrm{n}^{\circ} 10\right)$.

${ }^{210} \mathrm{Si}$ se considera el contexto político y las instancias operativas para la dictación de leyes en el Chile de 1980/1981 - en ausencia de un Parlamento democráticamente elegido - se comprende entonces hasta qué punto el proyecto original de LMV - emanado del Ministerio de Hacienda - puede ser considerado determinante en la especie, particularmente para la identificación de la visión técnica dominante.
} 
Polít. crim. Vol. 10, No 20 (Diciembre 2015), Art. 1, pp. 390-467.

[http://www.politicacriminal.cl/Vol_10/n_20/Vol10N20A1.pdf]

informativo, entonces se confirmaría una vocación más bien restrictiva, que es precisamente aquella que aquí se ha defendido ${ }^{211}$.

Dejando de lado el siempre poco fértil terreno especulativo, una afirmación es segura, atendiendo a la sistemática de la LMV original de 1981; y es que la ley adoptó al menos dos decisiones por lo que toca a las conductas o fenómenos en principio subsumibles bajo una disposición como la Regla 10b-5 (sea que la haya tenido a la vista, sea que no la haya siquiera considerado al momento de dictarse la ley):

(1) Por lo que se refiere al uso de información privilegiada, como ya se ha dicho ${ }^{212}$, decidió regularla muy someramente en un contexto diferenciado (el art. 13 ubicado en el título III relativo a los deberes de información), previendo sólo un remedio compensatorio, sin contemplar tipologías penales o sancionatorias especiales para ese supuesto. El art. 53 no cumplió ningún rol regulador en lo pertinente. Lo anterior significa sostener que la LMV no vio en el abuso de información privilegiada un supuesto equiparable a una forma de fraude por engaño ( si es que ello hubiese estado en juego en el inciso segundo del art. 53!), a diferencia de lo que la praxis jurisprudencial federal estadounidense venía entonces afirmando al leer la Regla 10b-5. La praxis y la legislación posterior vendrían a confirmar esta visión. Es importante hacer presente que toda la doctrina nacional es coincidente en este sentido. Ni un solo autor de los varios que se han ocupado de aspectos sancionatorios de la LMV ha planteado o sugerido la posibilidad de que el art. 53 tuviese alguna injerencia en la prohibición del uso de información privilegiada ${ }^{213}$.

(2) Por lo que toca en cambio a las formas de abuso informativo expresamente descritas en la hipótesis (b) de la Regla 10b-5 (falsedad o engaño en comunicación de hechos esenciales), desde el comienzo la LMV dispuso de tipologías especiales -distintas al art. 53- para ponerles atajo y sancionarlas. En este contexto, deben citarse las hipótesis de falsedad informativa del original art. 58 (actual art. 59, especialmente la de la letra a], aunque también la letra d] original, relativa a los auditores). Con esta decisión se simplificaron notablemente los presupuestos de procedencia de estas formas de abuso. En efecto, al menos por lo que toca a la responsabilidad administrativa y penal, se prescinde de la acreditación del carácter manipulativo, engañoso o perjudicial del hecho, así como de cualquier elemento subjetivo correlativo, bastando la acreditación del carácter falso (doloso, por tanto) de la información emitida. Esta simplificación es encomiable en sede de tutela de la integridad informativa. Si en cambio se pretendiera reconducir estas hipótesis de falsedad informativa al inciso segundo del art. 53, las dificultades probatorias se incrementarían significativamente.

\footnotetext{
${ }^{211}$ De todo modos ello hablaría de una forma muy curiosa de inspiración en la Regla 10b-5: una que excluiría el contenido propio de la law in action, para limitarse a uno meramente textual. Desde esa óptica, más fácil habría sido excluir toda posibilidad de "crecimiento" hacia el abuso informativo u otras formas de fraude por engaño, evitando el uso de expresiones tan amplias como aquellas usadas en el inciso segundo del art. 53.

${ }^{212}$ Cfr. supra 1.3.2.b).

${ }^{213}$ Cfr. supra nota ${ }^{\circ} 187$, con referencia a una porción importante de la bibliografía chilena en materia de uso de información privilegiada.
} 
LONDOÑO, Fernando. “Aproximación histórico-comparada al Título VIII de la Ley de Mercado de Valores: bases para el reconocimiento de un contenido anti-manipulativo".

Para estar a un ejemplo concreto, considérese hasta qué punto sería diferente perseguir bajo el artículo 53 un supuesto de difusión de estados financieros falsos por un emisor. Ello supondría exigir adicionalmente la prueba del intento de inducción a la compra o venta de valores. Sin ir muy lejos, no en vano el caso "La Polar" se ha perseguido desde el comienzo por infracción a las hipótesis de falsedad informativa del art. 59 (letras a] y f], en su caso), sin que se haya planteado jamás una hipótesis filo-manipulativa como la del art. 53 LMV. Lo anterior hace pleno sentido: pretender ver o exigir una "inducción a la compra de las acciones de La Polar" para sólo entonces afirmar la tipicidad de hechos presuntamente consistentes en la emisión de estados financieros falsos ${ }^{214}$, es algo inconducente, contradictorio con la sistemática de la LMV.

En síntesis, reconducir las hipótesis de falsedad informativa a formas engañosas de inducción a la compra o venta de valores (art. 53.2) significaría, a la vez que un esfuerzo contradictorio con la sistemática de nuestra LMV, un debilitamiento de la protección hoy dispensada a favor de la integridad informativa en el mercado de valores ${ }^{215}$.

f) Una (todavía) posible lectura alternativa para el inc. $2^{\circ}$ del art. 53 LMV (además de una segunda lectura alternativa, aún más problemática).

En lo demás no resta sino decir que, si todo lo anterior no convence y se quiere de todos modos ver en el inciso segundo del art. 53 un eco del estatuto conformado por la Sección 10(b) y su Regla 10b-5, entonces debe tomarse dicha afirmación en serio y estudiar el alcance que a dicho complejo normativo se da en su contexto de origen. Justamente por esa razón en los anteriores apartados se ha ofrecido una exposición sintética sobre el punto. El estudio revela que si bien dichas disposiciones fueron diseñadas con una vocación extensiva, a modo de una normativa "catch-all" (atrapa-todo), lo capturado debe necesariamente ser manipulativo o constitutivo de fraude por engaño. En palabras de un comentarista que no puede ser motejado de restrictivo: "En su conjunto, la sección 10(b) y la regla 10b-5 constituyen disposiciones amplias, a modo de "atrapa-todo" fraude, pero naturalmente lo que capturan debe ser fraude ${ }^{216}$,

En este punto debe retomarse la doctrina sentada por la Corte Suprema en el caso Santa Fe, de $1977^{217}$. Allí, los accionistas de minoría demandaron la infracción de la Regla 10b-5 argumentando que la notable pérdida de valor de sus acciones en el contexto de una polémica operación de fusión decidida por los controladores constituía por sí misma un

\footnotetext{
${ }^{214}$ Por cierto lo anterior sin prejuzgar sobre el mérito del caso, actualmente pendiente de juicio.

215 Con todo, debe advertirse que una objeción plausible a lo aquí defendido puede surgir desde la consideración de los objetos materiales comprendidos en el art. 53 LMV. Así, las problemáticas referencias del art. 53 a las negociaciones privadas (como medio manipulativo de acuerdo al inc. $1^{\circ}$ ) o a valores no regidos por la $L M V$ (como objeto de la conducta en el inc. $2^{\circ}$ ). Esas referencias - sobre todo la segunda de ellas - podrían llevar a pensar que la esfera de protección se extiende más allá (o más acá) del mecanismo de formación de precios en mercado el regulado de oferta pública de valores. Una propuesta de solución interpretativa - refutando esta posible objeción - se ofrecerá en un artículo en proceso de publicación (véase supra nota $\mathrm{n}^{\circ} 10$ ), a propósito de la discusión sobre estos elementos en los respectivos incisos del art. 53.

${ }^{216}$ PRENTICE, "Scheme liability", cit. nota $\mathrm{n}^{\circ}$ 164, p. 360, apoyando su afirmación en pronunciamientos de la Corte Suprema en casos Chiarella (1980) y Ernst \& Ernst v. Hochfelder (1976)

${ }^{217}$ Santa Fe Industries, Inc. V. Green, 430 U.S. 462 (1977).
} 


\section{Polít. crim. Vol. 10, № 20 (Diciembre 2015), Art. 1, pp. 390-467. \\ [http://www.politicacriminal.cl/Vol_10/n_20/Vol10N20A1.pdf]}

fraude, en el sentido de la sección 10(b) y la citada regla. La Corte rechazó el argumento, sosteniendo que la operación no había sido engañosa ni manipulativa, y que por tanto no habría violado la normativa en cuestión. En este contexto la Corte Suprema agregaría que:

“el lenguaje de la sección 10b no da ninguna indicación en orden a que el Congreso hubiese tenido la intención de prohibir alguna conducta que no involucre manipulación [manipulation] o engaño [deception], así como tampoco se ha ofrecido evidencia en la historia legislativa que pueda justificar apartarse del tenor de la ley",218_ ${ }^{219}$.

Comentando precisamente el caso Santa Fe, otro autor desarrolla su análisis afirmando que:

“(..) de acuerdo a la Corte Suprema, demandas que sólo cuestionen la legitimidad [fairness] de las transacciones o bien una mala administración societaria [corporate mismanagement] han de relegarse al derecho estatal"220 [en oposición al derecho federal servido por la sección 10(b) y la Regla 10b-5].

Este mismo autor cierra su comentario a Santa Fe, concluyendo:

"Santa Fe es una de las decisiones más importantes que la Corte Suprema ha dictado en el área del derecho federal del mercado de valores. Si la decisión hubiese seguido otra dirección, una rica variedad de demandas por la infracción de deberes fiduciarios ocurridos en conexión con la compra o venta de un valor (...) habrían resultado accionables bajo la Sección 10(b). Santa Fe en cambio significa que una demanda federal bajo la Sección 10(b) debe alegar la existencia de manipulación o engaño"221 222 .

Pues bien, ¿qué resulta de todo esto y cómo influye en la lectura del inciso $2^{\circ}$ del art. 53 LMV?

No hace falta decir que una interpretación perfectamente plausible del art. 53 puede hacerse con total prescindencia de lo que sea que signifique el estatuto de la sección 10(b) y su Regla 10b-5. En otras palabras, para las voces "engañoso" y "fraudulento" del inciso segundo del art. 53 puede muy bien postularse un significado que nada tenga que ver con lo que se haya afirmado a propósito del alcance de términos comparables en la Regla $10 \mathrm{~b}-5 .^{223}$ Ahora bien, quien postule una interpretación extensiva del inciso $2^{\circ}$ del art. 53, inspirada en el aludido estatuto comparado, deberá hacer cuentas con el alcance de dicho estatuto en su

\footnotetext{
${ }^{218}$ Santa Fe Industries, Inc. V. Green, 430 U.S. 462 (1977), 473.

219 Sobre este punto, cfr. lo dicho supra en nota $\mathrm{n}^{\circ} 206$ sobre la concepción alternativa (a la restrictivadominante, impulsada por la Corte Suprema), defendida en THEL, "The Original", cit. nota $\mathrm{n}^{\circ} 15$, esp. pp. 388-394.

${ }^{220}$ STEINBERG, Understanding Securities, cit. nota ${ }^{\circ} 14$, p. 255.

${ }^{221}$ STEINBERG, Understanding Securities, cit. nota ${ }^{\circ}{ }^{14}$. p. 255.

${ }^{222}$ Como se ha dicho supra nota $\mathrm{n}^{\circ} 206$, incluso un autor como Steve Thel, que no comparte la lectura que la Corte Suprema de los EE.UU. ha hecho sobre la sección 10(b) y su Regla 10b-5, es enfático en señalar que la principal preocupación del legislador del '34 coincidía con la tutela de los precios como mecanismo de mercado, buscando mediante la sección 10(b) “empoderar a la SEC para regular toda práctica que pudiera contribuir a la especulación con valores o que tendiera a alejar los precios de los instrumentos transados del valor de inversión" (THEL, "The Original", cit. nota $\mathrm{n}^{\circ} 15$, pp. 385-386).

${ }^{223}$ El punto es desarrollado por el suscrito en un trabajo posterior: véase supra la nota $\mathrm{n}^{\circ} 10$.
} 
LONDOÑO, Fernando. “Aproximación histórico-comparada al Título VIII de la Ley de Mercado de Valores: bases para el reconocimiento de un contenido anti-manipulativo".

propia jurisdicción. Siendo así, en principio tendrá una mayor carga argumentativa quien postule que bajo el inciso $2^{\circ}$ del art. 53 LMV se prohíben no sólo conductas manipulativas de los precios-de-mercado o conductas de fraude connotadas de alguna forma de engaño a otro (en un contexto de interacción transaccional con valores), sino también conductas que sólo involucren administración desleal o cualquier otra forma de infracción de deberes fiduciarios (es decir, en ambos casos, conductas cuyo modus operandi no suponga el recurso a la manipulación de los precios o el engaño dirigido a otro, en un marco de autolesión).

En extrema síntesis: aquí se ha defendido que el artículo 53 -como un todo y leído en coordinación con el art. 52- constituye una fórmula estrictamente anti-manipulativa del mercado de valores y nada más. Una primera lectura alternativa -inspirada o no en la Regla 10b-5- podría sin embargo sugerir que el rendimiento del inciso segundo del art. 53 permite también alcanzar conductas de fraude cometido mediante engaño, propiciando así la prohibición bajo su seno de casos subsumibles en general bajo tipologías como las de estafa de inversión u otras que supongan abusos informativos asimilables al engaño, como por ejemplo las tipologías de falsedad informativa (como la de la letras a] del art. 59, por ejemplo). Como se ha dicho, esta (primera) lectura alternativa deberá hacer frente a la inconsistencia sistemática, ya denunciada supra. Con todo, aquella lectura alternativa será siempre más plausible que una segunda lectura alternativa, que postule derechamente la subsunción de supuestos en los que ya nada hay de engaño a otro o de falsedad informativa. Esta segunda lectura alternativa se vería necesitada de una fuerte carga argumentativa, que entre otras cosas explique cómo es que se propone para el inciso $2^{\circ}$ del art. 53 un alcance más amplio que el de la ya muy amplia Regla 10b-5.

\subsection{El derecho de la Unión Europea en materia de manipulación del mercado: Directiva 2003/6/CE y la nueva regulación de 2014 (Reglamento 2014/596/UE y Directiva 2014/57/UE).}

Corresponde ahora dar una rápida mirada a la legislación pertinente de cuño europeocomunitario (hoy Unión Europea). La utilidad de esta revisión difiere parcialmente de aquella que se esperaba del estudio de la legislación federal estadounidense. En efecto, no se postula alguna forma de influencia del derecho de europeo-comunitario por lo que toca a las figuras anti-manipulativas de nuestra LMV. Una elemental razón cronológica impediría un argumento semejante, pues la regulación europea-comunitaria pertinente data recién de $2003^{224}$, mientras que el Título VIII de la LMV halla su origen en 1981. Con todo, tener a la vista las disposiciones anti-manipulativas de la Unión Europea ofrece una ocasión incomparable para apreciar la pertinencia regulatoria de nuestro Título VIII LMV, así como aquí se ha propuesto interpretar.

Dado que bajo la más amplia rúbrica de "abusos de mercado" la normativa europea recurre de modo explícito al nomen iuris "manipulación del mercado", el contraste del derecho europeo con los arts. 52 y 53 de LMV se demostrará especialmente fecundo, una

\footnotetext{
${ }^{224}$ Por lo que toca a la manipulación del mercado de valores, se inaugura con la Directiva 2003/6/CE, aunque ya de 1989 data la primera Directiva en materia de Insider trading: Directiva 89/592 del Consejo de Europa para la coordinación de la normativa sobre Insider Trading, de 13 de noviembre de 1989.
} 
vez captadas las notables coincidencias de diseño normativo. Como ya se ha anticipado supra (II.3) esas coincidencias no pueden ser consideradas casuales, habida cuenta del terreno común desde el cual han brotado una y otra regulación, tenida especialmente en cuenta la influencia del estado de la cuestión en los EE.UU y, por su intermedio, también en el Reino Unido ${ }^{225}$.

Ciertamente no es éste el espacio indicado para ofrecer una reconstrucción sobre el fenómeno de la armonización europeo-comunitaria en materia de derecho del mercado de valores $^{226}$. Aquí bastará con decir que, por lo que se refiere a los abusos de mercado de valores, éste se inicia tímidamente en 1989 con una Directiva del Consejo Europeo limitada a la coordinación para la regulación del insider trading ${ }^{227}$, para luego tomar un impulso decisivo a partir de la Directiva del Parlamento Europeo y el Consejo de la Unión Europea sobre las operaciones con información privilegiada y la manipulación del mercado (abuso del mercado) 2003/6/CE, de 28 de enero de 2003, por cierto ya comprensiva de la manipulación de mercado. Esta Directiva constituyó la base de la estrategia de armonización europea del sector, la que incluyó un set de cuatro cuerpos de regulaciones emanadas de la Comisión Europea, complementarias de la Directiva 2003/6 228 . Las regulaciones "internas" de los países miembros de la Unión Europa obedecen hoy a las directrices de esa estrategia. En buena medida ello hace que no sea problemático obviar aquí el análisis de las distintas regulaciones internas de los países miembros, un análisis que excedería con mucho los propósitos del presente artículo ${ }^{229}$.

\footnotetext{
${ }^{225}$ Como hace ver Enrico Amati, "en su conjunto, la Directiva [2003/6/CE, base para la armonización europea en la especie, según se verá a continuación] refleja tendencias globales de la regulación del abuso de mercado, como lo demuestra la comparación con el derecho estadounidense en materia de insider trading y de market manipulation. También los principios de la Directiva hallan justificación en los estudios (principalmente estadounidenses) de derecho y finanzas, que ofrecen una ratio tanto para la regulación como para la armonización normativa" (AMATI, Enrico, Abusi di mercato e sistema penale, Torino: Giappichelli, 2012, p. 47). Por lo que se refiere al diseño general y a los conceptos empleados, una influencia del derecho de sector del Reino Unido (de la FSMA de 2000 principalmente) no puede tampoco descartarse: cfr. para captar ciertos puntos de comparación, AVGOULEAS, The Mechanics, cit. nota n ${ }^{\circ}$ 13, pp. 250 y ss., esp. pp. 276 y ss.

${ }^{226}$ Bastará con decir que la armonización del sector - hoy ya en camino hacia una auténtica unificación - fue en gran medida una respuesta obligada a la integración e internacionalización de los mercados de valores en Europa (así como a ciertos escándalos financieros que sacudieron a Europa y al mundo hacia fines de los '90) y que la estrategia fue diseñada a partir de la Comisión Lamfalussy sobre la base de un sistema de creación normativa modular-descendiente a cuatro niveles, comenzando por aquellos instrumentos de alcance general o marco (y de contenido más político), hasta aquellos detallados, de generación eminentemente técnica y en cuya elaboración tuvieron fuerte incidencia las autoridades administrativas del sector, agrupadas a nivel europeo (CESR y su sucesora ESMA). Una panorama detallado - aunque hoy ya desactualizado - puede hallarse en AVGOULEAS, The Mechanics, cit. nota ${ }^{\circ}$ 13, pp. 239 y ss. (cap. 6). Igualmente, cfr. AMATI, Abusi di mercato, cit. nota ${ }^{\circ} 225$, pp. 41 y ss.

${ }^{227}$ Directiva del Consejo 89/592 de 13 de noviembre de 1989.

${ }^{228}$ Directiva de la Comisión 2003/124/CE del 22 de diciembre de 2003 (en materia de definiciones de uso de información privilegiada y manipulación); Directiva de la Comisión 2003/125/CE del 22 de diciembre de 2003 (en materia de recomendaciones de inversión y revelación de conflictos de interés); Reglamento de la Comisión del 22 de diciembre de 2003 (en materia de buy-back programmes y estabilización) y la Directiva de la Comisión 2004/72/CE de 29 de abril de 2004 (en materia de prácticas de mercado aceptadas, entre otras materias).

${ }^{229}$ De todos modos se pueden indicar semejanzas importantes por lo que se refiere a la legislación vigente en el Reino Unido (secciones118 [5-7] y 397 de la FSMA 2000), Alemania (parag. 20a, 38 e 39 de la WpHG) e Italia (arts. 185 e 187 ter del t.u.f. d.lg. 58/1998)
} 
LONDOÑO, Fernando. “Aproximación histórico-comparada al Título VIII de la Ley de Mercado de Valores: bases para el reconocimiento de un contenido anti-manipulativo".

Por otra parte, el proceso de unificación europea en materia de abusos de mercado de valores conoció hace menos de un año -ya bajo la vigencia del Tratado de Lisboa- un último estadio de desarrollo, cuya implementación por los países miembros está aún pendiente. Nos referimos al Reglamento de la Unión Europea 596/2014/UE del Parlamento Europeo y del Consejo de la U.E., de 16 de abril de 2014 sobre el abuso de mercado (Reglamento sobre abuso de mercado) y la Directiva 2014/57/UE del Parlamento Europeo y del Consejo de la Unión Europea, de 16 de abril de 2014, sobre las sanciones penales aplicables al abuso de mercado (Directiva sobre abuso de mercado). En virtud del Reglamento 596/2014 se introduce una nueva regulación marco para el sector, a la vez que se derogan la Directiva 2003/6 y sus Directivas complementarias. Por su parte, la Directiva 2014/57 avanza en el proceso de homologación europea disponiendo derechamente exigencias de incriminación penal en la materia, siempre sobre la base de las definiciones y regulaciones contenidas en el Reglamento 596/2014. En cuanto a la definición de manipulación de mercado, el Reglamento 596 y la Directiva 57 de 2014 se ubican perfectamente en la línea trazada por la Directiva 2003/6, aunque innovan en determinados aspectos que en su momento se indicarán (cfr. infra 1.4.3). De todos modos, por corresponder al estado de desarrollo del derecho interno todavía vigente en los países miembros de la Unión Europea, la revisión de la regulación europea se basará principalmente en aquella contenida en la emblemática Directiva 2003/6.

En lo que sigue se reproducen las disposiciones pertinentes de la Directiva 2003/6/CE, para luego ofrecer observaciones muy sintéticas en un plano comparativo ${ }^{230}$. Para esos efectos se ha tenido a la vista la Guideline de tercer nivel CESR/04-505b, emanada del Comité de Reguladores Europeos de Valores (aglutinador de las autoridades de vigilancia del sector). Esta guía orienta sobre el tipo de conductas en principio subsumibles bajo cada hipótesis del art. 1.2 de la Dir. 2003/6. Debe aclararse en todo caso que, como la propia Guía indica $^{231}$, los ejemplos de eventual subsunción no descartan un eventual traslape, en la medida que una misma conducta pueda resultar subsumible bajo dos o más fórmulas antimanipulativas de la Dir. 2003/6.

Pues bien, en su art. $1^{\text {o }}$ la Dir. 2003/6 define manipulación de mercado en los siguientes términos:

“Artículo 1. A efectos de la presente Directiva, se entenderá por:

(...)

2) manipulación de mercado:

a) transacciones $u$ órdenes para realizar operaciones,

- que proporcionen o puedan proporcionar indicios falsos o engañosos en cuanto a la

oferta, la demanda o el precio de instrumentos financieros, $o$

- que aseguren, por medio de una persona o de varias personas que actúen de manera concertada, el precio de uno o varios instrumentos financieros en un nivel anormal o

\footnotetext{
${ }^{230}$ Para esos efectos se ha tenido también a la vista la Guideline de tercer nivel CESR/04-505b, parágrafos 4.10 ss., orientadora sobre el tipo de conductas en principio subsumibles bajo cada hipótesis del art. 1.2 de la Dir. 2003/6. Debe aclararse en todo caso que, como la propia Guía indica, los ejemplos de eventual subsunción no descartan un eventual traslape, en la medida que una misma conducta pueda resultar subsumible bajo dos o más fórmulas anti-manipulativas de la Dir. 2003/6.

${ }^{231}$ Cfr. CESR/04-505b, parag. 4.10 (véase supra nota ${ }^{\circ} 230$ ).
} 
Polít. crim. Vol. 10, No 20 (Diciembre 2015), Art. 1, pp. 390-467.

[http://www.politicacriminal.cl/Vol_10/n_20/Vol10N20A1.pdf]

artificial, a menos que la persona que hubiese efectuado las transacciones o emitido las órdenes para realizar operaciones demuestre la legitimidad de sus razones y que éstas se ajustan a las prácticas de mercado aceptadas en el mercado regulado de que se trate; b) transacciones u órdenes de realizar operaciones que empleen dispositivos ficticios o cualquier otra forma de engaño o maquinación;

c) difusión de información a través de los medios de comunicación, incluido Internet, o a través de cualquier otro medio, que proporcione o pueda proporcionar indicios falsos o engañosos en cuanto a los instrumentos financieros, incluida la propagación de rumores y noticias falsas o engañosas, cuando la persona que las divulgó supiera o hubiera debido saber que la información era falsa o engañosa. Con respecto a los periodistas que actúen a título profesional, dicha divulgación de información se evaluará, sin perjuicio del artículo 11, teniendo en cuenta las normas que rigen su profesión, a menos que dichas personas obtengan directa o indirectamente una ventaja o beneficio de la mencionada difusión de información".

\subsubsection{Aspectos generales del art. 1.2) de la Directiva 2003/6/CE.}

La simple lectura revela un marcado "parecido de familia" con las fórmulas antimanipulativas que hasta aquí han sido objeto de estudio, tanto del derecho federal estadounidense como del derecho nacional.

En términos generales, puede decirse que el diseño normativo se apoya fuertemente en descriptores objetivos -representativos de un impacto en los precios (artificiales, por tanto) o en los medios idóneos para lograr dicho impacto-, eludiéndose la caracterización intent based (el recurso a la intención manipulativa) que, como vimos, está presente en el derecho federal estadounidense. No puede sorprender entonces que la Directiva 2003/6 se cuide de no recurrir a la conocida fórmula de "inducción a la compra o venta", característica de la faz subjetiva de la sección 9(a)(2) de la SEA'34. Por su parte, en la estrategia descriptiva de las fórmulas anti-manipulativa de la Directiva se aprecia una coincidencia con la estrategia dominante en el art. 53 de nuestra LMV (no así por lo que toca al art. 52 LMV, en el que, como ya se ha dicho, se aprecia una caracterización intent based).

Dos de las tres hipótesis de la Directiva 2003/6 suponen la realización de transacciones como modalidad comisiva, mientras una tercera fórmula se reserva para la manipulación puramente informativa.

1.4.2. Las tres hipótesis del art. 1.2) de la Directiva 2003/6/CE.

La fórmula (a) coincide con la categoría central de manipulación de los precios de valores de tipo trade based $^{232}$. Ella se descompone a su vez en dos variantes.

La primera variante -transacciones $u$ órdenes para realizar operaciones que proporcionen o puedan proporcionar indicios falsos o engañosos en cuanto a la oferta, la demanda o el precio de instrumentos financieros- ofrecería un marco para acoger aquellas transacciones que, estando a nuestro art. 53.1 LMV o a la sección 9(a)(1) de la SEA'34, habríamos de considerar ficticias, en cuanto idóneas para dar la apariencia de un mercado activo sobre un

${ }^{232}$ Cfr. AVGOULEAS, The Mechanics, cit. nota ${ }^{\circ}$ 13. pp. 276 y ss. 
LONDOÑO, Fernando. “Aproximación histórico-comparada al Título VIII de la Ley de Mercado de Valores: bases para el reconocimiento de un contenido anti-manipulativo".

determinado título; precisamente: indicios falsos sobre la oferta, demanda o precio del instrumento. De acuerdo a la Guideline CESR/04-505b, aquí serían subsumibles las washtrades e improper matched-orders, en principio equivalentes a aquellas descritas en la sección 9(a)(1) de la SEA'34. Siempre de acuerdo la Guideline de la CESR, aquí también tendría cabida una hipótesis como la painting the tape ${ }^{233}$, que puede considerarse subsumible bajo la voz cotizaciones ficticias de nuestro art. 53.1. LMV. De cualquier modo, descontando la faz subjetiva (el propósito inductivo), hay también importantes semejanzas con el tenor de la sección 9(a)(2) de la SEA'34: nótese que los indicios falsos sobre la oferta o demanda de instrumentos financieros se acercan a la creación de un aparente mercado activo del derecho federal estadounidense.

La segunda variante de la fórmula (a) -transacciones $u$ órdenes para realizar operaciones que aseguren, por medio de una persona o de varias personas que actúen de manera concertada, el precio de uno o varios instrumentos financieros en un nivel anormal o artificial- caracteriza a aquellas modalidades de fijación o alteración de los precios operativas directamente mediante transacciones disruptivas, a través del ejercicio de un poder de mercado u otra modalidad de conducta que no necesariamente suponga formas de engaño (inducción) a intervinientes en el mercado (manipulaciones operativas propias) ${ }^{234}$. Por asegurar el precio ha de tenderse la fijación o determinación del precio-de-mercado y no el mero acuerdo sobre el precio que haya de pagarse en una determinada operación. No en vano la guía $C E S R$ coloca aquí hipótesis de manipulación por vía de abuso de una posición dominante en mercados de futuro y derivados (abusive squeeze, muy conocido en la literatura especializada) ${ }^{235}$, así como la fijación de precios al cierre (marking the close $^{236}$. En relación con esta variante, un paralelo puede trazarse con las hipótesis de fijación de precios de la sección 9(a)(6) de la SEA'34, así como con el inciso $1^{\circ}$ del art. 52 LMV.

Precisamente en este contexto es que debe ubicarse la necesidad de una cláusula de autorización como la que cierra la hipótesis (a) en comento, o como la que se encuentra en el art. 8 de la Directiva 2003/6. En efecto, recuérdese que las variantes recién citadas constituyen manipulación proscrita, a menos que la persona que hubiese efectuado las transacciones o emitido las órdenes para realizar operaciones demuestre la legitimidad de sus razones y que éstas se ajustan a las prácticas de mercado aceptadas en el mercado regulado de que se trate. Por su parte, el art. 8 de la Dir. 2003/6 dispone que:

"Las prohibiciones establecidas en la presente Directiva no se aplicarán a las operaciones con acciones propias en programas de recompra ni a la estabilización de un instrumento financiero, siempre que la operación se realice de acuerdo con las medidas de ejecución adoptadas de conformidad con el procedimiento mencionado en (...)".

\footnotetext{
${ }^{233}$ CESR 04/505b, 4.11 (véase supra nota $\mathrm{n}^{\circ} 230$ ): “b) Painting the tape. This practice involves engaging in a transaction or series of transactions which are shown on a public display facility to give the impression of activity or price movement in a financial instrument".

${ }^{234}$ Cfr. AVGOULEAS, The Mechanics, cit. nota ${ }^{\circ} 13$. pp. 276 y ss.

235 Cfr. CESR 04/505b (véase supra nota $\mathrm{n}^{\circ} 230$ ). Igualmente, cfr. PIRRONG, "Commodity Market Manipulation", cit. nota $\mathrm{n}^{\circ} 52$ y MARKHAM, "Manipulation of Commodity", cit. nota $\mathrm{n}^{\circ} 52$.

${ }^{236}$ CESR 04/505b (véase supra nota ${ }^{\circ} 230$ ).
} 
Ciertamente estos pasajes revelan una solución en sintonía con la regulación que exceptúa del régimen de manipulaciones prohibidas determinadas transacciones inspiradas en el legítimo interés del mercado. En este contexto encontramos las estabilizaciones, entre otras prácticas de mercado aceptadas. El sistema europeo desarrolla detalladamente estos regímenes de autorización en el Reglamento de la Comisión del 22 de diciembre de 2003 (en materia de buy-back programmes y estabilización) y la Directiva de la Comisión 2004/72/CE de 29 de abril de 2004 (en materia de prácticas de mercado aceptadas). En cuanto a lo que específicamente atañe a la estabilización, ya se ha visto que el legislador federal estadounidense la enfrenta a través de su Regulation $M$, conforme a la técnica que anticipa la propia sección 9(a)(6) de la SEA'34. En cuanto a nuestra LMV, también se aludió ya al fundamento del inciso segundo del art. 52, coincidente también con la necesidad de autorizar determinadas estabilizaciones en el mercado primario.

La fórmula b) del art. 1.2 de la Directiva 2003/6 - transacciones u órdenes de realizar operaciones que empleen dispositivos ficticios o cualquier otra forma de engaño o maquinación - se asemeja en su capacidad de alcance a la primera variante de la letra a), hasta el punto que no es fácil delimitar sus alcances. Esto es así porque ambas figuras apuntan en la misma dirección pero desde puntos de vista descriptivos diferenciados: mientras la primera variante de la letra a) recurre a la cualidad del output o resultado de la conducta (los indicios falsos o engañosos en cuanto a la oferta, demanda o precio), la fórmula b] que aquí nos ocupa se basa en la descripción de la cualidad del input: el empleo de dispositivos ficticios o de otras formas de engaño o maquinación. Parece natural asumir que esos mismos inputs o dispositivos -en cuanto ficticios o engañosos- tenderán a producir outputs o indicios falsos en el mercado, ya sea en la demanda, la oferta o el precio. Se trataría por tanto de dos estrategias descriptivas para abarcar un mismo universo de casos. De acuerdo a la CESR tipologías manipulativas como la pump and dump ${ }^{237}$, su figura inversa de trash and $\operatorname{cash}^{238}$ o el scalping ${ }^{239}$-con su fuerte componente informativose ubicarían en el radio de la fórmula en comento. Los dos primeros representan casos centrales en la casuística de la manipulación, mientras que todos ellos suponen una intrínseca intención manipulativa de los precios. No puede sorprender que estas mismas tipologías puedan también reconducirse a la primera variante de la letra a), considerando además la advertencia efectuada por la propia CESR sobre un posible traslape.

\footnotetext{
${ }^{237}$ CESR 04/505b, parag. 413 c) (véase supra nota $\mathrm{n}^{\circ} 230$ ): "Pump and dump. This practice involves taking a long position in a security and then undertaking further buying activity and/or disseminating misleading positive information about the security with a view to increasing the price of the security. Other market participants are misled by the resulting effect on price and are attracted into purchasing the security. The manipulator then sells out at the inflated Price"

${ }^{238}$ CESR 04/505b, parag. 413 d) (véase supra nota n²30): “'Trash and cash'. This is the opposite of pump and dump. A party will take a short position in a security; undertake further selling activity and/or spread misleading negative information about the security with the purpose of driving down its price. The manipulator then closes their position after the price has fallen."

${ }^{239}$ CESR 04/505b, parag. 413 b) (véase supra nota $\mathrm{n}^{\circ} 230$ ): "Dissemination of false or misleading market information through media, including the internet, or by any other means (in some jurisdictions this is known as 'scalping'). This is done with the intention of moving the price of a security, a derivative contract or the underlying asset in a direction that is favourable to the position held or a transaction planned by the person disseminating the information."
} 
LONDOÑO, Fernando. “Aproximación histórico-comparada al Título VIII de la Ley de Mercado de Valores: bases para el reconocimiento de un contenido anti-manipulativo".

En fin, no puede pasarse por alto hasta qué punto el texto de la letra b) resulta comparable a la primera parte del inciso $2^{\circ}$ de nuestro art. 53 LMV. En efecto:

\begin{tabular}{|l|l|}
\hline Hipótesis b) del art. 1.2 Directiva 2003/6/CE & \multicolumn{1}{c|}{ Primera parte del art. 53.2 LMV } \\
\hline $\begin{array}{l}\text { "Se entenderá por manipulación de mercado: }(\ldots) \\
\text { (b) transacciones u órdenes de realizar } \\
\text { operaciones que empleen dispositivos ficticios o } \\
\text { cualquier otra forma de engaño o maquinación” }\end{array}$ & $\begin{array}{l}\text { "Ninguna persona podrá efectuar transacciones } \\
\text { mecanismo o artificio engañoso o fraudulento". }\end{array}$ \\
\hline
\end{tabular}

En cuanto a la fórmula c), ella se dirige a las manipulaciones informativas. Con todo, la descripción es tan amplia -en cuanto prescinde de una alusión a una específica idoneidad manipulativa o bien, en compensación, a una intención manipulativa- que bien podría dar cobertura a hipótesis de mera falsedad societaria, así como a hipótesis de fraude de inversión, principalmente en el mercado primario. Es precisamente éste un punto en el que la nueva regulación europea de 2014 resulta más enfocada que su antecesora de 2003, en la medida que introduce como objeto de la falsedad las variables de mercado que inciden en los precios, ofreciendo además como alternativa la idoneidad de la información para determinar un nivel anormal o artificial de los precios ${ }^{240}$.

Aunque se aprecia una técnica claramente distinta, paralelos con la regulación de 2003 pueden trazarse con las figuras de manipulación informativa del derecho federal estadounidense: hipótesis (3), (4) y (5) de la Sección 9(a) SEA'34 y la hipótesis (b) de la Regla 10b-5 en relación a la Sección 10(b) SEA'34. Por lo que toca a nuestra LMV, ya se ha dicho que la fórmula de "inducción" del art. 53.2 es lo suficientemente amplia como para contener toda manipulación informativa (como por lo demás el propio caso Schwager lo ha demostrado $)^{241}$. De todos modos, hay una coincidencia notoria con el art. $61 \mathrm{LMV}$, inequívocamente de valencia manipulativa. Paralelos con las demás formas de falsedad del art. 59 LMV pueden trazarse justamente dada la apertura descriptiva de la hipótesis c) en comento.

\subsubsection{La nueva regulación de la Unión Europea: Reglamento 2014/596/UE y Directiva} 2014/57/UE.

No resta más que dar una rapidísima mirada a las reformas del sector a partir de las regulaciones de 2014. Por ser más amplia - no limitada a la sola esfera penal- nos concentraremos en el Reglamento 596/2014/UE antes que en la Directiva 57/2014/UE ${ }^{242}$.

\footnotetext{
${ }^{240}$ En efecto, en el art. 12 del Reglamento UE de 2014/596 se lee: “c): difundir información a través de los medios de comunicación, incluido internet, o por cualquier otro medio, transmitiendo así o pudiendo transmitir señales falsas o engañosas en cuanto a la oferta, la demanda o el precio de un instrumento financiero, de un contrato de contado sobre materias primas relacionado o de un producto subastado basado en derechos de emisión, o pudiendo así fijar en un nivel anormal o artificial el precio de uno o varios instrumentos financieros, de un contrato de contado sobre materias primas relacionado o de un producto subastado basado en derechos de emisión, incluida la difusión de rumores, cuando el autor de la difusión sepa o debiera saber que la información era falsa o engañosa;"

${ }^{241}$ Cfr. infra Conclusiones; ulterior desarrollo en artículo en proceso de publicación (véase supra nota n 10 ).

${ }^{242}$ Cuyo artículo $5^{\circ}$ define manipulación de mercado, bajo un presupuesto de exigencia de incriminación, complementado por el artículo $6^{\circ}$ con la descripción de la incitación, complicidad y tentativa.
} 
Como señala su artículo $1^{\text {o }}$, el Reglamento 596/204 “establece un marco normativo común en el ámbito de las operaciones con información privilegiada, la comunicación ilícita de información privilegiada y la manipulación de mercado (abuso de mercado), así como medidas para impedir el abuso de mercado a fin de garantizar la integridad de los mercados financieros de la Unión y reforzar la protección de los inversores y su confianza en esos mercados". Es en el art. 12 del Reglamento 596 donde se contiene el concepto de manipulación de mercado. Como se apreciará, la similitud con el texto del art. 1.2) de la Directiva 2003/6 es patente y en ningún caso las modificaciones introducidas en el nuevo régimen alteran el sentido estrictamente anti-manipulativo de la regulación europea entonces vigente. Se anotarán abajo algunas de las principales diferencias entre los textos, aunque debe anticiparse desde ya que ellas no importan un giro sustantivo en la posición sentada por la normativa de 2003.

Pues bien, en el Reglamento 596/2014/UE se lee:

"Artículo 12. Manipulación de mercado

1. A efectos del presente Reglamento, la manipulación de mercado incluirá las siguientes actividades:

a) ejecutar una operación, dar una orden de negociación o cualquier otra conducta que:

i) transmita o pueda transmitir señales falsas o engañosas en cuanto a la oferta, la demanda o el precio de un instrumento financiero o de un contrato de contado sobre materias primas relacionado con él, o bien

ii) fije o pueda fijar en un nivel anormal o artificial el precio de uno o varios instrumentos financieros $\mathrm{o}$ de un contrato de contado sobre materias primas relacionado con ellos,

a menos que la persona que hubiese efectuado la operación o dado la orden de negociación o realizado cualquier otra conducta demuestre que esa operación, orden o conducta se han efectuado por razones legítimas y de conformidad con una práctica de mercado aceptada con arreglo a lo dispuesto en el artículo 13;

b) ejecutar una operación, dar una orden de negociación o cualquier otra actividad o conducta que afecte o pueda afectar, mediante mecanismos ficticios o cualquier otra forma de engaño o artificio, al precio de uno o varios instrumentos financieros, de un contrato de contado sobre materias primas relacionado o de un producto subastado basado en derechos de emisión;

c) difundir información a través de los medios de comunicación, incluido internet, o por cualquier otro medio, transmitiendo así o pudiendo transmitir señales falsas o engañosas en cuanto a la oferta, la demanda o el precio de un instrumento financiero, de un contrato de contado sobre materias primas relacionado o de un producto subastado basado en derechos de emisión, o pudiendo así fijar en un nivel anormal o artificial el precio de uno o varios instrumentos financieros, de un contrato de contado sobre materias primas relacionado o de un producto subastado basado en derechos de emisión, incluida la difusión de rumores, cuando el autor de la difusión sepa o debiera saber que la información era falsa o engañosa; d) transmitir información falsa o engañosa o suministrar datos falsos en relación con un índice de referencia, cuando el autor de la transmisión o del suministro de datos supiera o debiera haber sabido que eran falsos o engañosos, o cualquier otra conducta que suponga una manipulación del cálculo de un índice de referencia." 
LONDOÑO, Fernando. “Aproximación histórico-comparada al Título VIII de la Ley de Mercado de Valores: bases para el reconocimiento de un contenido anti-manipulativo".

Las diferencias más notables que esta definición de manipulación presenta respecto de su antecesora de 2003 son las siguientes. En primer lugar, una ampliación en las hipótesis a) y b) hacia "cualquier otra actividad o conducta", con lo cual se zanja toda duda sobre la inclusión de actividades manipulativas realizadas fuera del mercado (action based manipulation). En seguida, la inclusión de los contratos de contado sobre materias primas como objeto, junto a los demás instrumentos financieros ${ }^{243}$. La incorporación de una nueva hipótesis (d) directamente relativa a la manipulación de los índices de referencia, lo que se explica en cuanto su alteración se ubica en la misma ratio que la manipulación de los precios subyacentes. En fin, una comparativamente mayor precisión en la descripción de las hipótesis (b) y (c), por la vía de la incorporación de elementos alusivos a una idoneidad manipulativa de los precios.

\subsubsection{Conclusiones.}

Las coincidencias de diseño normativo entre la regulación europea y la nacional demuestran que, si por una parte es segura la finalidad anti-manipulativa del legislador europeo de 2003 y de $2014^{244}$, no es menos segura la finalidad con la cual se redactó en 1981 el Título VIII de nuestra LMV: ya entonces había razonable claridad en la literatura del sector y en el derecho comparado sobre en qué consistía la manipulación del mercado en lo fundamental, y cuáles eran las principales conductas que bajo dicha nomenclatura habían de prohibirse y sancionarse.

\section{La mecánica de la manipulación y su vinculación con las fórmulas descriptivas de derecho positivo (nacional y comparado).}

En otro trabajo se ha abordado esta temática con una considerable extensión ${ }^{245}$. Aquí bastará con dar cuenta de aquellos aspectos que puedan ser de mayor rendimiento en sede de interpretación de nuestro derecho positivo, en cuanto clarificadores del porqué de ciertas fórmulas descriptivas recurrentes.

\subsection{Tipos de manipulación atendiendo a la conducta externa.}

Si se atiende a la dimensión externa de la conducta manipulativa, ésta parece poderse reconducir a tres tipos de actividades ${ }^{246}$ :

(1) Actividades transaccionales realizadas en el mercado mismo, consistentes en negociaciones con valores (mismas que pueden afectar los precios por sí mismas o bien a través de su injerencia en la percepción de terceros participantes en el mercado). En este caso se habla de manipulación operativa o trade-based manipulation ${ }^{247}$.

\footnotetext{
243 Para detalles, véase el art. $2^{\text {o }}$ del Reglamento 596/2014.

244 Tan segura como que emplea el propio nomen iuris en todas las instancias regulatorias.

${ }^{245}$ Cfr. LONDOÑO, "Ilícito de manipulación”, cit. nota ${ }^{\circ} 1$, pp. 64-127.

246 Una clasificación tripartita que puede remontarse al trabajo de ALLEN/GALE, "Stock-Price Manipulation", cit. nota $n^{\circ} 78$. Cfr. en igual sentido, ESTRADA, "Alteración de precios", cit. nota n 14 , p. 16.

${ }^{247}$ Considérese el caso de las meras órdenes o bien las transacciones no ejecutadas: desde el punto de vista mecánico serían más bien informativas.
} 
Polít. crim. Vol. 10, No 20 (Diciembre 2015), Art. 1, pp. 390-467.

[http://www.politicacriminal.cl/Vol_10/n_20/Vol10N20A1.pdf]

a. Así, por ejemplo, quien sin contar con una razón de inversión legítima, vende cantidades disruptivamente significativas de un determinado valor en la proximidad al cierre del día o del año calendario, logrando con ello condicionar (a la baja) el precio de referencia del respectivo cierre.

b. Igualmente quien realiza transacciones a precios crecientes, desde dos cuentas bajo su titularidad o bien con una parte relacionada, con el propósito de llamar la atención al mercado sobre la actividad bursátil del título, induciendo así al mercado a adquirir los títulos en cuestión (mismos que el agente posee y que luego vende una vez que el precio se ha elevado producto de las compras realizadas por los terceros inducidos).

(2) Actividades directamente informativas, consistentes en la transmisión de información (en principio falsa o engañosa) relativa a los valores, el emisor o el mercado en general, en cuanto idónea para influir en la respectiva cotización. En este caso se habla de manipulación informativa o information-based manipulation.

a. Así, por ejemplo, el representante del emisor que informa como hecho esencial al mercado que ha adquirido una exclusiva patente para incrementar y mejorar la calidad del tipo de producción que constituye su giro principal (en circunstancias que ello no es efectivo).

(3) Actividades realizadas fuera del mercado, consistentes en hechos que por sí mismos tienen capacidad para influir en la cotización de los valores. Esta forma coincide con la manipulación mediante actividades o action-based manipulation (también conocida como manipulación de hecho $)^{248}$.

a. Así, por ejemplo, el representante del emisor que procede a cerrar una determinada planta de producción, para reabrirla pasados unos días, una vez que mediante esa acción - en cuanto viene a hacerse pública - ha conseguido una baja en el precio de las acciones del emisor (efecto que buscaba porque, por ejemplo, tenía la intención de aumentar su participación en la empresa). Nótese que para decidir cerrar la planta el representante en cuestión no tenía justificación racional alguna (fuera de aquella manipulativa).

\subsection{Tipos de manipulación atendiendo a la dimensión funcional de la conducta (injerencia directa e indirecta).}

Ahora bien, mucho más importante para efectos típicos-positivos es una segunda clasificación de las manipulaciones, atendiendo al mecanismo operativo en la conducta; esto es, atendiendo a la dimensión funcional-interna de la conducta. Esto supone la identificación del mecanismo a través del cual se logra o aspira a lograr el movimiento en el precio, característico de la manipulación. Pues bien, desde este punto de vista aparecen básicamente dos mecanismos manipulativos, mismos que suelen reflejarse en las caracterizaciones de derecho comparado:

(1) Mecanismo directo, mecánico-transaccional (mecánica de mercado o poder de mercado): en esta categoría se ubican las manipulaciones que operan sobre el precio directamente, ya por la mecánica del mercado -con base a transacciones disruptivas, que operan sobre la oferta y la demanda (ej. manipulación del cierre o marking the

${ }^{248}$ Cfr. ESTRADA, “Alteración de precios”, cit. nota n 14 , p. 16. 
LONDOÑO, Fernando. “Aproximación histórico-comparada al Título VIII de la Ley de Mercado de Valores: bases para el reconocimiento de un contenido anti-manipulativo".

close)- ya por el ejercicio abusivo de un poder de mercado (acaparamiento, contracción de la oferta), característico en los mercados de derivados, en los que el manipulador se hace con un stock suficiente de los objetos subyacentes como para condicionar el precio de los respectivos valores (ej. abusive squeeze).

Bajo esta rúbrica sólo pueden subsumirse casos de manipulación operativa o tradebased manipulation (a la que se agrega aquí la calificación de propia para representar esta cualidad $=$ manipulación operativa propia). Las manipulaciones informativas nunca pueden operar directamente sobre los precios.

a. Ejemplo: letra a) del ofrecido arriba en 2.1.(1), como característico de las manipulaciones operativas propias.

(2) Mecanismo indirecto, inductivo (formas de engaño): en esta categoría se ubican las manipulaciones que operan mediante una injerencia en la conducta de inversionistas activos en el mercado. La injerencia se realiza mediante alguna forma de engaño, típicamente representada por la directa difusión de información (falsa), pero también mediante transacciones que condicionan las apreciaciones del mercado (por ejemplo creando una apariencia de mercado activo, etc.). Todo ello supone una forma de interacción en un plano de causalidad psíquica.

Bajo esta rúbrica se ubican todas las formas de manipulación informativa, la manipulación ejecutada mediante actividades fuera del mercado (action-based), así como aquellas manipulaciones operativas que actúan mediante la creación de una determinada apariencia de mercado o que en cualquier caso están connotadas de valencia engañadora (manipulación operativa impropia). Evidentemente la fórmula positiva de "inducción a la compra o venta de valores" ofrece cobertura a este amplio rango de manipulaciones.

a. Ejemplo: mismos ofrecidos arriba en 2.1. (2) y (3), como característicos de las manipulaciones informativas y action-based.

b. Ejemplo: letra b) del ofrecido arriba en 2.1.(1), como característico de las manipulaciones operativas impropias.

\subsection{Vinculación con las fórmulas descriptivas en el derecho positivo (nacional y comparado).}

La clasificación anterior se presta muy bien para establecer una conexión con las fórmulas descriptivas de derecho positivo.

a) Por lo que se refiere a las manipulaciones que operan mediante un mecanismo directo, a su cobertura apuntan normalmente aquellas fórmulas descriptivas que aluden a la fijación de los precios u otra forma de alteración de los precios sin recurso a alguna calificante medial. Nuestro art. 52 responde sin duda a este tipo de caracterización, así como también lo hace la hipótesis (6) de la sección 9(a) de la SEA'34. Por lo que toca a Europa, al mismo cuño responde la segunda hipótesis de la letra a) del art. 1.2 Dir. 2003/6/CE (o bien la letra a] del art. 12 del Reglamento 2014/596/UE).

Ejemplos de derecho positivo ya analizado: 
Polít. crim. Vol. 10, No 20 (Diciembre 2015), Art. 1, pp. 390-467.

[http://www.politicacriminal.cl/Vol_10/n_20/Vol10N20A1.pdf]

LMV, Art. 52. "Es contrario a la presente ley efectuar transacciones en valores con el objeto de estabilizar, fijar o hacer variar artificialmente los precios".

SEA'34 §9(a)(6): "Efectuar, ya sea solo o con una o más personas cualquier serie de transacciones para la compra y /o venta de cualquier valor distinto a uno emitido por el gobierno, con el propósito de fijar, mantener o estabilizar el precio de aquel valor, en contravención a las normas y regulaciones que la Comisión [SEC] pueda dictar, en cuanto necesarias o apropiadas para el interés público o para la protección de los inversores".

Reglamento UE 2014/596, Art.12 (a).ii: "ejecutar una operación, dar una orden de negociación o cualquier otra conducta que (...)"transacciones u órdenes para realizar operaciones, (...) que aseguren, por medio de una persona o de varias personas que actúen de manera concertada, el precio de uno o varios instrumentos financieros en un nivel anormal o artificial."

b) Por lo que se refiere a las manipulaciones que operan mediante un mecanismo indirecto, es muy claro que la fórmula positiva alusiva a la "inducción a la compra o venta de valores" (que se observa en nuestro art. 53.2 LMV, pero también en la sección 9(a)(2) de la SEA'34) es especialmente eficaz en la cobertura del amplio rango de manipulaciones que operan mediante un mecanismo indirecto, sobre la base de alguna forma de engaño. Otras fórmulas descriptivas aluden al carácter ficticio de las transacciones (art. 53.1 LMV), a la creación de apariencias falsas o engañosas de mercado mediante la realización de transacciones ficticias (\$9[a][1]SEA’34) o a la realización de transacciones con el empleo de mecanismos o dispositivos engañosos (art.53.2 LMV o letra b] del art. 1.2 de la Directiva 2003/6/CE). En lo demás, es evidente que también las fórmulas que aluden directamente al uso de información falsa (inductiva) se ubican en este círculo (el art. 61 LMV sería un ejemplo).

Ejemplos de derecho positivo ya analizado:

LMV, Art. 53 inciso segundo: "Ninguna persona podrá efectuar transacciones o inducir o intentar inducir a la compra o venta de valores, regidos o no por esta ley, por medio de cualquier acto, práctica, mecanismo o artificio engañoso o fraudulento".

SEA'34, §9(a)(2) “Efectuar, solo o con una o más personas distintas, una serie de transacciones sobre cualquier valor registrado en una bolsa nacional o en relación a cualquier acuerdo swap basado en un valor de ese tipo, creando un mercado activo real o aparente para ese valor, o bien elevando o deprimiendo el precio de ese valor, con el propósito de inducir a la compra o venta de tal valor por otros."

Dir. 2003/6/CE, Art.1.2) b) : "transacciones u órdenes de realizar operaciones que empleen dispositivos ficticios o cualquier otra forma de engaño o maquinación;

LMV, Artículo 53. Inciso primero: "Es contrario a la presente ley efectuar cotizaciones o transacciones ficticias respecto de cualquier valor (...)"

SEA'34, §9(a)(1) “Con el propósito de crear una apariencia falsa o engañosa de negociación activa en cualquier valor registrado en una bolsa de valores nacional, o una 
LONDOÑO, Fernando. “Aproximación histórico-comparada al Título VIII de la Ley de Mercado de Valores: bases para el reconocimiento de un contenido anti-manipulativo".

apariencia falsa o engañosa con respecto al mercado de un valor semejante, (...) efectuar cualquier operación con semejante valor, que no implique un cambio en la titularidad beneficiada por ella $(\ldots)$ "

Dir. 2003/6/CE, Art.1.2) (a): "transacciones u órdenes para realizar operaciones, (...) que proporcionen o puedan proporcionar indicios falsos o engañosos en cuanto a la oferta, la demanda o el precio de instrumentos financieros (...)"

LMV, Art. 61. "El que con el objeto de inducir a error en el mercado de valores difunda información falsa o tendenciosa, aun cuando no persiga con ello obtener ventajas o beneficios para sí o terceros (...)”.

\section{Conclusiones.}

A partir de una valoración comparada e histórica, el presente artículo ha procurado sentar las bases para afirmar que tanto el artículo 52 como el 53 de la LMV constituyen fórmulas anti-manipulativas de los precios de mercado de los títulos transados en Bolsa. Como tal, estas prohibiciones no se dirigen directamente a la tutela de bienes individualespatrimoniales, sino a la de intereses institucionales o supra-individuales, asociados al buen funcionamiento de un sistema de mercado de valores y a la correcta formación de los precios en el mismo. Dicho en otros términos, aquí se han ofrecido razones para rechazar eventuales comprensiones alternativas de las citadas prohibiciones, especialmente del art. 53 LMV. Estando a las alternativas hermenéuticas anticipadas supra en la Introducción, aquí se plantea que sólo la primera de ellas -la subsunción de formas de manipulación de los precios de valores transados en Bolsa- se condice con la correcta interpretación del Título VIII LMV, especialmente de su art. 53.

Si bien una reconstrucción dogmática detallada del Título VIII LMV -incluyendo por cierto elementos de derecho positivo interno- será tarea de un trabajo posterior, ${ }^{249}$ sirva este apartado final para resumir las principales razones que justifican las anteriores conclusiones, a la vez que para ofrecer un marco esquemático - por ahora sólo general para la correcta captación del sentido de los artículos 52 y 53 de la LMV.

Debe recordarse antes que nada que en la apertura de la sección 1.1. de este artículo se ofreció la siguiente definición de manipulación bursátil:

“(...) manipulación de valores [securities manipulation] (...) significa una conducta dirigida a inducir a personas a negociar un valor [induce people to trade a security] o bien a forzar su precio a un nivel artificial [force its price to an artificial level]" 250

Debe notarse que ya en esta definición se aprecia con claridad -en las alternativas de inducción a negociar y forzamiento del precio- una summa divisio con la que muy eficazmente pueden caracterizarse las manipulaciones de mercado, atendiendo al mecanismo de injerencia en los precios. Así, la injerencia en los precios puede buscarse de

\footnotetext{
${ }^{249}$ Véase supra la nota $\mathrm{n}^{\circ} 10$.

250 THEL, “The Original", cit. nota $n^{\circ} 15$, p. 393.
} 
modo indirecto (a través de negociaciones inducidas, mediante engaño, las que a su turno obtendrán el movimiento de los precios) o bien de manera directa (forzando el movimiento de los precios mediante el ejercicio de un poder de mercado). Constituye un aspecto central de la tesis defendida en este trabajo la idea de que a esta dicotomía responderían perfectamente nuestros arts. 52 (injerencia directa) y 53 (injerencia indirecta).

Ahora bien, si se examinan dichos artículos con mayor detalle, se obtiene que el inciso $1^{\circ}$ del art. 52 y los incisos $1^{\circ}$ y $2^{\circ}$ del art. 53 de la $\mathrm{LMV}^{251}$ representan una tríada de fórmulas anti-manipulativas, complementarias entre sí. En conjunto, ellas se hacen cargo de las modalidades que universalmente -en literatura económica ${ }^{252}$ y derecho comparado ${ }^{253}$ - se reconocen pacíficamente como las figuras centrales de manipulación de mercado de valores. Con ello se da cobertura a lo que podría reconocerse como el canon o estándar en este campo. A la vez y como se ha dicho, esas tres fórmulas se dejan reconducir a la dicotomía expresiva de las variantes de injerencia en los precios.

Recuérdese que las anotadas disposiciones rezan:

a. [Art. 52 inc. $1^{\circ}$ ] "Es contrario a la presente ley efectuar transacciones en valores con el objeto de estabilizar, fijar o hacer variar artificialmente los precios".

b. [Art. 53 inc. $1^{\circ}$ ] "Es contrario a la presente ley efectuar cotizaciones o transacciones ficticias respecto de cualquier valor, ya sea que las transacciones se lleven a cabo en el mercado de valores o a través de negociaciones privadas".

c. [Art. 53 inc. $2^{\circ}$ ] "Ninguna persona podrá efectuar transacciones o inducir o intentar inducir a la compra o venta de valores, regidos o no por esta ley, por medio de cualquier acto, práctica, mecanismo o artificio engañoso o fraudulento".

De acuerdo a la lectura que aquí se ha propuesto, esta tríada de prohibiciones se explica del siguiente modo, en extrema síntesis:

(a) el artículo 52 prohibiría las manipulaciones efectuadas mediante el recurso a transacciones reales (no aparentes) con valores y que por sí mismas puedan afectar los precios, aún con independencia de su capacidad de influjo en las decisiones de terceros intervinientes en el mercado. Se comprenderían así manipulaciones que tienen injerencia directa en los precios. Ello coincide con una modalidad de manipulación operativa propia (o actual trade based manipulation, en la jerga empleada por la literatura ${ }^{254}$. La fórmula del art. 52 sería especialmente comprensiva de aquellas manipulaciones disruptivas o que

\footnotetext{
${ }^{251}$ A los que debe sumarse el art. 61 LMV.

252 Cfr. por todos, AVGOULEAS, The Mechanics, cit. nota $\mathrm{n}^{\circ} 13$, pp. 103 y ss. Igualmente cfr. ALLEN/GALE, "Stock-Price Manipulation", cit. nota n 78, pp. 503 y ss.

${ }^{253}$ Fundamentalmente de cuño estadounidense y europeo-comunitario: cfr. el apartado 1 del presente artículo.

${ }^{254}$ Aquí se ha variado levemente la jerga estándar, recurriendo a la sub-clasificación propia e impropia para dar cuenta del diverso mecanismo de injerencia sobre los precios. Sólo en las manipulaciones operativas propias se alterarían directamente los precios, mientras que en la impropias ello se lograría incidiendo en las decisiones de inversión de terceros, valiéndose de alguna forma de engaño. Es en este punto que las manipulaciones operativas impropias resultan asimilables a la manipulación informativa. Cfr. supra apartado 2, para mayor detalle.
} 
LONDOÑO, Fernando. “Aproximación histórico-comparada al Título VIII de la Ley de Mercado de Valores: bases para el reconocimiento de un contenido anti-manipulativo".

operan mediante ejercicio de un poder de mercado. Esta rúbrica comprende las estabilizaciones, modalidades especialmente incidentes en los mercados primarios o mercados de primera emisión, detalladamente reguladas en derecho comparado.

(b) el inciso primero del artículo 53 prohibiría las manipulaciones efectuadas mediante falsas o aparentes (ficticias) transacciones con valores (manipulación operativa impropia $=$ ficticious trade based manipulation). La rúbrica de transacciones ficticias comprendería, entre otras, las modalidades de wash sales y matched orders $^{255}$, ampliamente conocidas en literatura y derecho comparado ${ }^{256}$. Por su parte, la referencia a "cotizaciones ficticias" (que debe entenderse como la falsación de los precios hechos públicos) asegura una interpretación amplia del inciso (comprensiva incluso de ciertas modalidades informativas de manipulación), a la vez que estrictamente conforme al sentido de protección antimanipulativo.

(c) cierra este catálogo de prohibiciones el inciso segundo del art. 53, con una fórmula antimanipulativa amplia, caracterizada por dos conductas, a modo de variantes: (c.1.) transacciones efectuadas mediante un acto, práctica, mecanismo o artificio engañoso o fraudulento, por una parte; y (c.2) la (tentativa de) inducción engañosa o fraudulenta a la compra o venta de valores (una perífrasis alusiva al incremento artificial de la demanda o de la oferta, con su consecuente impacto en el precio). Bajo la primera hipótesis se comprenderían modalidades de manipulación operativa impropia ${ }^{257}$, esto es, aquellas que actúan no tanto mediante un ejercicio de poder de mercado, sino a través de su capacidad de influjo en las decisiones de terceros intervinientes en el mercado; es decir, aquellas cuya injerencia en el precio es indirecta. La segunda hipótesis, más amplia, comprendería por una parte las tradicionales manipulaciones informativas (information based manipulation), pero también otras clases de manipulación realizadas mediante el recurso a actividades engañosas ejecutadas fuera de bolsa o en el mundo de los hechos (action based manipulation), así como otras de naturaleza compleja, conformadas por estrategias informativas y operativas, conjuntamente ${ }^{258}$.

\footnotetext{
${ }^{255} \mathrm{Al}$ menos en el derecho federal estadounidense, por wash sales se puede entender en general transacciones ficticias que no implican un cambio en la titularidad beneficiada por ellas, mientras que matched orders son órdenes para la compra o venta de un valor con el conocimiento de que otras tantas órdenes de sustancialmente el mismo tamaño y precio serán ingresadas básicamente a la misma hora, ya por la misma persona, ya por otras partes. Ambas tipologías de transacciones pueden usarse para crear una falsa apariencia de mercado activo en el valor de que se trate. Así, STEINBERG, Understanding Securities, cit. nota $\mathrm{n}^{\circ} 14, \mathrm{p}$. 259, sobre la base del contenido de la sección 9(a)(1) de la SEA'34. Véase con detalle la explicación supra 1.3.1.b)., a propósito del tratamiento de la $\S 9(\mathrm{a})(1)$ de la SEA '34.

${ }^{256} \mathrm{Cfr}$. detalle supra en sub apartados 1.3.1.b) y 1.4

${ }^{257}$ Ver supra nota ${ }^{\circ} 254$

${ }^{258}$ El sentido general de estas prohibiciones es correctamente captado en el parágrafo 27.920, aparatado 7.I.2 del Manual de Operaciones en Acciones de la Bolsa de Comercio, especialmente allí donde tras parafrasear las prohibiciones de los arts. 52 y 53 de la LMV, agrega una hipótesis de propio cuño que se lee: "e) En general, los corredores no pueden realizar ningún tipo de operaciones que provoquen aumentos artificiales en las transacciones de un mismo valor y que alteren la información de un título en particular o del mercado en general". Sobre esto se volverá en un trabajo posterior, en proceso de publicación (cfr. supra en nota $n^{\circ} 10$ ).
} 
Polít. crim. Vol. 10, No 20 (Diciembre 2015), Art. 1, pp. 390-467.

[http://www.politicacriminal.cl/Vol_10/n_20/Vol10N20A1.pdf]

Lo anterior puede esquematizarse del siguiente modo:

\begin{tabular}{|c|c|c|c|c|c|}
\hline Título & (a) $\quad$ Art. 52 & \multicolumn{2}{|c|}{ (b) $\quad$ Art. 53.1 } & \multicolumn{2}{|l|}{ (c) $\quad$ Art. 53.2} \\
\hline $\begin{array}{l}\text { Fórmula } \\
\text { sintética }\end{array}$ & $\begin{array}{l}\text { Transacciones } \\
\text { con el objeto de } \\
\text { estabilizar o hacer } \\
\text { variar } \\
\text { artificialmente los } \\
\text { precios }\end{array}$ & $\begin{array}{l}\text { Cotizaciones } \\
\text { Ficticias }\end{array}$ & $\begin{array}{l}\text { Transaccione } \\
\text { s ficticias }\end{array}$ & $\begin{array}{lr}\text { (c.1) Transacciones } \\
\text { efectuadas } & \text { mediante un } \\
\text { actor, práctica, } \\
\text { mecanismo o artificio } \\
\text { engañoso o fraudulento }\end{array}$ & $\begin{array}{l}\text { (c.2) Inducción engañosa o } \\
\text { fraudulenta a la compra o } \\
\text { venta de valores }\end{array}$ \\
\hline \multirow[t]{3}{*}{$\begin{array}{l}\text { Cobertu } \\
\text { ra }\end{array}$} & \multirow{3}{*}{$\begin{array}{l}\text { Manipulación } \\
\text { operativa propia } \\
\text { (especialmente } \\
\text { estabilización y } \\
\text { otras formas } \\
\text { disruptivas o } \\
\text { ejercidas mediante } \\
\text { poder de mercado } \\
\text { =injerencia directa } \\
\text { en los precios) }\end{array}$} & \multirow{3}{*}{\multicolumn{2}{|c|}{$\begin{array}{l}\text { Manipulación } \\
\text { impropia (incluyendo hipótesis } \\
\text { informativas por vía de la } \\
\text { alteración de las cotizaciones) } \\
=\text { injerencia indirecta en los } \\
\text { precios }\end{array}$}} & \multirow{3}{*}{$\begin{array}{l}\text { Manipulación operativa } \\
\text { impropia } \\
\text { formas especialmente } \\
\text { mediante engaño al } \\
\text { mercado = injerencia } \\
\text { indirecta en los precios) }\end{array}$} & $\begin{array}{l}\text { Manipulación informativa } \\
\text { en general } \\
\text { (injerencia indirecta en los } \\
\text { precios) }\end{array}$ \\
\hline & & & & & $\begin{array}{l}\text { Manipulación por vía de } \\
\text { actividades engañosas } \\
\text { extra bursátiles (action } \\
\text { based manipulation) } \\
\text { (injerencia indirecta en los } \\
\text { precios) }\end{array}$ \\
\hline & & & & & $\begin{array}{l}\text { Manipulaciones realizadas } \\
\text { mediante un complejo de } \\
\text { transacciones } \\
\text { informaciones } \\
\text { (injerencia indirecta en los } \\
\text { precios) }\end{array}$ \\
\hline
\end{tabular}

Como se sabe, estas tres fórmulas de prohibiciones anti-manipulativas se traducen además en responsabilidad penal, por reenvío del tipo penal de la letra e) del art. 59, el que contempla sanciones privativas de libertad que van desde los 541 días a los 10 años de presidio. ${ }^{259}$ Siempre en sede penal y ya al margen de esta tríada de prohibiciones especiales, el cuadro trazado se ve completado por la figura residual de manipulación informativa del art. 61, sancionada con penas privativas de libertad inferiores a las del art. 59, consistentes en presidio de 61 días a 5 años en el supuesto agravado.

El presente trabajo ha buscado demostrar que el contenido del Título VIII LMV se encuentra en plena sintonía con el moderno derecho comparado del sector, de vocación anti-manipulativa del mercado de valores. Esta sintonía se advierte tanto en la comparación con el vigente derecho europeo del sector, como - especialmente- con el muy influyente derecho federal estadounidense. Como se ha visto, ciertas coincidencias regulatorias -tanto de sistemática como de texto- permiten incluso conjeturar que aquel derecho federal pudo haber efectivamente ejercido influencia en sede de elaboración de la LMV original $^{260}$.

Una tarea pendiente -materia de un trabajo posterior ${ }^{261}$ - supone demostrar que esta lectura es también consistente con el material de "derecho interno" disponible: por de pronto con la sistemática e historia $^{262}$ de la LMV, pero también con la (auto)regulación del sector en

\footnotetext{
${ }^{259}$ A las que toca añadir la eventual pena de inhabilitación especial contemplada en el art. 61 bis LMV.

${ }^{260}$ Especialmente coincidente con las hipótesis 1, 2 y 6 de la sección 9(a) de la Securities Exchange Act de 1934: cfr. supra 1.3 con detalle.

${ }^{261}$ Véase supra la nota $\mathrm{n}^{\circ} 10$.

262 Téngase especialmente presente el art. 48 del Mensaje de 1980: cfr. lo dicho supra en 1.3.
} 
LONDOÑO, Fernando. “Aproximación histórico-comparada al Título VIII de la Ley de Mercado de Valores: bases para el reconocimiento de un contenido anti-manipulativo".

general $^{263}$, la (todavía muy escasa) jurisprudencia administrativa y penal pertinente ${ }^{264}$, amén de la también escasa doctrina que se ha ocupado del asunto ${ }^{265}$.

Por de pronto, no parece aventurado afirmar que la clave de lectura aquí defendida da razones para explicar la muy elevada penalidad asociada a la infracción de las prohibiciones comentadas. Otras lecturas enfrentarían dificultades adicionales para fundamentar la pertinencia de sanciones que, por lo que toca a la dimensión penal, alcanzan grados previstos en nuestro ordenamiento para crímenes como el homicidio, el secuestro o la violación (y por cierto superiores a los tradicionales delitos patrimoniales). Se trata en efecto de sanciones que, en su extremo superior, alcanzan hasta los diez años de presidio. Ya en el plano administrativo sancionatorio, es también llamativo que las infracciones de los artículos 52 y 53 sean las únicas que específicamente den lugar a la más drástica sanción de expulsión de las bolsas de valores (art. 49 b] LMV). Todo ello habla del especial contenido de injusto que desde su génesis se ha atribuido a esas infracciones. Con independencia de la sede disciplinaria de que se trate, estas severas consecuencias jurídicas ponen al intérprete en alerta al tiempo de atribuir contenido a los presupuestos normativos.

En este contexto, forzamientos del sentido literal posible de los textos en juego no resultan aconsejables. Como se ha dicho, ello se haría a espaldas del contexto (del sistema, de las consecuencias jurídicas y del derecho comparado, por de pronto). Más importante aún, determinadas interpretaciones -orientadas a posibilitar la subsunción bajo el Título VIII de hechos excéntricos a la fenomenología manipulativa- resultarían contraproducentes para el sistema en su conjunto, tornándolo incongruente e incluso oscureciendo resortes normativos hoy fácilmente al alcance de la Superintendencia de Valores y del Ministerio Público. ${ }^{266}$

263 Reglamentación de operaciones de las Bolsas: de Bolsa de Comercio, arts. 65-67; de Bolsa Electrónica, arts. 63-65. De especial interés es también el Manual de Operaciones en Acciones de la Bolsa de Comercio, especialmente el parágrafo 27.920, apartado 7.I.2, dedicado a las actividades prohibidas. Deben igualmente considerarse en este contexto, como manifestación de la auto-comprensión del medio, las Reglas del Comité de Regulación y Autorregulación de las Bolsas de Comercio de Santiago y Electrónica de Chile, abril de 2009. Reglas para prevenir y combatir el uso de información privilegiada y la manipulación del mercado.

${ }^{264}$ Cfr. supra nota ${ }^{\circ} 3$, al menos por lo que toca a los casos Schwager y MBI.

${ }^{265}$ Es por lo demás tendencialmente coherente con la lectura que puede desprenderse del más reciente proyecto de ley modificatorio de los ilícitos de mercado de valores, en el contexto de una propuesta de nuevo Código Penal (Mensaje de S.E. el Pdte. de la República, Boletín 9.274-07 de marzo de 2014): cfr. los artículos 366 y 367 del proyecto de nuevo $\mathrm{CP}$, que sintetizan el injusto manipulativo en sus variantes operativa e informativa.

${ }^{266}$ Cfr. especialmente lo dicho supra 1.3.2 e), en relación con el art. 59 letras a) y f). 
Polít. crim. Vol. 10, No 20 (Diciembre 2015), Art. 1, pp. 390-467.

[http://www.politicacriminal.cl/Vol_10/n_20/Vol10N20A1.pdf]

\section{BIBLIOGRAFIA}

AA.VV., "Illegality of Stock Market Manipulation (Note)", Colum. L. Rev., vol. 34, 1934, pp. 500 y ss.

ALCALDE, Enrique, "Uso de información privilegiada: algunas consideraciones sobre el sentido y alcance de la prohibición en relación con su sujeto, objeto y sanción", Revista Chilena de Derecho, Vol. 27 N¹ (2000), pp. 11-28;

ALLEN, Franklin; GALE, Douglas, "Stock-Price Manipulation”, Rev. Fin. Stud. (1992), n. 5, pp. 503-529.

AMATI, Enrico, Abusi di mercato e sistema penale, Torino: Giappichelli, 2012.

AVGOULEAS, Emilios, The Mechanics and Regulation of Market Abuse. A legal and Economic Analysis, Oxford: Oxford University Press, 2005.

BASCUÑÁN R., Antonio, "La regulación de la información privilegiada en el mercado de valores después de la ley N. 20.382", en WILLENMANN, Javier (coord.), Gobiernos Corporativos. Aspectos esenciales de las reformas a su regulación, Santiago: Legal Publishing, 2011, pp. 87-137.

BERLE, Adolf. A., "Stock Market Manipulation”, Colum. L. Rev., n. 38 (1938), pp. 393 y ss.

BRAGE, Santiago, Los delitos de alteración de precios, Granada: Comares, 2001.

CHOI, Stephen J.; PRITCHARD, Adam C., Securities Regulation. Essentials. New York: Aspen Publishers, 2008.

EASTERBROOK, Frank H., "Monopoly, Manipulation, and the Regulation of Futures Markets", The Journal of Business, Vol. 59 (1986), n. 2, pp. 103-127.

EASTERBROOK, Frank H.; FISCHEL, Daniel, The Economic Structure of Corporate Law, Cambridge: Cambridge University Press, 1991.

ESTRADA, Albert, "Presente y futuro del delito de alteración de precios (art. $284 \mathrm{Cp}$ )", en InDret, $1 / 2014$.

ETCHEBERRY, Alfredo, Derecho Penal. Parte Especial, Tomo IV, $3^{\text {a }}$ ed., Santiago: Editorial Jurídica de Chile, 1998.

FERNÁNDEZ, Pedro Javier, Código Penal de la República de Chile esplicado $i$ concordado, T.II, 2da. Santiago de Chile: Ed, Imprenta, litografía y encuadernación Barcelona, 1900.

FRIEDMAN, Richard D., "Stalking the squeeze: understanding commodities market manipulation", Mich. L. Rev., n. 89 (1990), pp. 30-68.

GARCÍA, Gonzalo, "Modelo de protección en normas administrativas y penales que regulan el abuso de Información Privilegiada en la legislación chilena". Política criminal, Vol. 8, $\quad \mathrm{N}^{\mathrm{o}} 15 \quad$ (2013), Art. 2, pp. 23 - 63. http://www.politicacriminal.cl/Vol_08/n_15/Vol8N15A2.pdf

"La idealización y la administrativización de la punibilidad del uso de Información Privilegiada. Un análisis de los discursos penales en la doctrina chilena". Política criminal Vol. 10, No 19 (Julio 2015), Art. 5, pp. 119-158, p. 151, en http://www.politicacriminal.cl/Vol_10/n_19/Vol10N19A5.pdf

GASPAR, José Antonio; ARAYA, Fernando, "Uso de información privilegiada: Superintendencia de Valores y Seguros, 14 de abril de 2011, Resolución Exenta N ${ }^{\circ}$ 229”, Revista Chilena de Derecho Privado, No 17 (2011), pp. 277-305. 
LONDOÑO, Fernando. “Aproximación histórico-comparada al Título VIII de la Ley de Mercado de Valores: bases para el reconocimiento de un contenido anti-manipulativo".

GILSON, Ronald; KRAAKMAN, Reinier, “The Mechanism of Market Efficiency”, $V a$. L Rev. (1984), vol. 70, pp. 549 y ss.

GREEN, Stuart P., Lying, Cheating and Stealing, A moral Theory of White-Collar Crime, Oxford: Oxford University Press, 2006.

GUZMÁN, Francisco, Información privilegiada en el mercado de valores chileno, Santiago: Legal Publishing: 2009.

HAZEN, Thomas Lee, Securities Regulation. In a nutshell, St. Paul (MN): West (Thomson Reuters), $10^{\text {th }}$ ed., 2009.

HERNÁNDEZ, Héctor, "Aproximación a la problemática de la estafa. Problemas actuales de Derecho Penal”, en: AAVV., Problemas actuales en Derecho Penal, Temuco: Universidad Católica de Temuco, 2003, pp. 147-190. "La punibilidad de la colusión (secreta) de precios en el derecho chileno".

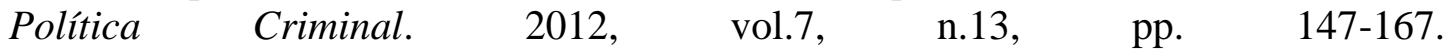
http://www.politicacriminal.cl/Vol_07/n_13/Vol7N13A4.pdf.

LAZO, Santiago, Código Penal, Orígenes, Concordancias, Jurisprudencia, Santiago: Poblete Cruzat Hnos. Ed., 1917, pp. 240-2141 (art. 285).

LONDOÑO, Fernando, "Ilícito de manipulación bursátil: fenómeno y lesividad. Aspectos de política sancionatoria", Política criminal, Vol. 8, No 15 (2013), Art. 3, pp. 64 127, en http://www.politicacriminal.cl/Vol_08/n_15/Vol8N15A3.pdf.

LOSS, Louis; SELIGMAN, Joel, Securities Regulation, versión digital Lexis.com, 2004 (3a. ed.).

MAGRO, Beatrice, Manipolazioni dei mercati finanziari e diritto penale. Una critica al modello di razionalità economica, Milano: Giuffrè, 2012.

MANNE, Henry, "In Defense of Insider Trading”, Harvard Business Review, 1966 (NovDec), pp. 113 y ss.

MARINUCCI, Giorgio; DOLCINI, Emilio, Manuale di Diritto Penale. Parte Generale, Milano: Giuffrè, 2004.

MARKHAM, Jerry W., "Manipulation of Commodity Futures Prices - The Unprosecutable Crime", Yale J. Reg., n. 8 (1991), pp. 281 y ss.

MATUS, Jean Pierre, "Acerca de la actual falta de punibilidad en Chile de los acuerdos de precios". Política Criminal. Vol. 7, No 14 (Diciembre 2012), Art. 3, pp. 318 - 356. http://www.politicacriminal.cl/Vol_07/n_14/Vol7N14A3.pdf

, "De nuevo sobre la falta de punibilidad de los atenta dos contra la libre competencia, de conformidad con el Art. 285 del Código penal. Algunos aspectos de la discusión con Héctor Hernández en Política Criminal” en Política Criminal Vol. 8, $\quad \mathrm{N}^{\mathrm{o}} 15 \quad$ (Julio 2013), Doc. 1, pp. 314-362. http://www.politicacriminal.cl/Vol_08/n_15/Vol8N15D1.pdf

MERA, Jorge, Fraude civil y penal. El delito de entrega fraudulenta, Santiago: Conosur, $2^{\mathrm{a}}$ Ed., 1994.

MUÑOZ CONDE, Francisco, Derecho Penal. Parte Especial, Valencia: Tirant Lo Blanch, $14^{\mathrm{a}}$ ed., 2002.

ONADO, Marco, Economia e regolamentazione del sistema finanziario, Bologna: Il Mulino, 2004.

PACHECO, Joaquín Francisco, El Código penal concordado y comentado, $4^{\mathrm{a}}$ edición, Madrid: Imprenta de Manuel Tello, 1870, T. III. 
Polít. crim. Vol. 10, No 20 (Diciembre 2015), Art. 1, pp. 390-467.

[http://www.politicacriminal.cl/Vol_10/n_20/Vol10N20A1.pdf]

PEDRAZZI, Cesare, Problemi dell'aggiotaggio, Milano, 1958; reed. en Diritto Penale IV, Scritti di diritto penale dell'economia, Milano: Giuffrè, 2003, pp. 3-97.

, "Turbativa dei mercati” (voce), en Dig.Disc. Pen., 1999, pp. 421-432.

PENSO DE LA VEGA, José, Confusión de confusiones, Ámsterdam, 1688.

PERDUE, Wendy C., "Manipulation of futures markets: redefining the offense", Fordham L. Rev., n. 56 (1987), pp. 345 y ss.

PERRONE, Andrea, "Información en el mercado de valores y tutela del inversor". Polít. Crim. Vol. 4, $\mathrm{N}^{\circ} 7$ (Julio 2009), Art. 7, pp. 197-229 (1-33), en http://www.politicacriminal.cl/Vol_04/n_07/Vol4N7A7.pdf.

PFEFFER, Francisco, "Concepto de información privilegiada y deberes de conducta de quienes están en posesión de ella, a la luz de la jurisprudencia emanada de la Excma. Corte Suprema", Revista de Derecho Comercial. Año 1 No 1 (2010), pp. 155-181.

PIÑA, Juan Ignacio, "Algunos problemas del delito de uso de información privilegiada", en Regulaciones del Mercado de Valores, Cuadernos de Extensión jurídica, U. Andes, Santiago, 2010, pp. 113 y ss.

PIRRONG, Craig, "Commodity Market Manipulation Law: A (Very) Critical Analysis and a Proposed Alternative", Wash. \& Lee L. Rev., n. 51 (1994), pp. 945 y ss.

POLITOFF, Sergio, MATUS, Jean Pierre y RAMÍREZ, María Cecilia, Lecciones de Derecho Penal Chileno, Parte General, Santiago: Ed. Jurídica de Chile, 2da. ed., 2003.

PRADO, Arturo, "Acerca del concepto de información privilegiada en el mercado de valores chileno: su alcance, contenido y límites", Revista Chilena de Derecho, Vol. $30 \mathrm{~N}^{\circ}$ (2003), pp. 237-269.

PRENTICE, Robert A., "Scheme liability: Does it have a future after Stoneridge?", Wis. L. Rev. (2009), pp. 351 y ss.

RIED, José Miguel "Fundamentos de la prohibición del uso de la información privilegiada en Chile: una visión crítica", Revista Chilena de Derecho, Vol. 31 N $^{\circ} 3$ (2004), pp. $439-463$.

ROMANO, Mario, Commentario Sistematico del Codice Penale, t.I, Giuffrè, Milano, $3^{\circ}$ ed., 2004.

ROSAS, Juan Ignacio, "El delito de abuso de información privilegiada en el mercado de valores: análisis crítico de la regulación contenida en la Ley N. 18.045", Gaceta Jurídica N. 299 (2005), pp. 7-24.

ROSENBLUT, Verónica, “El denominado caso 'Schwager': análisis de histórica condena por uso de información privilegiada y manipulación bursátil”, Revista Jurídica del Ministerio Público, N. 46 (marzo 2011), pp. 185-209.

SALAH, María Agnes, Responsabilidad por uso de información privilegiada en el mercado de valores, Santiago: Lexis Nexis, 2004.

SEMINARA, Sergio, Insider Trading e Diritto Penale, Milano: Giuffrè, 1989.

"I reati di aggiotaggio", en: PEDRAZZI, Cesare; ALESSANDRI, Alberto; FOFFANI, Luigi; SEMINARA, Sergio; SPAGNOLO, Giuseppe, Manuale di diritto penale dell'impresa, Bologna: Monduzzi, 2000, pp. 635-663.

STEINBERG, Marc I, Understanding Securities Law, $5^{\text {th }}$ ed., New Providence: Lexis Nexis, 2009.

THEL, Steve, "\$ 850,000 in Six Minutes -- The Mechanics of Securities Manipulation", en Cornell L. Rev., n.79, 1994, pp. 219 y ss. 
LONDOÑO, Fernando. “Aproximación histórico-comparada al Título VIII de la Ley de Mercado de Valores: bases para el reconocimiento de un contenido anti-manipulativo".

, "The Original Conception of Section 10(b) of The Securities Exchange Act", Stan. L. Rev., vol. 42, 1989-1990, pp. 3885 y ss.

TIEDEMANN, Klaus, Wirtschaftsstrafrecht: Besonderer Teil, Köln: Heymanns, 2006 (en castellano, trad.de la 2da. edición alemana: TIEDEMANN, Klaus, Manual de Derecho Penal Económico. Parte General y Especial, Valencia: Tirant Lo Blanch, 2010).

TWENTIETH CENTURY FUND, INC., The Security Markets, New York: The Fund, 1935.

VÁSQUEZ, María Fernanda, "Revisión del ámbito de aplicación subjetivo y objetivo de la noción de uso de información privilegiada en Chile: un examen de la normativa a la luz de las tendencias doctrinales y jurisprudenciales", Revista de Derecho Universidad Católica del Norte, Año 17 - N. 2 (2010), pp. 239-297.

VOGEL, Joachim, $\$ \S 20 a, 38-40 b$ (kommentar), en: ASSMANN, H.D.; SCHNEIDER, U.H., Wertpapierhandelsgesetz Kommentar, Köln: Otto Schmidt, 2006, pp. 727 y ss. y 1669 y ss. 